Universidade de São Paulo

Instituto de Astronomia, Geofísica e Ciências Atmosféricas

\title{
CARACTERIZAÇÃO GRAVIMÉTRICA DA ZONA DE FRATURA SÃO PAULO E ARQUIPÉLAGO SÃO PEDRO E SÃO PAULO NA PORÇÃO EQUATORIAL DO OCEANO ATLÂNTICO
}

ROBERTA LADISLAU DE MEDEIROS ${ }^{\dagger}$

Orientador:

EDER CASSOLA MOLINA

São Paulo

Julho/2010

${ }^{\dagger}$ Este trabalho contou com apoio financeiro da CAPES 
Universidade de São Paulo

Instituto de Astronomia, Geofísica e Ciências Atmosféricas

\section{CARACTERIZAÇÃO GRAVIMÉTRICA DA ZONA DE FRATURA SÃO PAULO \\ E ARQUIPÉLAGO SÃO PEDRO E SÃO PAULO \\ NA PORÇÃO EQUATORIAL DO OCEANO ATLÂNTICO}

ROBERTA LADISLAU DE MEDEIROS

Dissertação apresentada ao Instituto de Astronomia, Geofísica e Ciências Atmosféricas da Universidade de São Paulo para a obtenção do título de Mestre em Ciências em Geofísica. 


\section{FICHA CATALOGRÁFICA}

Medeiros, Roberta Ladislau de

Caracterização gravimétrica da Zona de Fratura São Paulo e Arquipélago São Pedro e São Paulo na porção equatorial do Oceano Atlântico

Orientador: Eder C. Molina

Dissertação (mestrado) - Universidade de São Paulo- USP, Instituto de Astronomia, Geofísica e Ciências Atmosféricas, IAG- USP, 2010.

1. Modelo Geopotencial EGM2008. 2. Gravimetria. 3. Zona de Fratura São Paulo 
"BEM-AVENTURADOS

OS AFLITOS PORQUE SERÃO CONSOLADOS" 


\section{Agradecimentos}

Agradeço a todos os funcionários do IAG-USP. Especialmente a Célia, a Conceição e a todos os funcionários da biblioteca e da gráfica. Agradeço também a Teca e a Vírgina e a todos os funcionários da secretária de pósgraduação. Muito obrigada por todas as gentilezas.

Quando eu consegui minha vaga no CRUSP minha vida em São Paulo melhorou muito. Por isso agradeço a assistente social Neusa e também agradeço aos amigos André, Gerby, Dannielle, Zuzi e Celyna.

No dia-a-dia, agradeço aos amigos Gleidson, Higo, Grasiane, Henrique, Erika, Selma e Carlos Alberto. Agradeço a amizade de todos. Muito obrigada.

Em especial, agradeço ao amigo Carlos Alberto. Muito obrigada por toda a sua ajuda com o processamento dos dados e paciência com minhas dúvidas.

Quando a saudade, a chuva, o frio, a greve e outros obstáculos me fizeram pensar em desistir... Agradeço aqueles que ficaram no Rio ou em Resende me esperando.

Agradeço a CAPES por ter me fornecido condições para estudar. Jamais poderia me manter sem este apoio. Desta forma, aprimorei meu conhecimento sobre a Terra.

Agradeço ao avaliador do meu projeto e dos relatórios que me forneceu mais tempo a fim de concluir esta pesquisa.

Agradeço especialmente ao meu orientador, prof. Eder Molina, por toda a sua dedicação. Ele não é só um excelente geofísico. Ele é também um excelente pedagogo, professor e pesquisador. A gravimetria tornou-se significativa para mim devido à paixão com que ele realiza seu trabalho no IAG.

Por fim agradeço a Deus...

Pela recuperação da irmã que esteve gravemente doente após erro cirúrgico.

Pela recuperação do meu pai que foi operado e tudo correu muito bem...

Pela recuperação do meu sogro que há três anos foi operado... e o será novamente... contamos com a ajuda de Deus para uma nova recuperação muito tranquila e sem complicações posteriores.

Agradeço a Deus pelo meu casamento e pelo amor do Tiago em minha vida. Ele é meu norte, meu sul, meu leste, meu oeste. Se às vezes eu pareço sem direção e um pouco atrapalhada demais... Tenham certeza, sou apenas sincera e feliz... minha embarcação tem rumo. Nunca perdi o norte magnético. Nenhuma tempestade pode me fazer adernar... 


\section{Resumo}

A investigação da Terra através da gravimetria implica um grande número de informações sobre o seu interior em diferentes escalas de observação. O presente estudo considerou pesquisas anteriormente realizadas na área da Zona de Fratura São Paulo (ZFSP) e Arquipélago São Pedro e São Paulo (ASPSP), no Oceano Atlântico Equatorial, cujos dados geoquímicos e petrológicos apontam a presença de uma anomalia térmica. Nesta área alguns levantamentos geofísicos já foram realizados, mas nada que contribuísse de forma significativa através de dados gravimétricos.

O objetivo principal deste trabalho é a caracterização gravimétrica da Zona de Fratura São Paulo através de dados de gravidade, anomalia ar livre, anomalia bouguer, tensor gradiente da gravidade e altura geoidal residual. Como objetivo secundário, procurou-se a expressão desta anomalia térmica no campo gepotencial . Entretanto, os dados obtidos indicam que o efeito da batimetria sobre critérios analisados é intenso nesta região próximo a dorsal mesoceânica. Sendo necessário a confluência de outros métodos geofísicos para detectar sua expressão. 


\section{Abstract}

The investigation of the Earth by gravity implies a lot of information about the interior at different scales of observation. This study considered research previously conducted in the area of St. Paul Fracture Zone (ZFSP) Archipelago and St Peter and St Paul (ASPSP), the Equatorial Atlantic Ocean, whose petrological and geochemical data indicate the presence of a thermal anomaly. In this area some geophysical surveys have been conducted, but nothing that would contribute significantly by gravity data.

The main objective of this work is the characterization of gravimetric St. Paul Fracture Zone by gravity data, free air anomaly, Bouguer anomaly, the gravity gradient tensor and residual geoid height. As a secondary objective, we found the expression of this thermal anomaly in the field gepotencial. However, the data indicate that the effect of bathymetry on criteria examined is intense in this region near the mid-oceanic ridge. If necessary the confluence of other geophysical methods to detect its expression. 


\section{Lista de Ilustrações}

Ilustração 1: Bandas de comprimento de onda incluindo dados de gravidade, geóide obtido de radar altimétrico. Em escala logarítmica. Bowin (1986). 3 Ilustração 2: Detalhe do Arquipélago São Pedro e São Paulo. Motoki et al (2008).

Ilustração 3: Processo de formação de Megamullion. Tucholke (1998). __ 5

Ilustração 4: Mapa batimétrico com grade de 1' do ETOPO _ 7 Ilustração 5: Localização do Arquipélago São Pedro e São Paulo. Sichel et al. (2008).

Ilustração 6: Representação da estrutura interna da Terra (Winter, 2001).

llustração 7: Mapa da região estudada por Bonatti (1990). Os círculos escuros indicam a região de amostragem e os números os valores médios. O triângulo indica a amostra de peridotitos do ASPSP e a área pontilhada indica o hotspot dos Açores.

Ilustração 8: Mapa morfotectônico simplificado da região equatorial mostrando a localização da amostragem no eixo da dorsal (círculos abertos). Note a posição conjugada da cadeia assísmica Ceará e a Elevação Sierra Leoa. Os círculos sólidos representam os montes submarinos (localização de Epp e Smooth, 1983). O mapa geológico de 0 a 100 Ma mostra a posição da litosfera cratônica em relação as zonas de fratura equatoriais. Hotspots representados: CV (Cabo Verde), SL (Sierra Leoa), F (Fernando de Noronha), Asc (Ascension), SH (Santa Helena) e St.P \& P são as ilhas do ASPSP. O rifteamento da litosfera cratônica do período Arqueano durante o final do Cretáceo foi baseado Fairhead e Green (1989). Extraído de Schilling et al., (1995).

Ilustração 9: Reconstrução geográfica baseada em dados paleomagnéticos do final do período Ordoviciano (Torvis e Trench, 1991). Note que paleolatitude do continente Laurásia foi alterada em sentido horário em relação à posição de Gondwana. O eixo simétrico do campo magnético foi obtido pela posição das margens proto-Andina e proto-Apalachiana. Daziel (1997).

Ilustração 10: Detalhe do sistema de falhas trasnformantes da ZFSP .Hekinian et al. (2000).

Ilustração 11: Mapa batimétrico da Zona de Fratura São Paulo (porção leste da área sismicamente ativa) intervalo de $200 \mathrm{~m}$. agapova (1994). 15 llustração 12: Mapa morfoestrutural da zona de fratura São Paulo. 1fragmentos de rift; 2-montes submarinos dentro de rift na dorsal; 3- zonas depressivas na falha com topografia relativamente enrrugada e espessura sedimentar de $500 \mathrm{~m}$; 4- zonas depressivas na falha com fundo relativamente plano e espessura sedimentar superior a 500 m; 5- rift valleys; 6- nodal deeps.

Ilustração 13: Representação da altitude ortométrica $(H)$, altura ortométrica $(h)$, altura geoidal (N). Li, X e Götze, H-J (2001). _ 20 llustração 14: Correlação entre os altos geoidais e as zonas de subducção, utilizando harmônicos de grau 4 a 9. intervalo de contorno de $10 \mathrm{~m}$. anomalias geoidais negativas geoidal estão marcadas. 25 


\section{Lista de Mapas}

Mapa 1: Grade com resolução de 1 min. Ondulação geoidal gerada a partir dos programas disponibilizados na homepage do NGA e a partir das grades geradas pelo aplicativo disponibilizado na homepage do Instituto Geodésico de Potsdam. 23 Mapa 2: Alturas geoidais residuais sobre a região da ZFSP. intervalo de contorno 0.5 metro. 24 Mapa 3: Altura geoidal residual grau 10 a 2160. Resolução $1 \mathrm{~min} . \_26$ Mapa 4: Altura geoidal residual grau 15 a 2160. Resolução $1 \mathrm{~min}$ __ 26 Mapa 5: Altura geoidal residual grau 20 a 2160. Resolução $1 \mathrm{~min}$ —— 26 Mapa 6: Altura geoidal residual grau 25 a 2160. Resolução $1 \mathrm{~min}$ —— 27 Mapa 7: Altura geoidal residual grau 30 a 2160. Resolução 1 min. __ 27 Mapa 8: Altura geoidal residual grau 35 a 2160. Resolução 1 min. $\longrightarrow 27$ Mapa 9: Mapa batimétrico da ZFSP. Dados obtidos pelo geoidas. Resolução 1'.

Mapa 10: Grade obtida após estimativa do efeito da batimetria sobre o geóide simulando a construção de prismas através do programa prismas3d (chaves. 2007). 32 Mapa 11: Anomalia de altura geoidal residual grau 10 a 2160 subtraído efeito batimétrico. resolução 1 min. 32

Mapa 12: Anomalia de altura geoidal residual grau 15 a 2160 subtraído efeito batimétrico. resolução 1 min.

Mapa 13: Anomalia de altura geoidal residual grau 20 a 2160 subtraído efeito batimétrico. resolução 1 min.

Mapa 14: Anomalia de altura geoidal residual grau 20 a 2160 subtraído efeito batimétrico. resolução 1 min. 33 Mapa 15: Anomalia ar livre residual grau 10 a 2160. Resolução 5 min.__ 35 Mapa 16: Anomalia ar livre residual grau 15 a 2160. Resolução 5 min.__ 35 Mapa 17: Anomalia ar livre residual grau 20 a 2160. Resolução 5 min.__ 35 Mapa 18: Anomalia ar livre residual grau 25 a 2160. Resolução 5 min.__ 36 Mapa 19: Anomalia ar livre residual grau 30 a 2160. Resolução 5 min.__ 36 Mapa 20: Anomalia ar livre residual grau 35 a 2160. Resolução 5 min.__ 36 Mapa 21: Anomalia Bouguer (campo total) a partir de anomalia ar livre (0 a 2160).

Mapas 22 a 27: Gravidade residual obtida pelo programa grafim.job a partir do modelo egm 2008 (30 a 2160) aplicando o método de ajuste polinomial__ 42 Mapa 23: Gravidade considerando o efeito da compensação isostática cujos valores foram obtidos a partir do programa parker. $\mathrm{m}$ (Chaves, 2008) __ 43 Mapa 24: Gravidade residual após subtração do efeito da compensação isostática.

Mapa 25: Tensor gradiente da gravidade calculado na ZFSP. 45 


\section{Sumário}

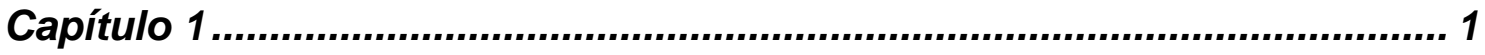

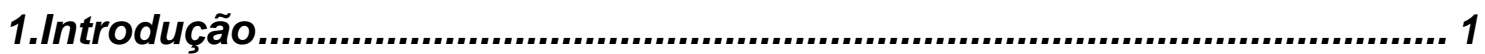

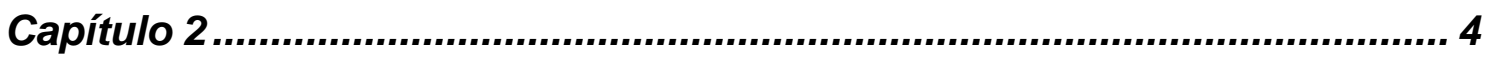

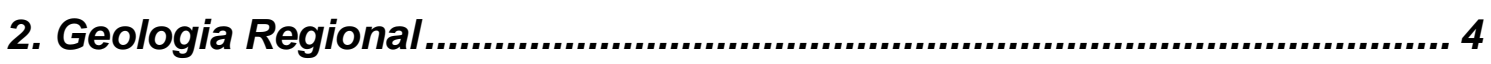

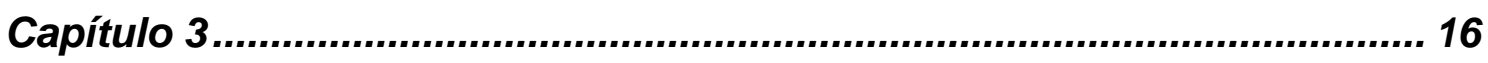

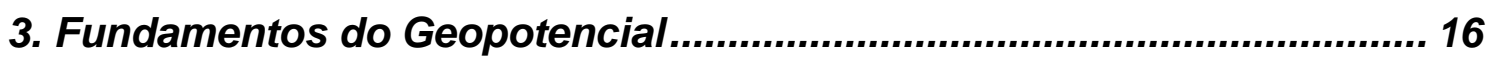

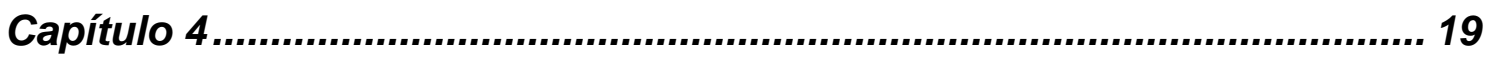

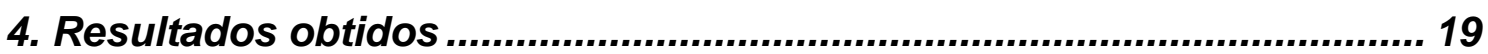

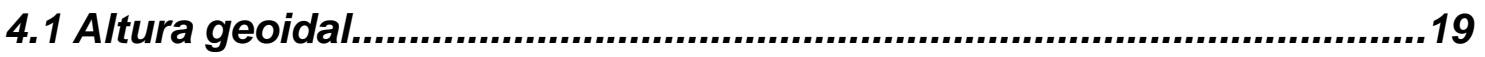

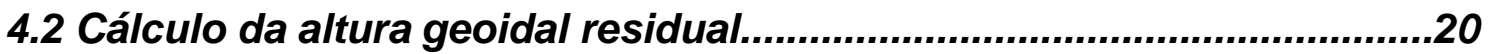

4.3 Anomalia ar livre e anomalia ar livre residual......................................34

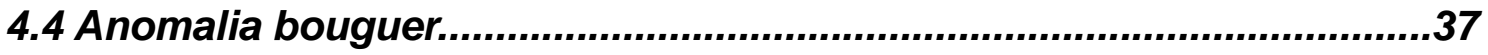

4.5 Separação de componentes: residual e regional....................................38

4.6 Ajuste polinomial para a interpretação de dados de gravidade residual e implementação do método de parker...........................................................39

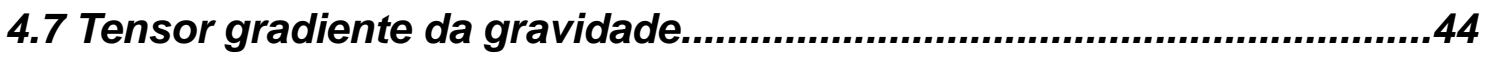

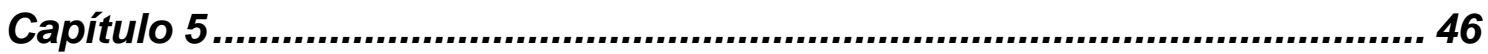

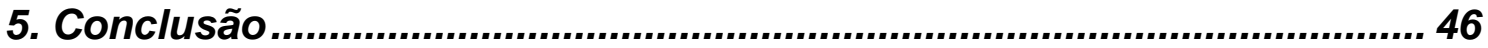

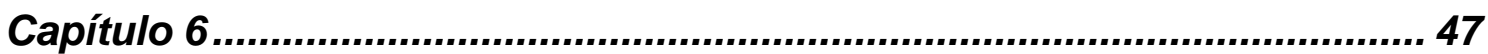

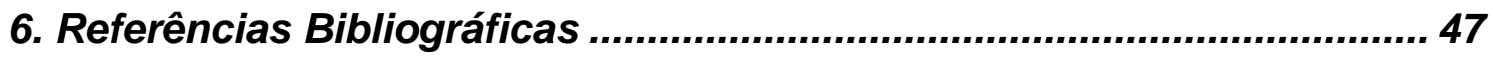




\section{CAPÍTULO 1 \\ 1.INTRODUÇÃO}

A investigação da Terra através da gravimetria implica um grande número de informações sobre o seu interior em diferentes escalas de observação. O presente estudo considerou pesquisas anteriormente realizadas na área da Zona de Fratura São Paulo (ZFSP) e Arquipélago São Pedro e São Paulo (ASPSP), no Oceano Atlântico Equatorial, cujos dados geoquímicos e petrológicos apontam a presença de uma anomalia térmica no manto.

Nesta área, existe um debate acerca da origem desta anomalia. Trata-se de uma região muito especial onde ocorreu um afloramento de rochas do manto, peridotitos expostos no Arquipélago São Pedro e São Paulo (ASPSP), conhecido na literatura pelo termo megamullion (Sichel et al. 2008).

O termo mullion é utilizado para identificar feições topográficas presentes em limites divergentes em placas litosféricas geralmente com lentas taxas de expansão. Estas feições localizam-se na região de entrucamento dorsal mesoceânica-falha transformante. Formam-se quando as rochas que compõem a lapa (ou footwall) são soerguidas conforme a ação da tectônica extensional durante o processo de espalhamento do assoalho oceânico. Já o termo megamullion é aplicado às feições que apresentam porções suavemente arredondadas com diâmetro maior do que $10 \mathrm{~km}$ (Tucholke et al. 2001).

As falhas transformantes estão presentes em todo 0 assoalho oceânico. São caracterizadas pelo movimento extensional seccionando eixos da dorsal mesoceânica. Entretanto, a zona de fratura compreende a porção sismicamente ativa e também o dito traço fóssil da falha formado por um desnível batimétrico e tectônicamente inativo (Fowler, C.M.R. 2005).

O ASPSP encontra-se encaixado na borda norte da Zona de Fratura São Paulo numa porção do Oceano Atlântico onde estão localizados os maiores deslocamentos que separam eixos da cordilheira meso-atlântica. As ilhas representam o ponto mais oriental do território brasileiro e devido ao interesse estratégico para o país a Comissão Interministerial para Recursos do Mar (SECIRM), iniciou em 1996, o Programa Arquipélago São Pedro e São Paulo (PROARQUIPÉLAGO). Em 1998, foi inaugurada uma estação científica na região, 
em 2004, o arquipélago foi reconhecido internacionalmente como território pertencente à Zona Econômica Exclusiva (ZEE) do Brasil (Campos et al.,2002).

Bonatti (1990) foi pioneiro na investigação da origem do cold spot no Atlântico Equatorial. Ele comparou às rochas encontradas nas llhas Zabargad (Mar Vermelho) as encontradas no ASPSP cujos peridotitos milonitizados (grãos que apresentam dimensões variadas) sofreram processo semelhante de serpentinização (metamorfismo de baixo grau com hidratação dos minerais). Ele apontou um cenário geológico de afinamento crustal com posterior ruptura onde teria ocorrido o aprisionamento de litosfera subcontinental semelhante ao processo de formação do Rift Valley do Leste Africano. Ele também conjecturou a hipótese de ter ocorrido um evento metassomático que alterou a temperatura do manto superior. Uma possível injeção de fluídos nas atuais zonas de cisalhamento ocasionando a redução da temperatura no manto. Considerando a presença de "bolsões" de diferentes densidades em diversos domínios no manto superior.

Entretanto, Schilling e colaboradores (1987) a bordo do navio de pesquisa Robert Conrad mapearam a distribuição de idade da crosta oceânica, realizaram análises geoquímicas, acompanharam a atividade magmática do local através de sonar de varredura lateral (GLORIA) e levantaram outras hipóteses para explicar a presença da anomalia: um padrão global de circulação do manto cujos cinturões formariam sobre a região equatorial uma área de downwelling e aprisionamento de slab devido aos processos de agregação e dispersão de continentes no decorrer do tempo geológico. Esta última hipótese é baseada na reconstrução paleogeográfica elaborada por Daziel (1997) a qual descreve eventos de subducção anteriores a formação de Pangéia ocorridos na região equatorial do que hoje é o atual Oceano Atlântico. Quando devido ao fechamento dos Oceanos Rheico e lapetus ocorreu a subducção de arco de ilhas e encontro dos continentes Báltica e Laurentia. (Sichel et al. 2008).

A fim de caracterizar esta fonte anômala através da gravimetria utilizaram-se dados de anomalia ar livre, anomalia Bouguer, altura geoidal residual e tensor gradiente da gravidade. A utilidade em combinar informações sobre o geóide, gravidade e as derivadas do gradiente vertical da gravidade para delinear anomalias de massa e comparar através destes métodos a 
descrição do campo geopotencial foi descrita por Bowin e colaboradores (1986). Onde diferentes métodos encontram-se descritos para delinear a distribuição de massa em sub-superfície conforme uma estimativa de máxima profundidade segundo cada conjunto de dado.

Em princípio, o geóide e o campo da gravidade são descrições equivalentes do campo potencial da Terra no sentido que a componente vertical da gravidade pode ser transformada em geóide e vice-versa (via Integral de Stokes ou Operador de Molodesnkii). Entretanto, cada conjunto de dados pertencentes ao campo potencial pode ser visto como "uma saída de um determinado filtro" que atenuou certa banda de freqüência.

Bowin (1986) em análises de profundidade de massas anômalas e sua dada contribuição para cada grau dos coeficientes harmônicos esféricos do campo geopotencial indicou que o "cone de soluções" torna-se mais restrito quando aplicadas análises dos perfis da anomalia conforme uma dada geometria (linha de massa ou centro de massa) do que uma tradicional análise de freqüência de um tipo de dado.

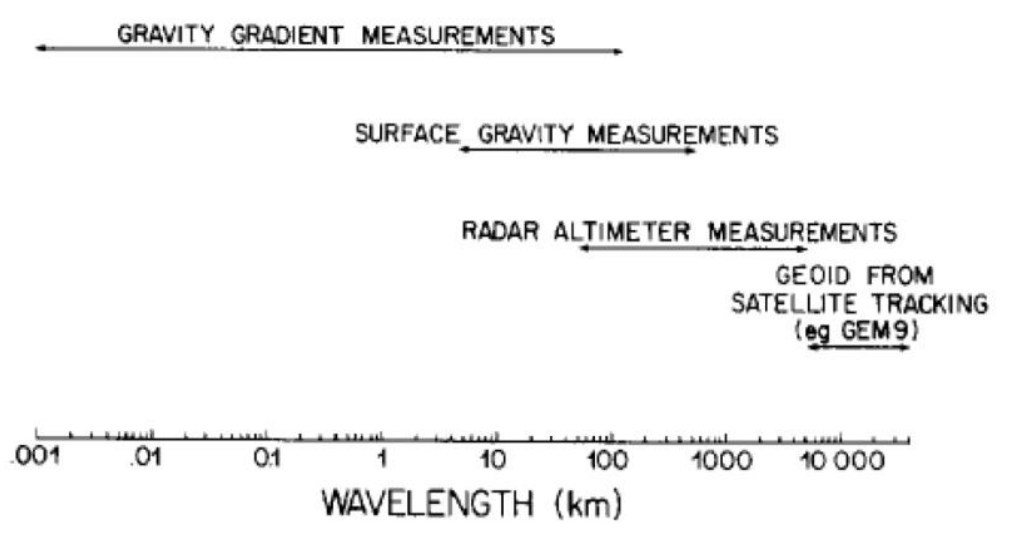

ILUSTRAÇÃO 1: BANDAS DE COMPRIMENTO DE ONDA INCLUINDO DADOS DE GRAVIDADE, GEÓIDE OBTIDO DE RADAR ALTIMÉTRICO. EM ESCALA LOGARÍTMICA. BOWIN (1986). 


\section{CAPÍTULO 2 \\ 2. GEOLOGIA REGIONAL}

Falhas transformantes que cortam cordilheiras mesoceânicas são as feições topográficas mais abundantes nos oceanos por todo o planeta. A área equatorial do Oceano Atlântico é caracterizada por grandes deslocamentos dos eixos da dorsal mesoceânica. Nesta região está localizado o ASPSP formado por 5 ilhas e 4 penedos (Campos et al.,2002).

Trata-se de um raro afloramento de peridotitos. Os peridotitos são rochas ultramáficas que fornecem muitas informações sobre o manto. $O$ arquipélago na verdade é a expressão de uma cadeia submarina em forma de "S" encaixada na falha transformante (Moraes, J.F.S. 1996).

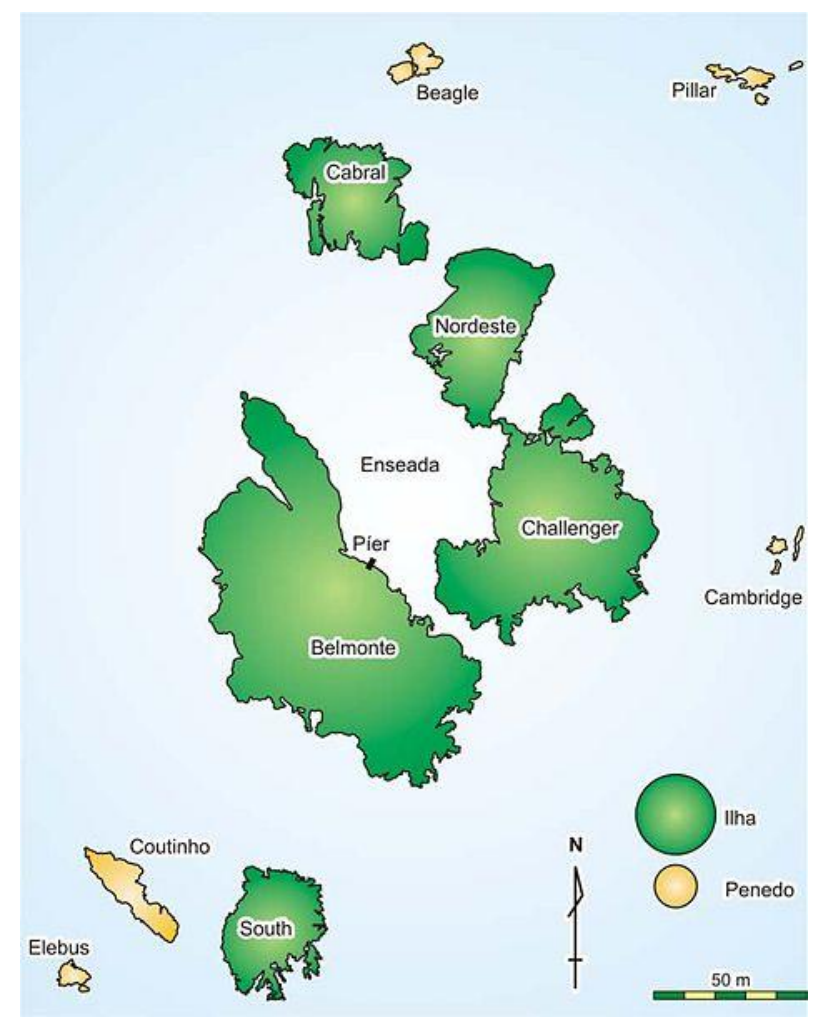

ILUSTRAÇÃO 2: DETALHE DO ARQUIPÉLAGO SÃO PEDRO E SÃO PAULO. MOTOKI ET AL (2008). 


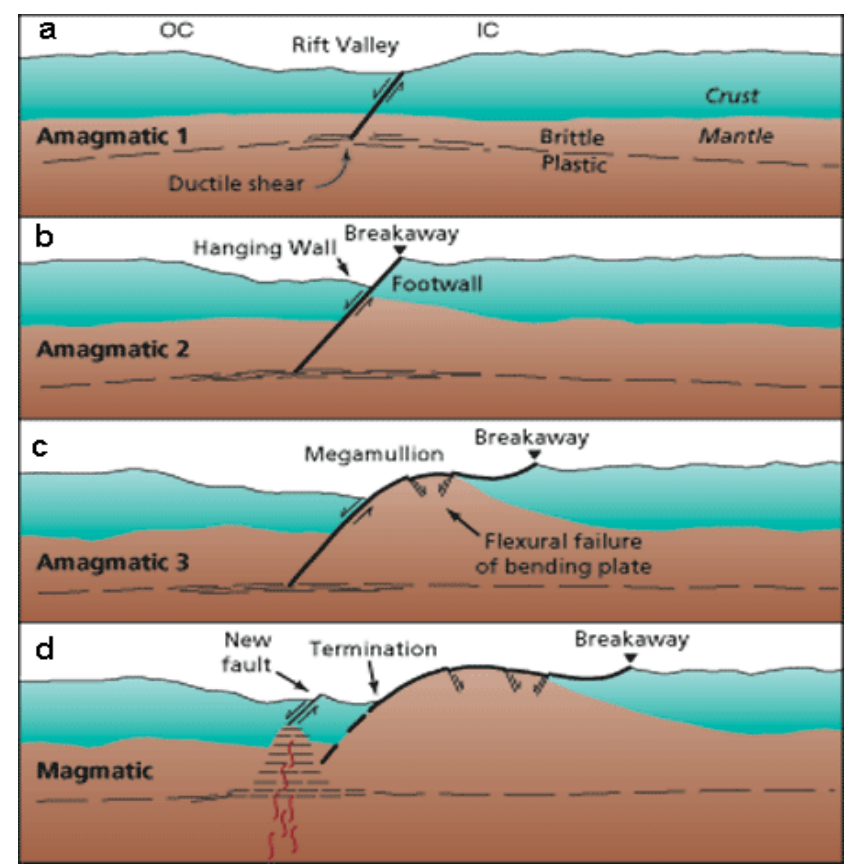

ILUSTRAÇÃO 3: PROCESSO DE FORMAÇÃO DE MEGAMULLION. TUCHOLKE (1998).

A formação do ASPSP ainda está em discussão. De acordo com Tucholke (1998), nesta região é comum ocorrer a "exumação" (ascensão de blocos devido a movimentos tectônicos). Estes blocos são conhecidos como núcleos complexos oceânicos e provavelmente são formandos quando 0 suprimento magmático se torna limitado por algum motivo permitindo que a movimentação falhamento prossiga. Até que o bloco conhecido como lapa (ou footwall) seja soerguido. O processo de formação de um megamullion encontra se descrito a seguir:

a) Seção em perfil de um rift-valley a partir do cume externo ou outside corner (OC) e cume interno ou inside corner (IC). Fase amagmática;

b) Com o tempo a falha aumenta em profundidade acompanhando o aprofundamento da transição rúptil-dúctil;

c) Uma porção da crosta e do manto superior foi exumada após a rotação do bloco-lapa eventualmente formando um megamullion;

d) Com o retorno do magmatismo termina o crescimento do megamullion, assim como a formação de uma nova falha é enfraquecida através da construção de um rift-valley; 
Uma zona de fratura é caracterizada por um alinhamento de feições tais como grabens e bacias sedimentares associadas a altos vulcânicos e montes submarinos cujo comportamento alongado é marcado por um desnível batimétrico (Gary et al. 1973 apud Asmus e Guazelli, 1981).

De acordo com Alves (2002), as primeiras investigações em zonas de fratura (ZFs) foram realizadas por Murray (1939) e Menard e Dietz (1952) na porção norte do Oceano Pacífico. Atualmente, devido à grande importância do tectonismo em compartimentar ambientes sedimentares tais como bacias marginais, diversos estudos têm contribuído para a compreensão morfo-estrutural das ZFs em todos os oceanos.

No Brasil, a porção sudeste da margem continental foi intensamente estudada, principalmente as regiões das bacias de Santos e Campos, devido ao interesse exploratório da indústria petrolífera na região. Foram descritas inicialmente através do projeto REMAC (Reconhecimento da Margem Continental Brasileira). Na porção equatorial do Oceano Atlântico, os primeiros levantamentos geofísicos foram realizados durante a década de 70 e 80 a partir do projeto REMARC (Projeto de Reconhecimento Global da Margem Continental Brasileira) e Centratlan (Acordo de Cooperação Brasil-EUA) (Gorini, 1981).

São denominadas Zonas de Fratura Equatoriais as seguintes feições: Zona de Fratura São Paulo, Romanche e Chain/Fernando de Noronha. Quanto à classificação, as falhas poderão ser devididas conforme a complexidade de suas estruturas e extensão (Pushcharovsky, 1991; Timofeev et al., 1990 apud Agapova, 1994), a saber, transoceânicas (transoceanic), transcordilheira (transridge), intra-cordilheira (intraridge). Falhas do tipo transoceânicas são aquelas que separam grandes segmentos de cordilheiras mesoceânicas, os quais diferem em mergulho, ambiente batimétrico, largura, estrutura geológica e parâmetros geofísicos. A Zona de Fratura São Paulo (ZFSP) é do tipo transoceânico. A ZFSP é contígua a porção sul do segmento equatorial da CMO. É composta por um conjunto de três falhamentos (Agapova, 1984).

Em 1987, 1990 e 1991 o navio Akademik Nikolaj Strakhov realizou levantamentos geofísicos na região através do programa EQUARIDGE (Equatorial Segment of the Mid-Atlantic Ridge) desenvolvido pela Comissão Oceanográfica Intergovernamental (Unesco). Em 1996, os resultados desse programa foram 
publicados incluindo nestes um levantamento gravimétrico realizado entre $2^{\circ} 30^{\prime} \mathrm{N}$ e $5^{\circ} \mathrm{N}$ na cordilheira Meso-Atlântica (CMA) (EQUARIDGE, 1996).

Outros trabalhos na área equatorial do Oceano Atlântico foram publicados. A maioria realizou investigação geoquímica de amostras de rochas: Bonatti (1996), Bonatti et al. (1994), Bonatti et al. (1993), Bonatti et al. (1992), Bonatti (1990), Bonatti et al. (1971), Bonatti et al. (1970), Hekinian et al. (2000), Ligi et al. (2005), Mello (1993), Palma (1998), Schilling et al. (1995), Sichel et al. (2001), Sichel et al. (2008) e Stanton et al. (2006).

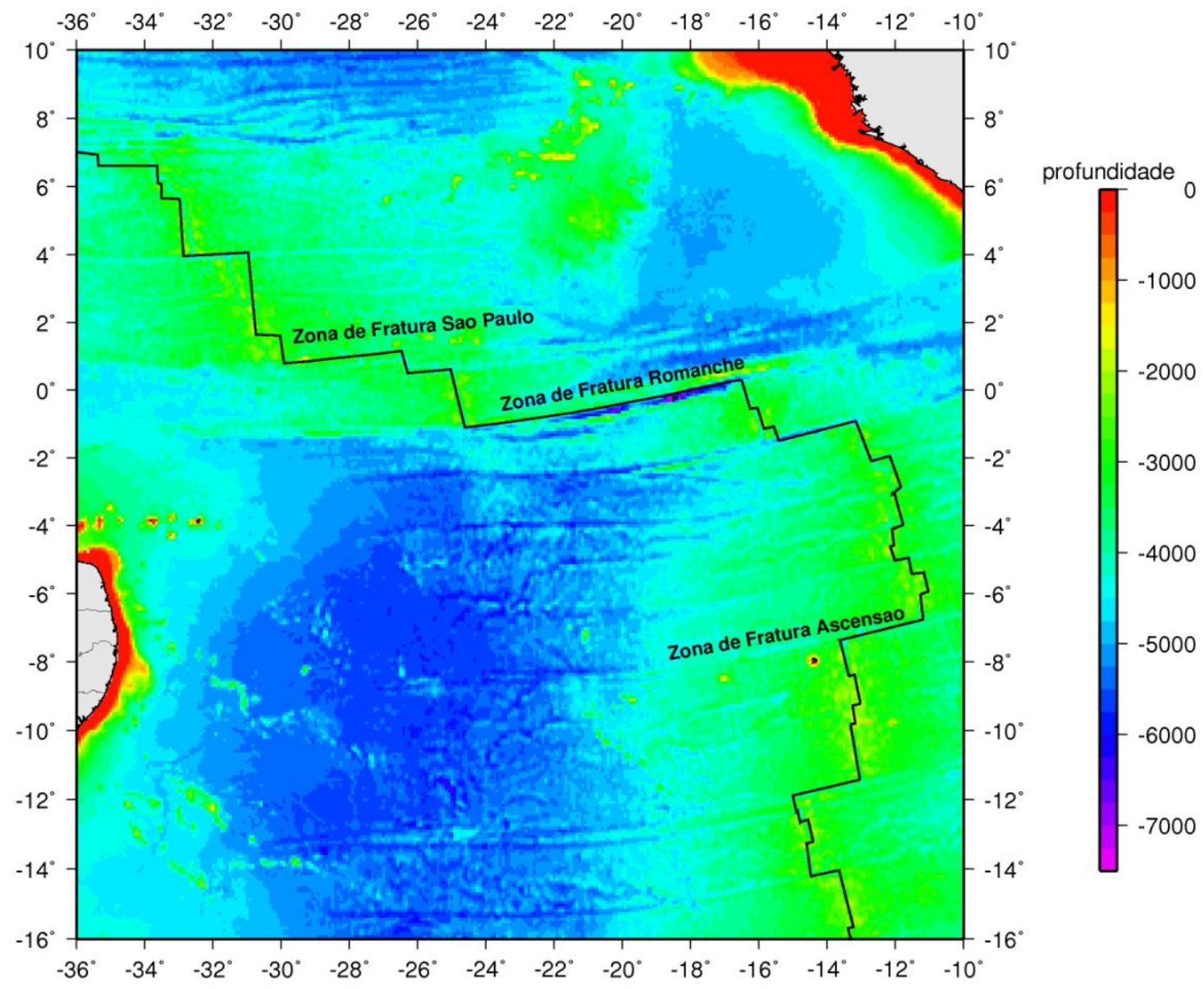

GMT 2009 Aug 31 20:54:44 Batimetria ETOPO 1 

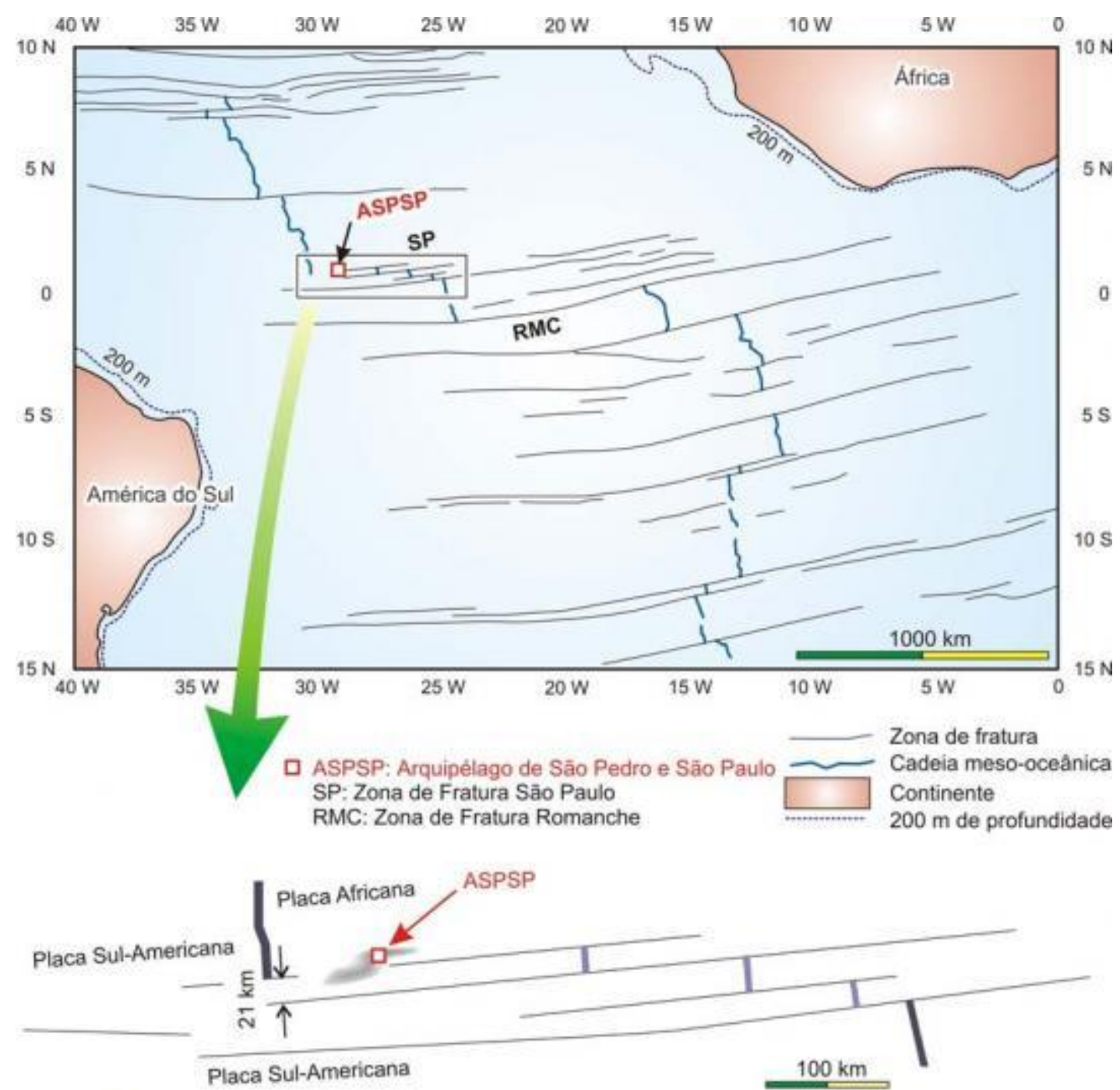

Cadeia meso-oceânica

Megamullion de Sảo Pedro e São Paulo

ILUSTRAÇÃO 5: LOCALIZAÇÃO DO ARQUIPÉLAGO SÃO PEDRO E SÃO PAULO. SICHEL ET AL. (2008).

Em um breve resumo sobre o interior do planeta, cabe recordar que existe uma classificação segundo a atenuação da velocidade de propagação das ondas sísmicas $\mathrm{P}$ (longitudinais) e S (shear = cisalhantes), sendo que estas últimas não se propagam em meios líquidos. Então, subdivide-se a Terra em crosta, manto superior, zona de transição, manto inferior, núcleo externo e núcleo interno. A Zona de Baixa Velocidade está localizada entre as profundidades de 60 a 200 km. Já a astenosfera faz parte de uma classificação reológica da Terra, ou seja, em função do comportamento de seus constituintes. 
A astenosfera encontra-se a partir da isoterma de $1200^{\circ} \mathrm{C}$. Trata-se de um limite crosta-manto que engloba parte do manto superior e da zona de transição. A litosfera apresenta um comportamento mais rígido e engloba a crosta e uma porção do manto conhecida como manto litosférico. A espessura de litosfera é variável de acordo com sua idade, gradiente térmico e natureza composicional (Fowler, C.M.R. 2005).

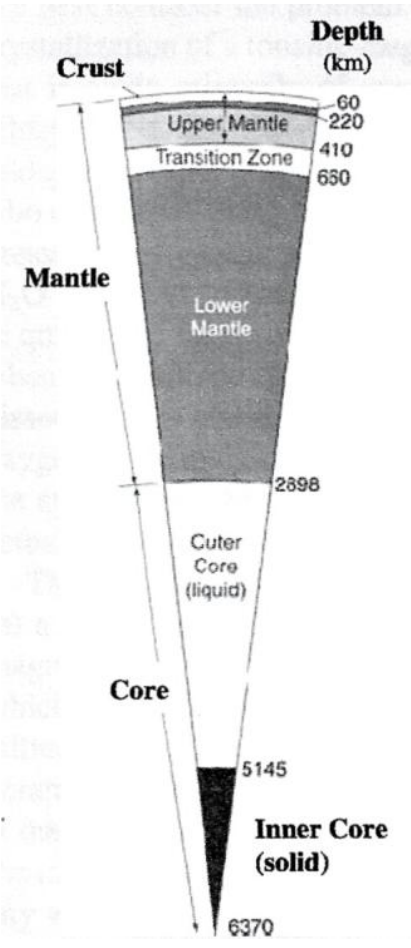

ILUSTRAÇÃO 6: REPRESENTAÇÃO DA ESTRUTURA INTERNA DA TERRA (WINTER, 2001).

Esta pesquisa tem por objetivo a caracterização gravimétrica da ZFSP. A interpretação de dados gravimétricos conforme uma análise morfotectônica do assoalho oceânico tornou-se uma grande ferramenta para a compreensão da organização espacial das placas litosféricas.

A possível existência de fragmentos frios originados de uma placa subductada abaixo da ZFSP é uma das hipóteses consideradas por diversos autores para explicar a anomalia térmica encontrada no manto. Entretanto, existem muitas outras considerações a serem feitas a este respeito. Seguem listadas as cinco hipóteses consideradas por Schilling e seus colaboradores: 
1. A possibilidade de um duto subaxial ao longo da cordilheira conduzindo um fluxo de magma em direção à porção norte da ZFSP consecutivamente formando um resfriamento seguido de cristalização fracionada do magma. A taxa de espalhamento nesta região é de 1,3 cm/ano (lenta);

2. A outra hipótese é que esta área fria do manto sob o Atlântico equatorial estaria relacionada a modelos locais ou globais de downwelling do manto. Assim as bacias do Oceano Índico e Pacífico também estariam sofrendo este mesmo processo (Schilling et al., 1995 apud Bonatti et al., 1993).

3. O gradiente de temperatura presente na porção sul da Zona de Fratura São Paulo está relacionado à natureza do processo de abertura do Oceano Atlântico. A abertura do Oceano Atlântico Central ( 190 Ma) foi acomodada ao longo de suturas pré-existentes e cinturões móveis localizados na antiga margem oriental do Cráton Oeste Africano. A abertura do Atlântico equatorial a partir de falhas strike-slip formadas por rifteamento indicaria possível contribuição deste processo para a formação de heterogeneidades atualmente presentes no manto.

4. A crosta fria e fraturada da listosfera nesta região pode resfriar a astenosfera através de processos hidrotermais abaixo da Zona de Fratura São Paulo. Lembrando que a formação do assoalho oceânico nesta região indica uma grande oscilação do centro de espalhamento e mudanças na direção das falhas transformantes além dos movimentos compressivos com soerguimento de blocos. Embora alguns desses processos sejam respostas à reorganização das placas são evidências de uma atividade tectônica incomum.

5. A aparente natureza fria do manto superior embaixo da Zona de Fratura São Paulo poderia representar fenômenos de agregação e dispersão de supercontinentes no decorrer do tempo geológico. 


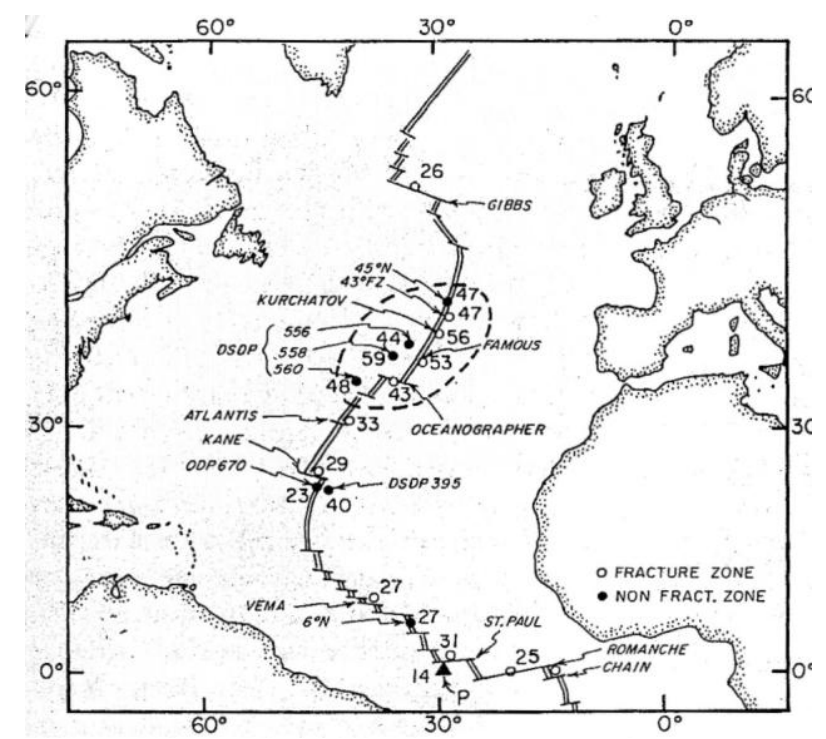

ILUSTRAÇÃO 7: MAPA DA REGIÃO ESTUDADA POR BONATTI (1990). OS CÍRCULOS ESCUROS INDICAM A REGIÃO DE AMOSTRAGEM E OS NÚMEROS OS VALORES MÉDIOS. O TRIÂNGULO INDICA A AMOSTRA DE PERIDOTITOS DO ASPSP E A ÁREA PONTILHADA INDICA O HOTSPOT DOS AÇORES.
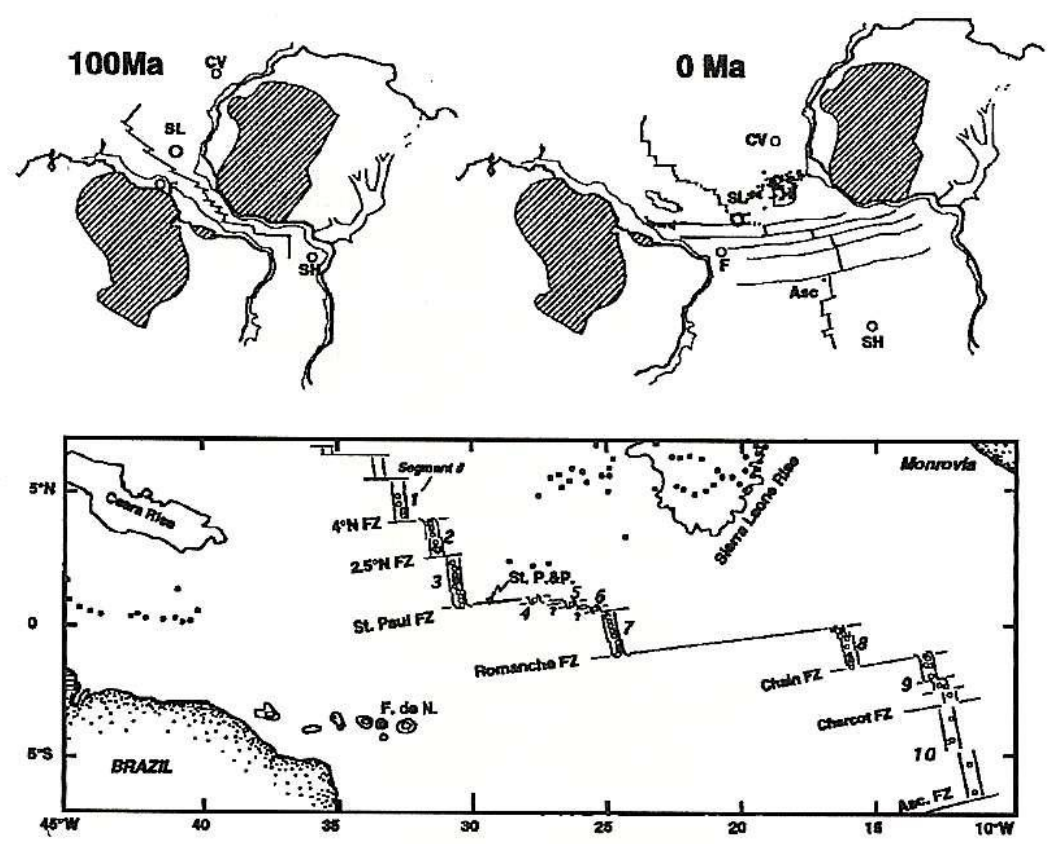

ILUSTRAÇÃO 8: MAPA MORFOTECTÔNICO SIMPLIFICADO DA REGIÃO EQUATORIAL MOSTRANDO A LOCALIZAÇÃO DA AMOSTRAGEM NO EIXO DA DORSAL (CÍRCULOS ABERTOS). NOTE A POSIÇÃO CONJUGADA DA CADEIA ASSÍSMICA CEARÁ E A ELEVAĈ̃̃ SIERRA LEOA. OS CÍRCULOS SÓLIDOS REPRESENTAM OS MONTES SUBMARINOS (LOCALIZAÇÃO DE EPP E SMOOTH, 1983). O MAPA GEOLÓGICO DE 0 A 100 MA MOSTRA A POSIÇÃO DA LITOSFERA CRATÔNICA EM RELAÇÃO AS ZONAS DE FRATURA EQUATORIAIS. HOTSPOTS REPRESENTADOS: CV (CABO VERDE), SL (SIERRA LEOA), F (FERNANDO DE NORONHA), ASC (ASCENSION), SH (SANTA HELENA) E ST.P \& P SÃO AS ILHAS DO ASPSP. O RIFTEAMENTO DA LITOSFERA CRATÔNICA DO PERÍODO ARQUEANO DURANTE O FINAL DO CRETÁCEO FOI BASEADO FAIRHEAD E GREEN (1989). EXTRAÍDO DE SCHILLING ET AL., (1995). 
Os autores ressaltam ainda que o termo coldspot utilizado por Bonatti não quer dizer que região em questão seja reabastecida pelos mesmos tipos de processos que operam em um hotspot.

A hipótese de fragmentos de slab foi baseada na paleoreconstrução geográfica de continentes elaborada por Daziel (1997). Esta considera os seguintes aspectos: o fechamento dos Oceanos lapetus e Rheico e a colisão entre os continentes Báltica e Laurentia com posterior subducção de arco de ilhas. $\mathrm{Na}$ região que atualmente se encontra a porção equatorial do Oceano Atlântico (Sichel et al., 2008).

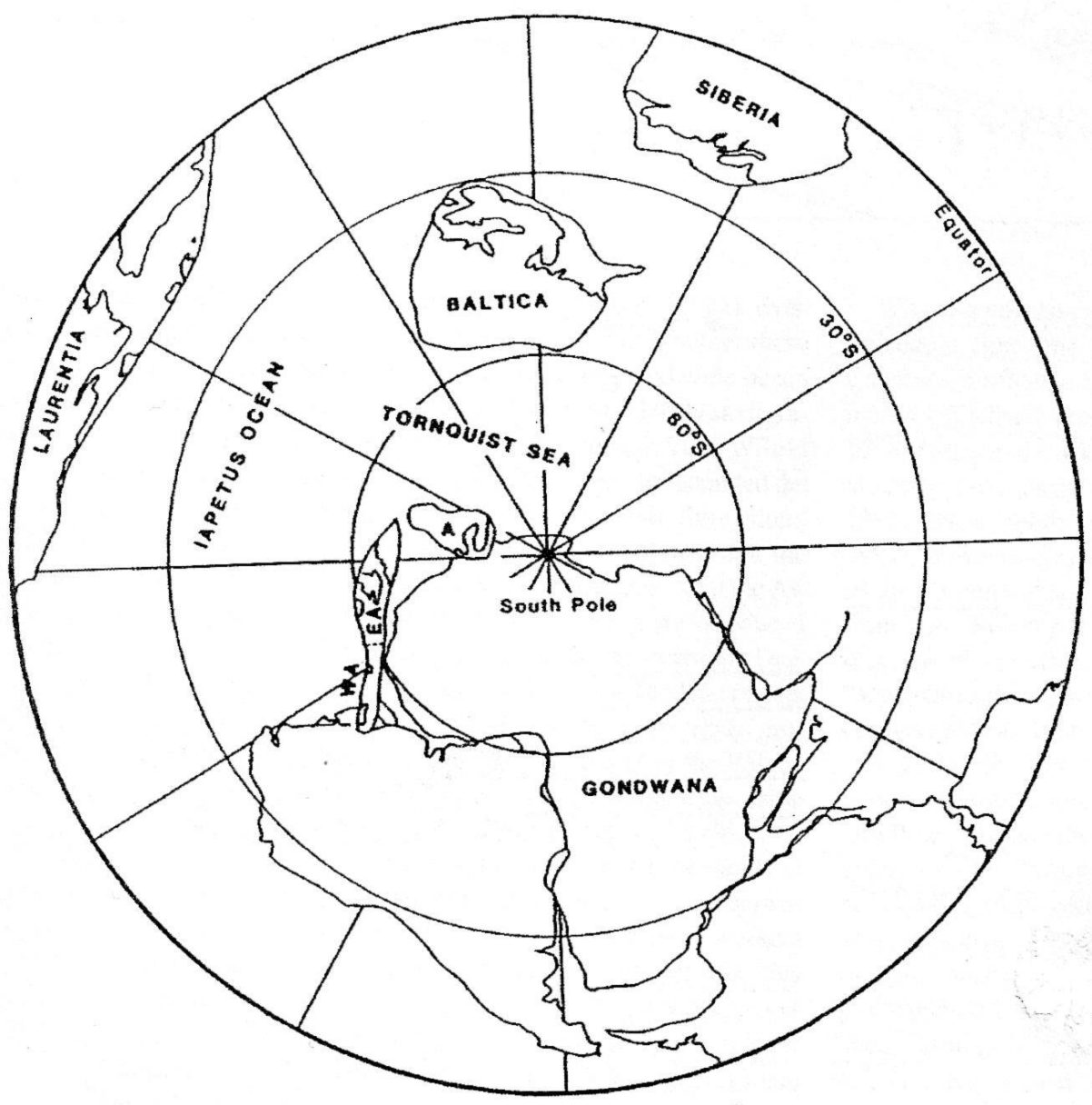

llustração 9: Reconstrução geográfica baseada em dados paleomagnéticos do final do período Ordoviciano (Torvis e Trench, 1991). Note que paleolatitude do continente Laurásia foi alterada em sentido horário em relação à posição de Gondwana. $O$ eixo simétrico do campo magnético foi obtido pela posição das margens proto-Andina e proto-Apalachiana. Daziel (1997). 
De acordo com a classificação apresentada em Agapova (1994), as falhas transformantes são classificadas quanto à complexidade estrutural e extensão na província fisiográfica da cordilheira mesoceânica. Denominam-se transoceânicas (transoceanic) quando separam os segmentos da cordilheira em longas distâncias, transcordilheira (transridge) quando separam os segmentos em distâncias não muito longas e intra-cordilheira (intra-ridge) quando separam curtos segmentos. A Zona de Fratura São Paulo é formada por um sistema de falhas classificadas como transoceânica porque separam os eixos da dorsal em aproximadamente $600 \mathrm{~km}$ (Sichel et al., 2008).

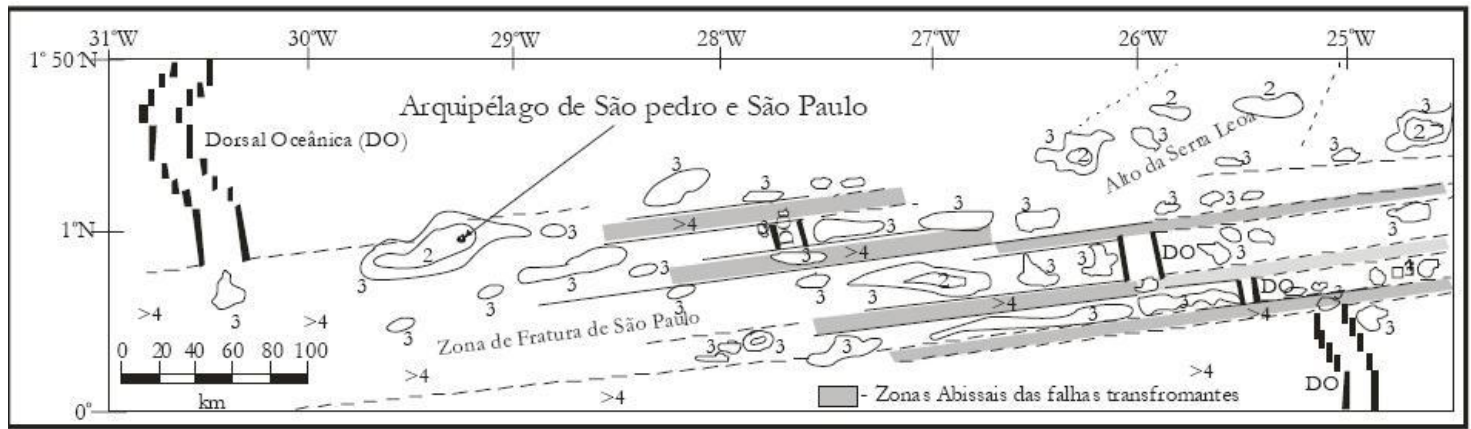

ILUSTRAÇÃO 10: DETALHE DO SISTEMA DE FALHAS TRASNFORMANTES DA ZFSP .HEKINIAN ET AL. (2000).

Agapova (1994) através de um ecobatímetro multifeixe realizou um levantamento detalhado durante o sétimo cruzeiro $R / V$ Akademik Nikolai Strakhov em 1988. Os dados resultaram em mapas batimétricos em escala de 1:250.000 com um intervalo de isobátas de $100 \mathrm{~m}$. e $200 \mathrm{~m}$.

Ainda de acordo com Agapova, a ZFSP não havia sido estudada em detalhe até então. Ele cita um mapeamento realizado anteriormente por Gorini (Gorini, 1981), o qual realizou poucas linhas de perfilagem produzindo mapas em escala de 1: 1.000.000.

Neste trabalho, Agapova revelou muitas estruturas morfológicas complexas do segmento ativo da porção leste da ZFSP. Ele classificou a ZFSP como um sistema de falhas no qual a cordilheira é deslocada em pequenos segmentos formando zonas de depressão. 
Foram reconhecidas quatro zonas de depressão sublatidunais onde a profundidade aumenta de norte para sul conforme visualiza-se na ilustração 10.

Agapova identificou na porção leste da ZFSP blocos angulares e maciços vulcânicos isolados. Esses blocos estão separados por pequenas formas anticlinais com mergulho oblíquo e submeridional.. Foram encontrados dois gaps (relacionados aos "pulos" do eixo da cordilheira).

A profundidade dos gaps chega a $4500 \mathrm{~m}$ os quais são compatíveis com a profundidade das depressões adjacentes a zona de fratura e excedem, em torno de $1000 \mathrm{~m}$, a profundidade do rift no segmento norte da cordilheira mesoatlântica da ZFSP.

A topografia de fundo do rift foi comparada por Agapova a favos de mel (ilustração 12) onde sedimentos foram encontrados em alguns locais. Esses locais formam pequenos anéis e outras formas anticlinais separando blocos que foram encontrados cobertos por sedimento.

A zona de fratura em si é uma região cortada por 3 depressões. Esse conjunto é denominado por cavidades nodulares profundas (nodal deeps) que se encontram na junção cordilheira-falha formando depressões. São pronunciadas bacias angulares onde não foi encontrada sedimentação.

Outras depressões foram encontradas, mas classificadas de interrift porque estão na porção mais interna da região ativa cuja topografia do fundo tem formato em " $V$ ". Essas depressões em formato de calha se alternam bruscamente do eixo da cordilheira em direção a porção central. A maior delas é uma calha cobertas por sedimento com espessura em torno de 300 a $500 \mathrm{~m}$.

A diferença no grau de sedimentação entre as bacias interrift e as depressões marginais indica a idade relativamente jovem desta parte do rift. 


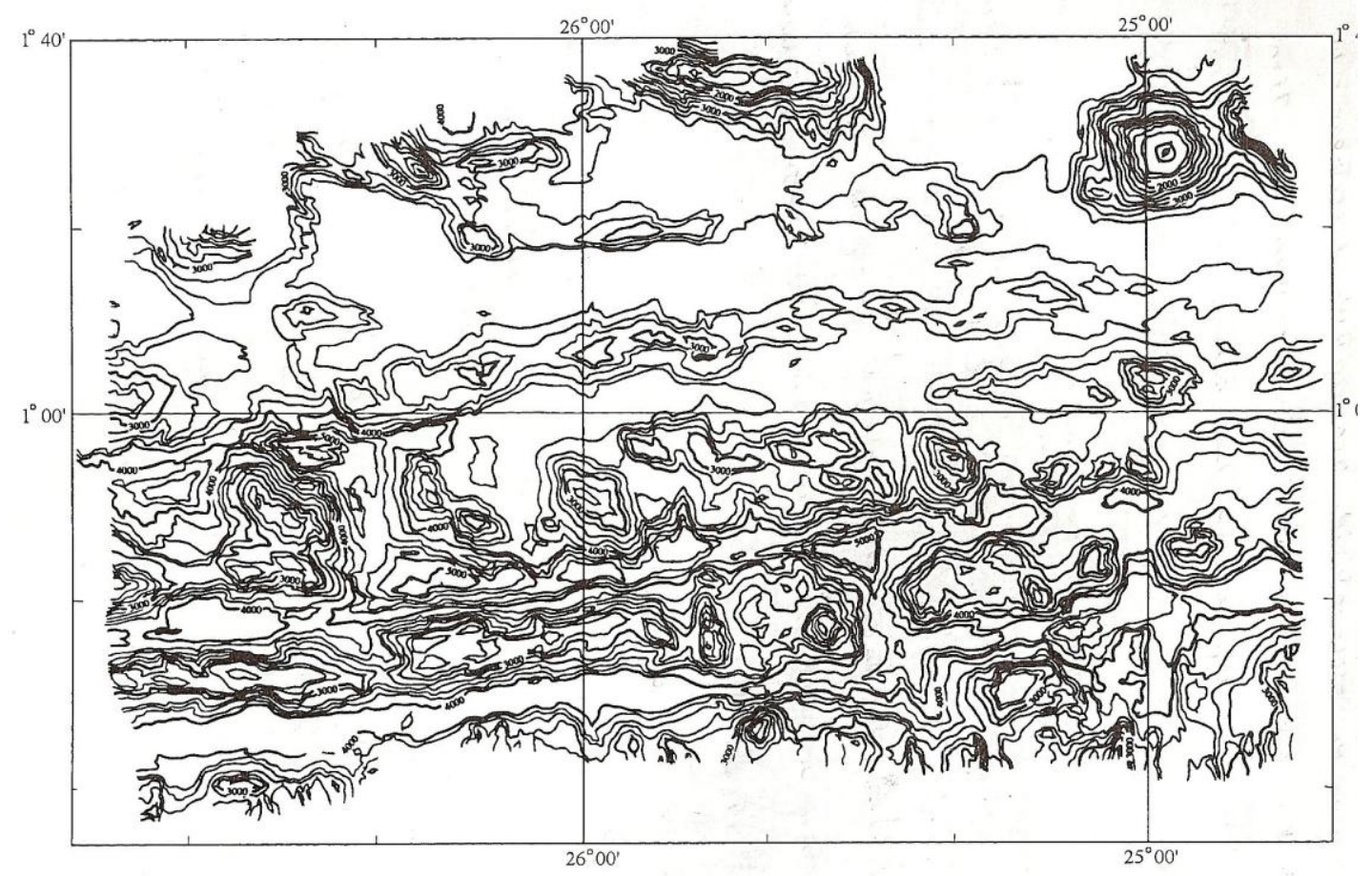

ILUSTRAÇÃO 11: MAPA BATIMÉTRICO DA ZONA DE FRATURA SÃO PAULO (PORÇÃO LESTE DA ÁREA SISMICAMENTE ATIVA) INTERVALO DE 200 m. AGAPOVA (1994).

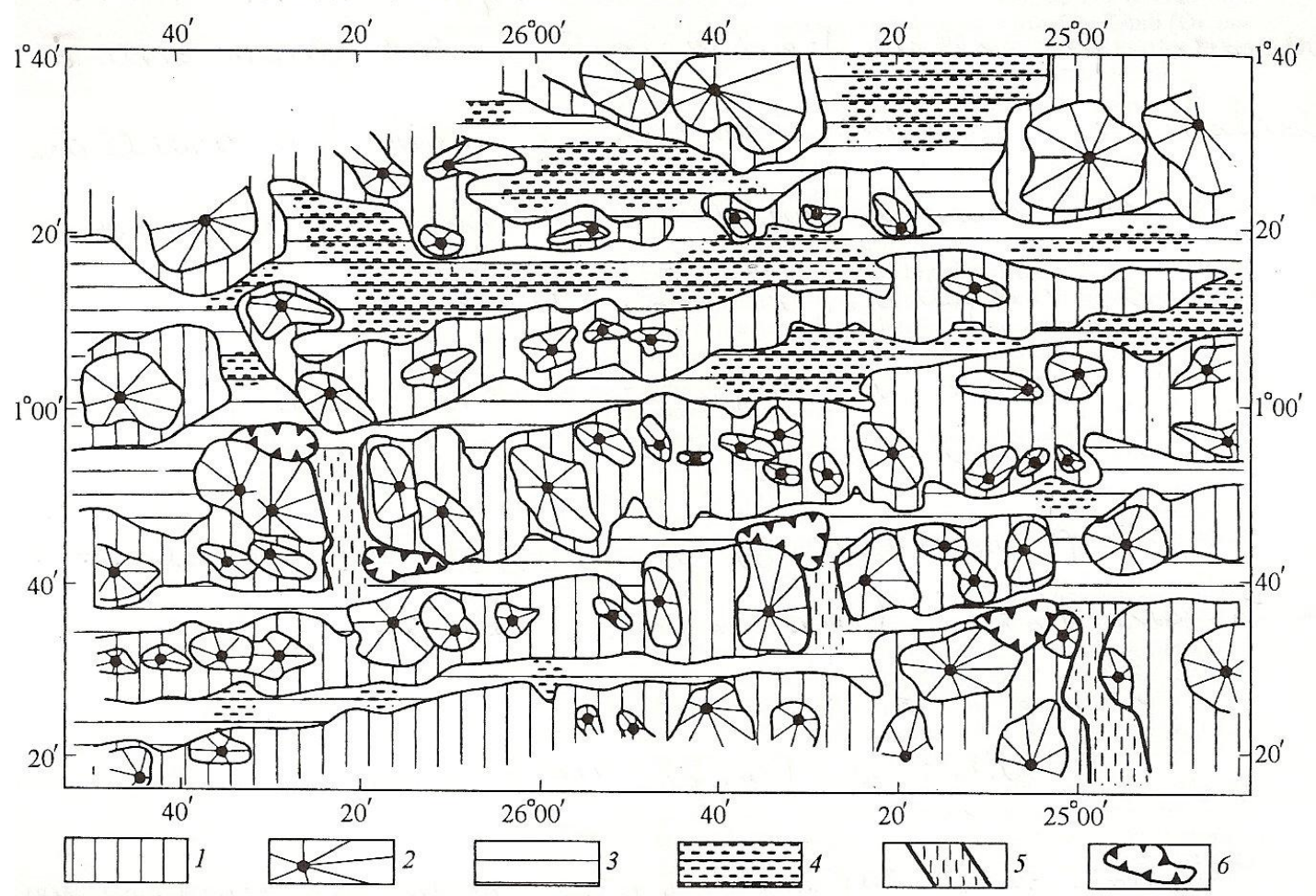

ILUSTRAÇÃO 12: MAPA MORFOESTRUTURAL DA ZONA DE FRATURA SÃO PAULO. 1-FRAGMENTOS DE RIFT; 2-MONTES SUBMARINOS DENTRO DE RIFT NA DORSAL; 3- ZONAS DEPRESSIVAS NA FALHA COM TOPOGRAFIA RELATIVAMENTE ENRRUGADA E ESPESSURA SEDIMENTAR DE $500 \mathrm{M}$; 4- ZONAS DEPRESSIVAS NA FALHA COM FUNDO RELATIVAMENTE PLANO E ESPESSURA SEDIMENTAR SUPERIOR A $500 \mathrm{M}$; 5- RIFT VALLEYS; 6- NODAL DEEPS. 


\section{CAPÍTULO 3 \\ 3. FUNDAMENTOS DO GEOPOTENCIAL}

Pela teoria desenvolvida desde Galileu a Newton, a Lei da Gravitação Universal define a força de atração gravitacional que gera um campo o qual está submetida uma massa puntiforme $\mathrm{m}$ ao redor de uma massa atrativa $\mathrm{M}$.

$$
|\vec{F}|=G \frac{M \cdot m}{r^{2}}
$$

onde:

$r=$ distância entre as duas massas

$\mathrm{G}=$ constante gravitacional $\left(6,67.10^{-11} \mathrm{Nm}^{2} \mathrm{~kg}^{-2}\right)$

Entretanto, o campo da gravidade é formado pela ação conjunta da força centrífuga e força gravitacional. Portanto, a aceleração da gravidade (ou simplesmente gravidade) é a soma destas acelerações:

(2) $\vec{g}=\overrightarrow{a_{c}}+\vec{a}$

A aceleração gravitacional $\vec{a}$ tem intensidade aproximadamente constante sobre a Terra sendo dirigida em sentido radial, enquanto a aceleração centrífuga $\overrightarrow{a_{c}}$ tem direção perpendicular ao eixo de rotação da Terra. Por isso, o Potencial da Gravidade (ou Geopotencial) é expresso pela soma do Potencial Gravitacional com o Potencial Centrífugo:

$$
W(x, y, z)=V(x, y, z)+\Phi(x, y, z)
$$


Considerando que campo exercido pela força da gravidade é representado através de uma função potencial. A aplicação do operador diferencial gradiente $\nabla$ torna possível relacionar campo da aceleração da gravidade ao geopotencial.

(4) $\vec{g}=\nabla(W)$

O gradiente é descrito através das derivadas parciais de primeira ordem de acordo com o sistema de referência adotado (polar ou cartesiano). Formando a chamada "derivada direcional":

$$
\nabla F=\frac{\partial}{\partial x} \vec{i}+\frac{\partial}{\partial y} \vec{j}+\frac{\partial}{\partial z} \vec{k}
$$

Aplicando o operador laplaciano a função potencial gravitacional obtém-se a equação de Laplace (equação 8). Trata-se da soma de todas as derivadas parciais de segunda ordem. Com isto, o geopotencial é reduzido a uma série de funções harmônicas que são soluções da equação de Laplace (Moritz, 1980).

(6) $\Delta=\nabla(\nabla)=\nabla^{2}$

(7) $\nabla^{2} F=\frac{\partial^{2}}{\partial x} \vec{i}+\frac{\partial^{2}}{\partial y} \vec{j}+\frac{\partial^{2}}{\partial z} \vec{k}$

(8) $\nabla^{2} V=0$

(9) $\nabla^{2} W(r, \theta, \lambda)=\nabla^{2} V(r, \theta, \lambda$,

A equação de Laplace é resolvida em coordenadas polares ou planas. De ambas as formas obtêm-se um modelo matemático que representa 0 geopotencial. 
As funções que satisfazem a equação de Laplace em todos os pontos de uma região do espaço são chamadas harmônicas nessa região, pois essas funções são contínuas quanto as suas derivadas (Gemael, C., 2002).

$$
\nabla^{2} V=\frac{\partial^{2} V}{\partial r^{2}}+\frac{2}{r} \frac{\partial V}{\partial r}+\frac{1}{r^{2} \sin \theta} \frac{\partial}{\partial \theta}\left(\sin \theta \frac{\partial V}{\partial \theta}\right)+\frac{1}{r^{2} \sin ^{2} \theta}\left(\frac{\partial^{2} V}{\partial \lambda^{2}}\right)
$$

Por meio de artifícios matemáticos obtém-se uma equação com coeficientes constantes formada por uma combinação linear de soluções. As funções $V \ll, \theta, \lambda$, são chamadas de harmônicos esféricos sólidos. Qualquer solução da equação de Laplace, homogênea em $x, y$ e $z$ constitui "um harmônico esférico sólido" e o grau da homogeneidade $n$ é o grau do harmônico.

$$
\left.V(\boldsymbol{r}, \theta, \lambda)=\sum_{n=0}^{\infty} \frac{1}{r^{n+1}} \sum_{m=0}^{n} \mathbf{t}_{n m} . P_{n m} \cos \theta \cdot \cos m \cdot \lambda+b_{n m} \cdot P_{n m} \cos \theta\right) \operatorname{senm} \lambda_{-}^{-}
$$

Onde a função de Legendre ou Polinômio de Legendre (de grau n) só faz sentido fisicamente se ' $n$ ' e ' $m$ ' forem inteiros e se $m \leq n$ (Gemael, C., 2002).

$Y_{n}(\boldsymbol{Q}, \lambda) P_{n m} \cos \theta \operatorname{gos} m \lambda$

$$
Y_{n}(\theta, \lambda) P_{n m} \cos \theta \operatorname{senm} \lambda
$$

Onde $a_{n m}$ e $b_{n m}$ são constantes arbitrárias e as funções $Y_{n} \boldsymbol{\theta}, \lambda$, são chamadas de harmônicos esféricos de superfície. Os polinômios de Legendre representam graficamente os coeficientes harmônicos do geopotencial, ou seja, representam as deformações da Terra em relação a uma Terra perfeitamente esférica e a distribuição de massa (simétrica ou assimétrica) em relação aos três eixos principais de inércia. 


\section{CAPÍTULO 4 \\ 4. RESULTADOS OBTIDOS}

\subsection{ALTURA GEOIDAL}

Cabe um breve resumo sobre o géoide e o cálculo de sua altura ou ondulação geoidal. Sabe-se que um dos primeiros modelos adotados considerava a Terra com a forma esférica. Posteriormente, compreendendo que seu movimentação de rotação tornava os pólos levemente achatados adotou-se o modelo elipsoidal. Conforme os parâmetros matemáticos, o modelo regurlarizado do campo gravimétrico é conhecido por elipsóide de referência. O campo da gravidade do modelo tornou-se conhecido como esferepotencial. Este campo da gravidade difere do campo da gravidade da Terra real. Conhecemos este campo pelo nome de geopotencial e este representa a soma do potencial gravitacional ao potencial centrífugo. $O$ esferopotencial difere do geopotencial devido às diferenças na distribuição da densidade que ocorre na Terra real.

O esferopotencial desenvolvido matematicamente conduz ao esferóide enquanto que o geóide é mais do que uma superfície matemática. Trata-se da forma real do planeta Terra apresentando o ajuste de superfícies eqüipotenciais, ou seja, elas ondulam formando cavados e cristas mantendo-se em torno do mesmo potencial gravitacional. Para melhor exemplicá-lo é comum comparar o geóide ao nível médio dos mares excetuando as perturbações. As ondulações ou alturas geoidais $(\mathrm{N})$ são medidas a partir do geóide até a superfície do elipsóide de referência. A altitude ortométrica ( $h$ ) é medida da superfície da Terra até a superfície do elipsóide. Porém a altitude ortométrica considera a perpendicular (normal) ao elipsóide, enquanto a ondulação ou altura geoidal considera a vertical em relação à superfície da Terra. Logo $\mathrm{N}$ e h não são colineares. Por isso, realizase uma aproximação onde:

$H \approx N+h$ 


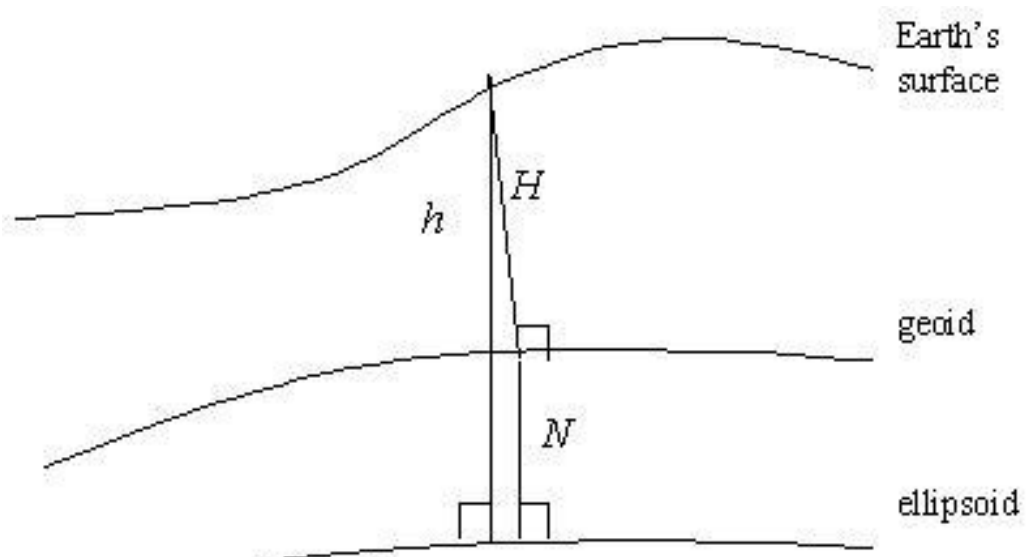

ILUSTRAÇÃO 13: REPRESENTAÇÃo DA ALTITUDE ORTOMÉTRICA (H), ALTURA ORTOMÉTRICA (h), ALTURA GEOIDAL (N). LI, X E GÖTZE, H-J (2001).

\subsection{CÁLCULO DA ALTURA GEOIDAL RESIDUAL}

Conforme mencionado anteriormente, a altitude ortométrica $(H)$ e a altitude geométrica (h) não são colineares, mas pode-se estabelecer a distância entre o geóide e o elipsóide de referência $(\mathrm{N})$ através desta convenção: $H-h \cong \Delta \mathrm{N}$ (Vaníček, P e Christou, N. T. 1993).

É possível relacionar a ondulação do geóide ao campo gravitacional da Terra por meio da seguinte equação (Heiskanen \& Moritz, 1967): $N=\frac{G M}{\gamma r} \sum_{n=2}^{n_{\max }}\left(\frac{a}{r}\right)^{n} \sum_{m=0}^{n}\left[\bar{C}_{n m} \cos (m \lambda)+\bar{S}_{n m} \operatorname{sen}(m \lambda)\right] P_{n m}(\operatorname{sen} \theta)$

- r é a distância do ponto à origem do sistema de coordenadas esféricas;

- $\theta$ é a distância polar;

- $\quad \lambda$ é a longitude geocêntrica;

- a é o raio equatorial;

- G é a constante gravitacional $\left(G=6,67300 \times 10^{-11} \mathrm{~m}^{3} \mathrm{~kg}^{-1} \mathrm{~s}^{-2}\right)$; 
- M é a massa da Terra $\left(5,98 \times 10^{24} \mathrm{~kg}\right)$;

- n é o grau e m é a ordem dos coeficientes;

- $\mathrm{n}_{\max }$ é o grau máximo de expansão utilizado;

- Pnm $(\cos \theta)$ são as funções associadas de Legrende normalizadas de grau $n$ e ordem $m$

- $\overline{C_{n m}}$ e $\overline{S_{n m}}$ são os coeficientes dos harmônicos esféricos normalizados;

Neste caso, foi utilizado o modelo EGM 2008. Cabe ressaltar que este é um modelo do tipo combinado porque utiliza dados gravimétricos terrestres, marinhos e de levantamentos aéreos associados a dados de rastreio de satélite (sistema de retransmissão de mensagens para correção do tempo), altimetria por satélite e missões espaciais exclusivas para medição do campo geopotencial (Amos e Featherstone, 2003).

Quanto maior for o número de dados incluídos no modelo que apresentem melhor distribuição maior será o grau de expansão dos coeficientes que representam o potencial gravitacional terrestre. Conforme equação a seguir (Pavlis et al. 2008):

$$
V \ll, \theta, \lambda \risingdotseq \frac{G M}{r}\left[1+\sum_{n=2}^{N \max }\left(\frac{a}{r}\right)^{n} \sum_{m=0}^{n} \overline{\mathbf{C}_{n m}} \cdot \cos m \lambda+\overline{S_{n m}} \cdot \operatorname{sen} m \lambda ; \overline{P_{n m}} \cos \theta\right]
$$

Utilizando os aplicativos do modelo EGM2008 disponibilizados na homepage do $\mathrm{NGA}^{1}$ é possível calcular a ondulação do geóide através das seguintes formas:

1. Está disponível para download o programa executável em Windows <hsynth_WGS84.exe> que calcula ondulação do geóide por meio dos harmônicos esféricos. Este programa trabalha associado ao aplicativo <EGM2008_to2190_TideFree.gz> que aplica a correção para converter as anomalias de altura em ondulação geoidal referente ao WGS84 acessando os

1 National Geospatial-Intelligence Agency (NGA) - http://earth-info.nga.mil/ 
coeficientes normalizados no aplicativo <Zeta-to-N_to2160_egm2008>. O arquivo de entrada <input.dat> contém valores de latitude e longitude e 0 arquivo de saída <output.dat> contém latitude, longitude e ondulação geoidal.

2. Estão disponíveis para donwload dois programas <interp_1min.exe> e <interp_2p5min.exe> que acessam as respectivas grades globais de ondulação geoidal <Und_min1x1_egm2008_isw=82_WGS84_TideFree> e <Und_min2.5x2.5_egm2008_isw=82_WGS84_TideFree>; é possível a interpolação de valores do arquivo de entrada <input.dat> que contém latitude e longitude gerando um arquivo de saída <output.dat> que contém latitude, longitude e ondulação geoidal.

3. Estão disponíveis para download dois programas executáveis em Windows < gridget_1min.exe $>$ e <gridget_2p5min.exe $>$ que fornecem valores de ondulação sem interpolação.

Inicialmente foi utilizado o programa <hsynth_WGS84.exe> para gerar valores de ondulação geoidal considerando o modelo completo $(n=m=2190)$. Utilizando também o serviço disponível no site do Centro Internacional para Modelos Globais da Terra 2 no serviço oferecido pelo Instituto Potsdam GFZ obteve-se a mesma grade com resolução de 1'. Entretanto, pode-se escolher o modelo de elipsóide de referência (WGS-84), de modelo geopotencial (EGM2008) e seu grau máximo de expansão (completo) e do tipo de sistema de correção de maré (tide free, mean tide ou zero tide). Utilizou-se a opção Tide Free (na qual os efeitos diretos e indiretos de deformação de maré foram retirados). Ainda não inclui-se o termo de grau zero. A seguir, as grades plotadas comparando os dois resultados obtidos para este primeiro contato com o geóide:

2 International Centre for Global Earth Models (ICGEM) - http://icgem.gfzpotsdam.de/ICGEM/ICGEM.html 


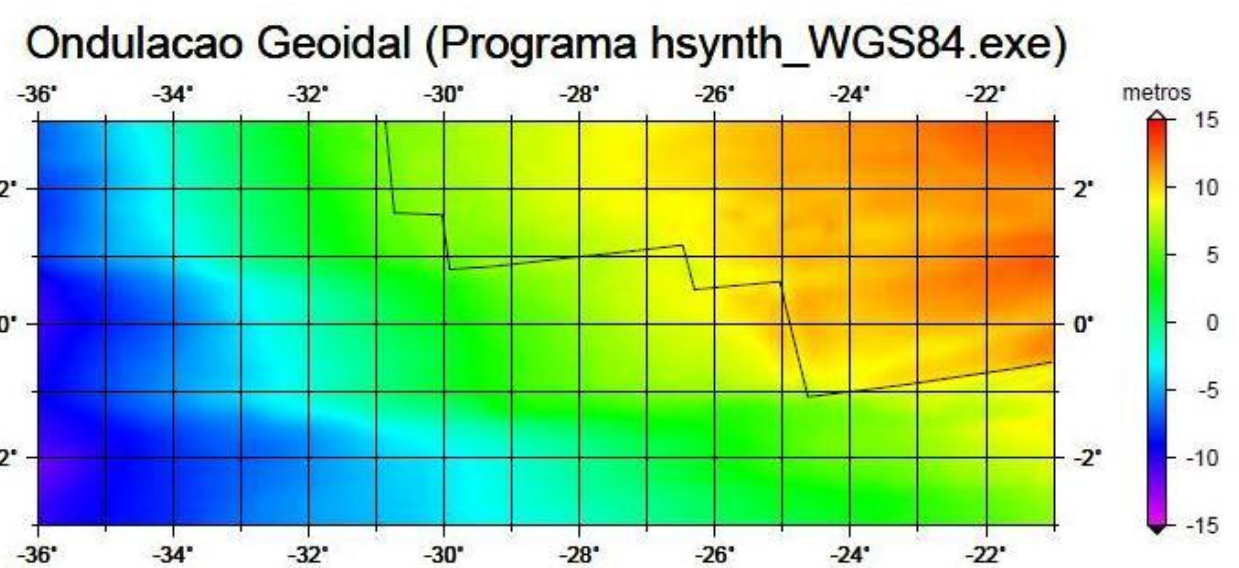

\section{Ondulacao Geoidal (Programa GFZ - POTSDAM)}

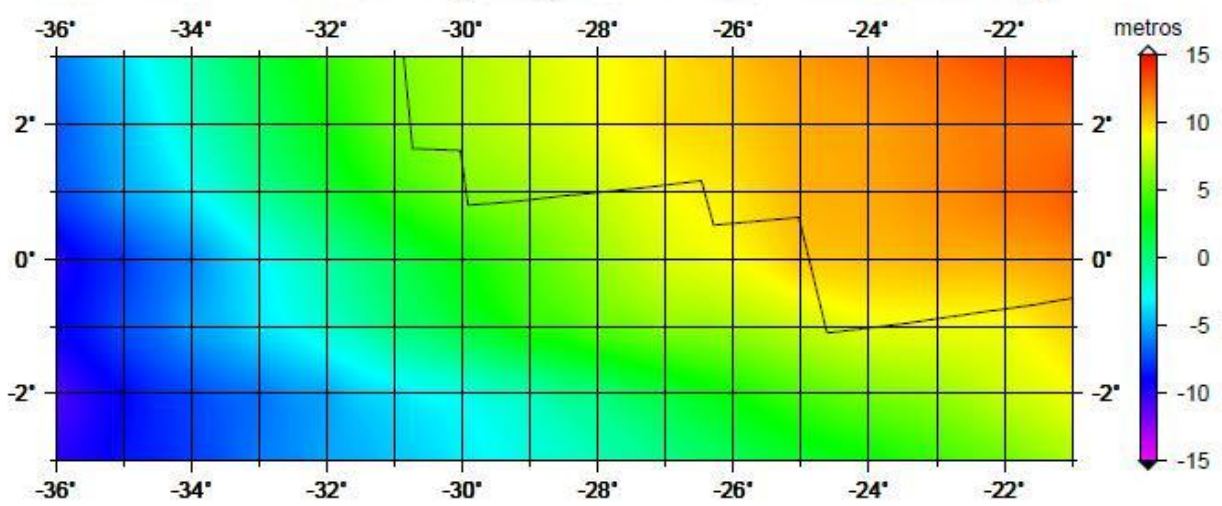

GM] 2009 SEP 3021:52:22. EARTH GRAVITATIONAL MODEL 2008

MAPA 1: GRADE COM RESOLUÇÃO DE 1 MIN. ONDULAÇÃO GEOIDAL GERADA A PARTIR DOS PROGRAMAS DISPONIBILIZADOS NA HOMEPAGE DO NGA E A PARTIR DAS GRADES GERADAS PELO APLICATIVO DISPONIBILIZADO NA HOMEPAGE DO INSTITUTO GEODÉSICO DE POTSDAM.

Os valores de altura geoidal foram calculados a partir de um conjunto de programas disponibilizados pela Universidade de Trieste (Itália) em parceria com a Universidade de Tecnologia da Eslováquia (M. Šprlák and J. Janák, 2006) disponiblizados no curso realizado em setembro de 2008 no IAG.

A partir os programas grafim.job, e g2grd_grafim.exe obtevem-se as grades com resolução de 5 min para a altura geoidal nos seguinte graus: 0 a 10, 0 a 15,0 a 20, 0 a 25,0 a 30 e de 0 a 2160. 
Posteriormente, foi realizada a subtração destas obtendo-se as grades de altura geoidal residual nos seguintes graus: 10 a 2160,15 a 2160, 20 a 2160, 25 a 2160, 30 a 2160 e 35 a 2160. Conforme visualiza-se nos mapas a seguir:

Altura ou Ondulaçẫo Geoidal Residual (N)
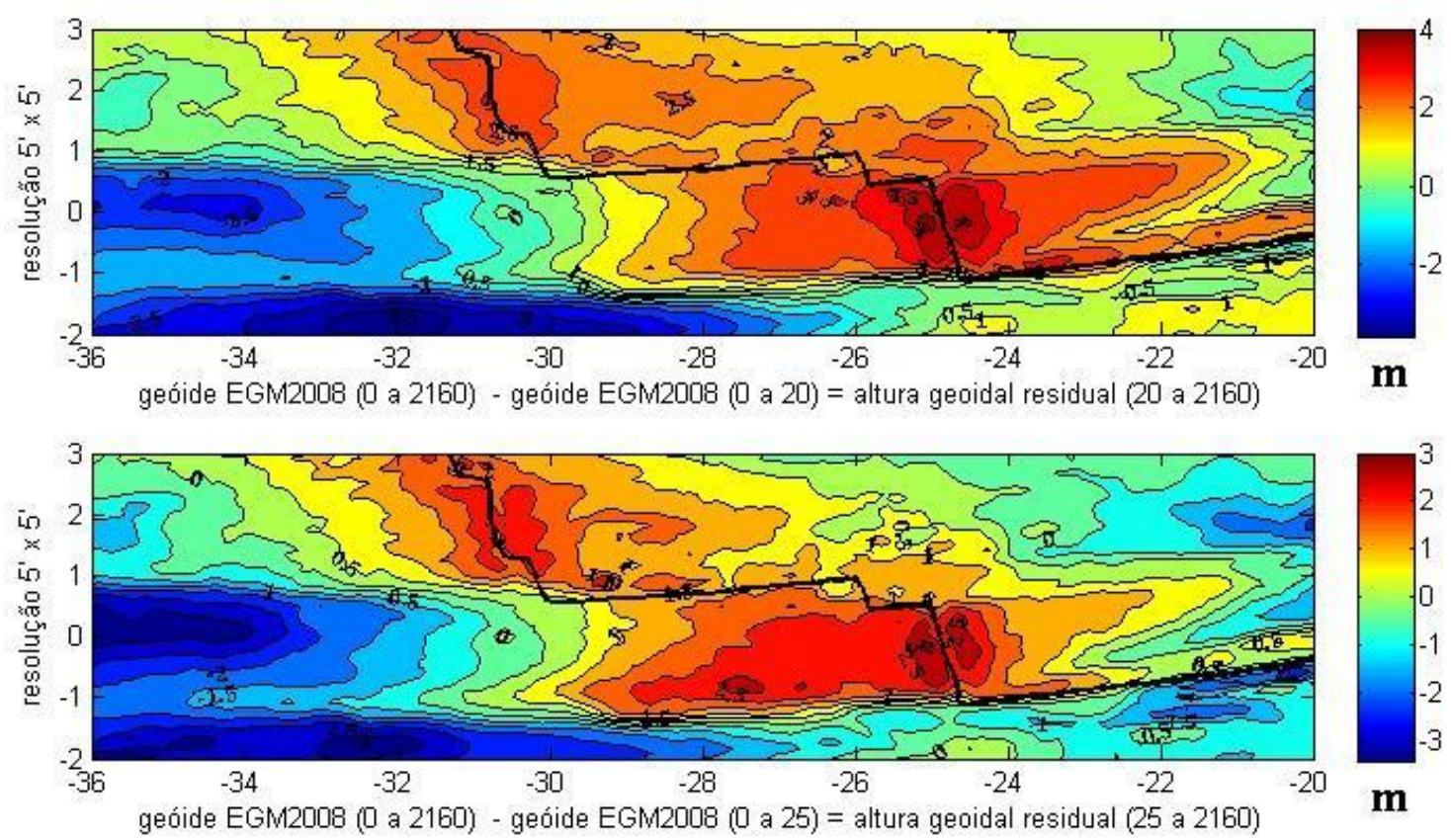

geóide EGM2008 (0 a 2160) - geóide EGM2008 (0 a 25) = altura geoidal residual (25 a 2160)
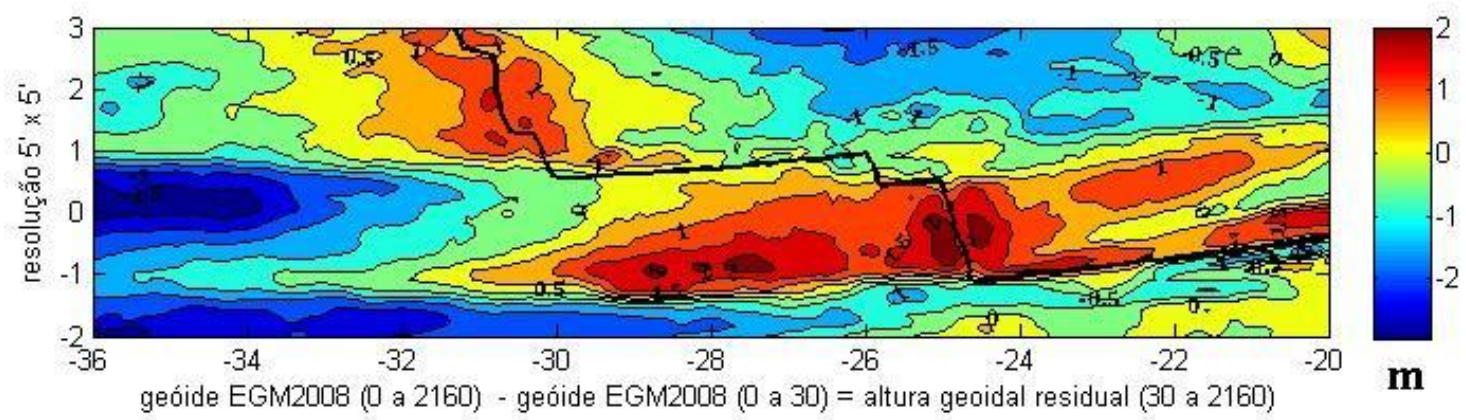

MAPA 2: ALTURAS GEOIDAIS RESIDUAIS SOBRE A REGIÃO DA ZFSP. INTERVALO DE CONTORNO 0.5 METRO.

As mesmas grades foram re-interpoladas através de scripts gerados para GMT utilizando a resolução de 1 min para destacar as feições encontradas. Conforme se observa nos mapas localizados nas páginas 26 e 27.

Sabe-se que as anomalias de altura geoidail "traduzem" os contrastes de densidade que fornecem informações sobre a movimentação das placas litosféricas e sobre o processo de convecção no manto. Um exemplo que ilustra bem este tipo de investigação são os modelos que correlacionam zonas de convergência a altos geoidais (Vaníček e Christou, 1993). 
As anomalias geoidas cujo comprimento de onda é menor ou igual a 10 metros geralmente está associada a um excesso de densidade resultante da estrutura termal de um slab subductado. Entretanto, as anomalias geoidais de curto comprimento ainda não possuem modelos termais precisos devido a grande variedades de parâmetros influentes nestas situações. De uma maneira geral, as anomalias de altura geoidal de curto comprimento de onda indicam um processo de compensação regional. Um exemplo a citar foi o bom ajuste encontrado de anomalias geoidalis e zonas de subducção considerando os graus $(4 \leq n \leq 9)$ do modelo geopotencial (Hager, 1984 apud Chase, 1985). Conforme se visualiza na ilustração a seguir:

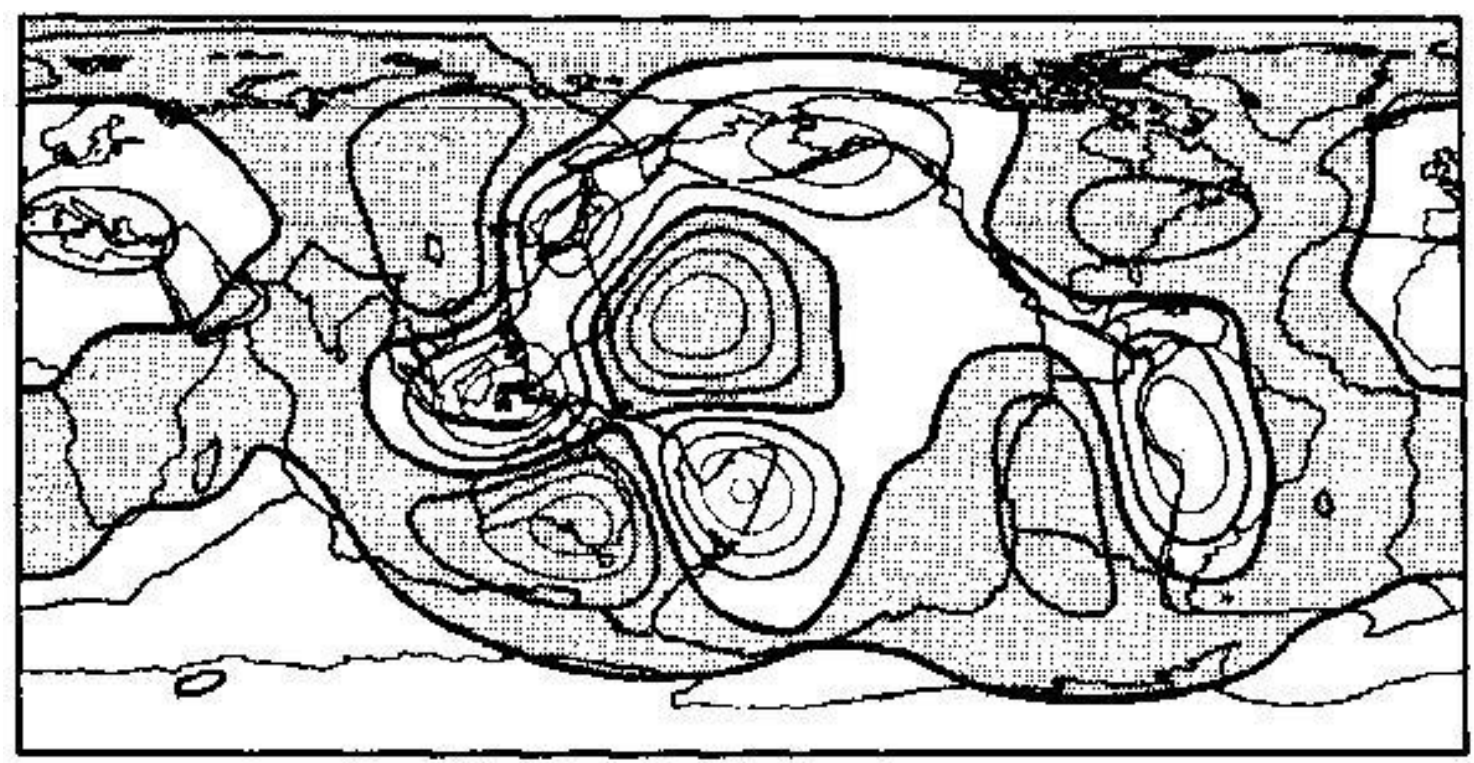

ILUSTRAÇÃO 14: CORRELAÇÃO ENTRE OS ALTOS GEOIDAIS E AS ZONAS DE SUBDUCÇÃO, UTILIZANDO HARMÔNICOS DE GRAU 4 A 9. INTERVALO DE CONTORNO DE 10 M. ANOMALIAS GEOIDAIS NEGATIVAS GEOIDAL ESTÃO MARCADAS. 


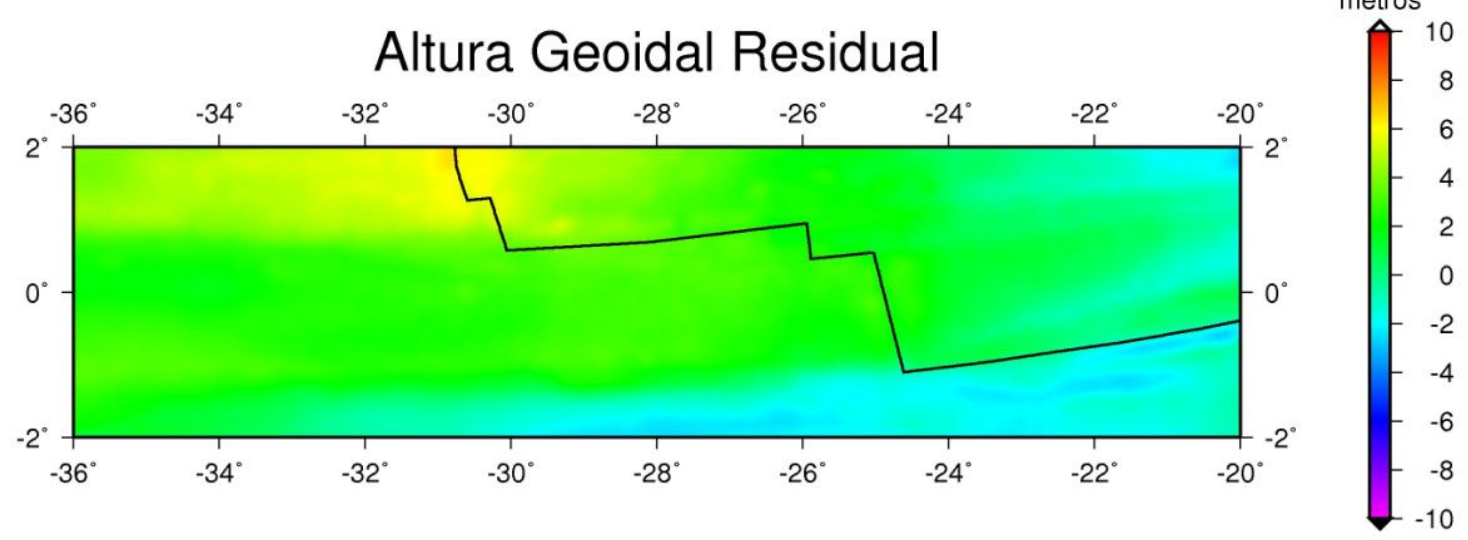

MAPA 3: ALTURA GEOIDAL RESIDUAL GRAU 10 A 2160. RESOLUÇÃO 1 MIN.

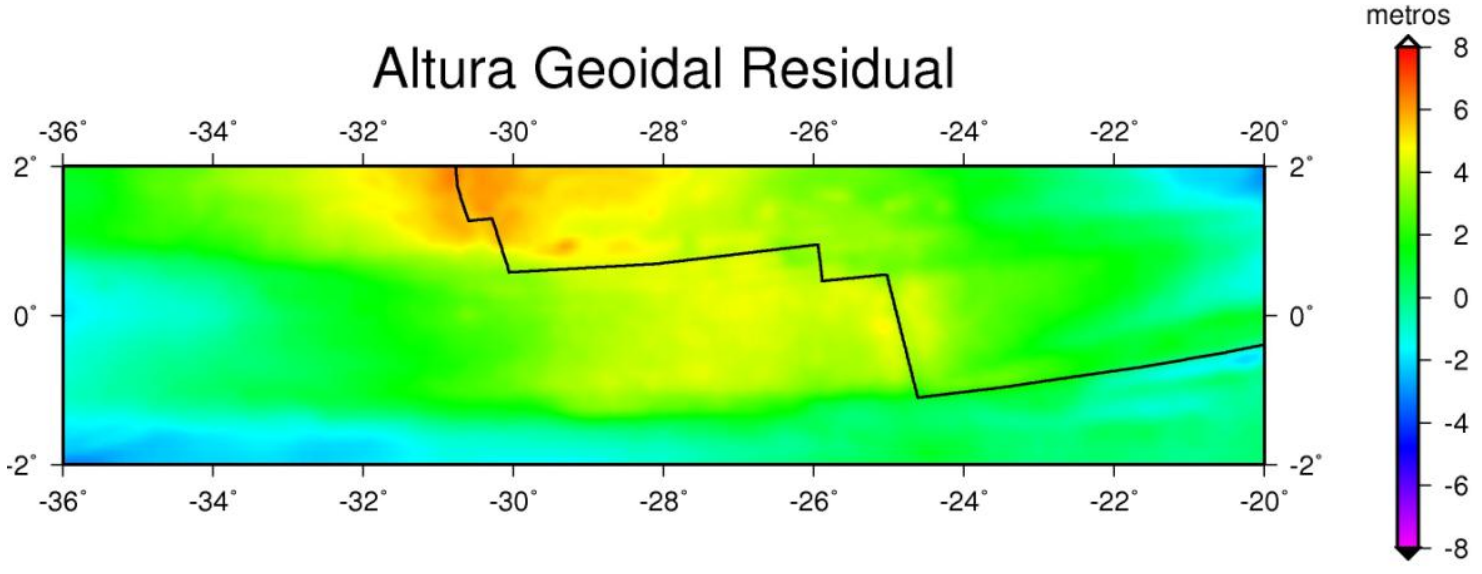

MAPA 4: ALTURA GEOIDAL RESIDUAL GRAU 15 A 2160. RESOLUÇÃO 1 MIN.

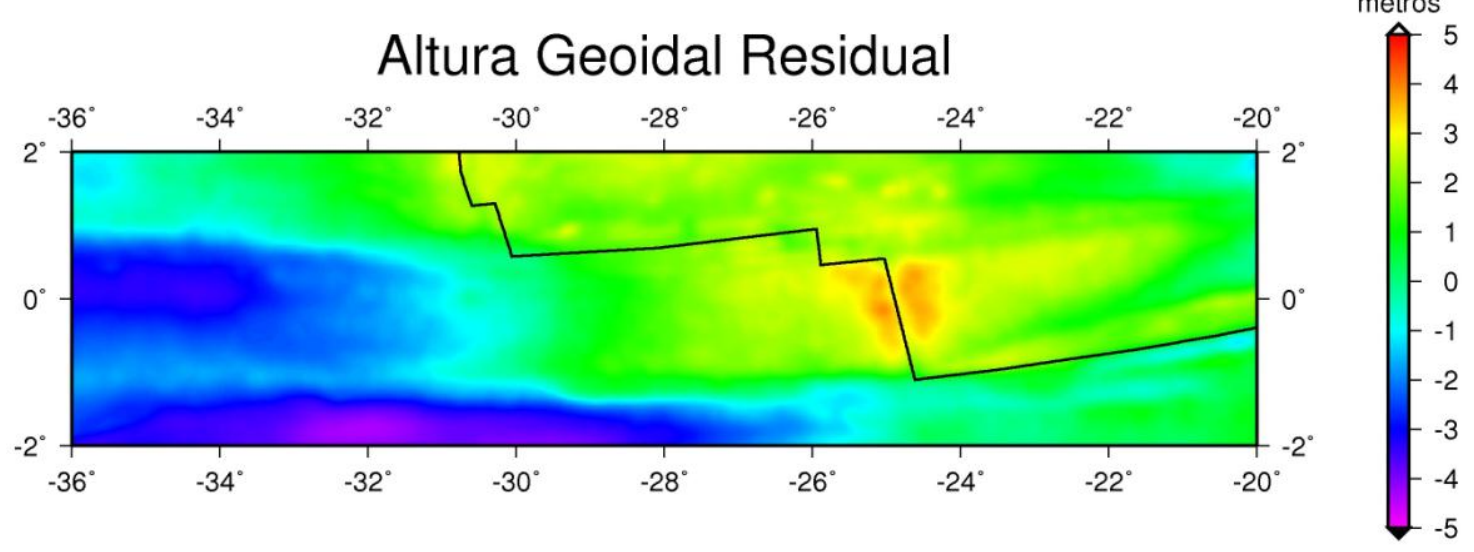

MAPA 5: ALTURA GEOIDAL RESIDUAL GRAU 20 A 2160. RESOLUÇÃO 1 MIN. 


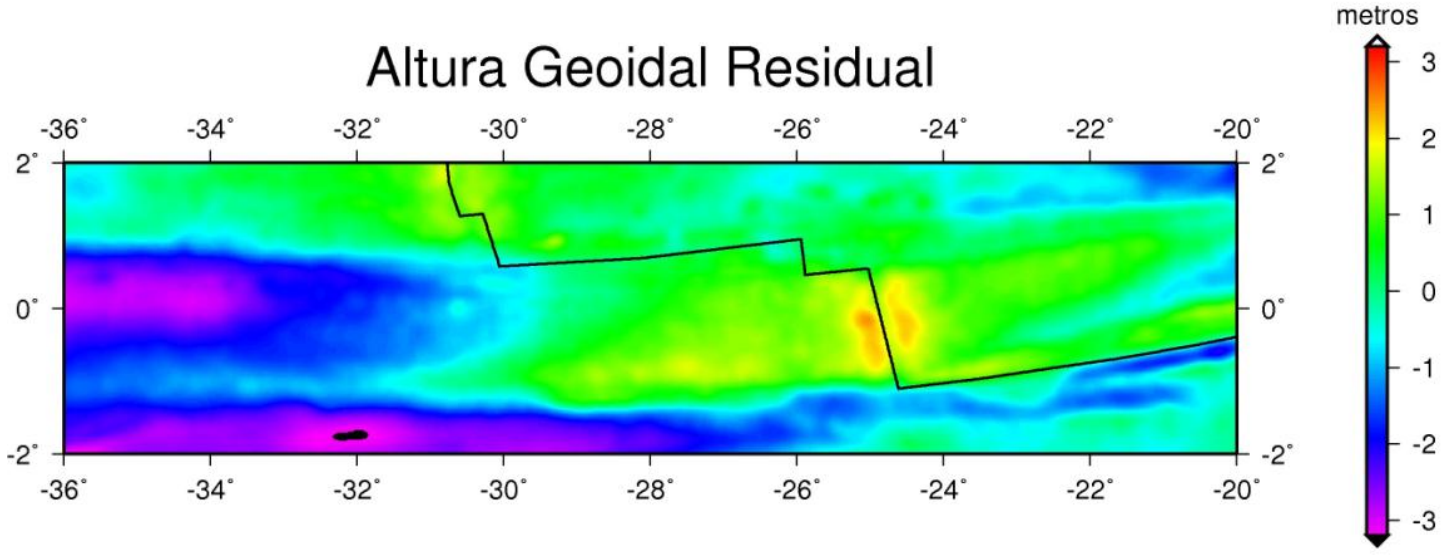

MAPA 6: ALTURA GEOIDAL RESIDUAL GRAU 25 A 2160. RESOLUÇÃO 1 MIN.

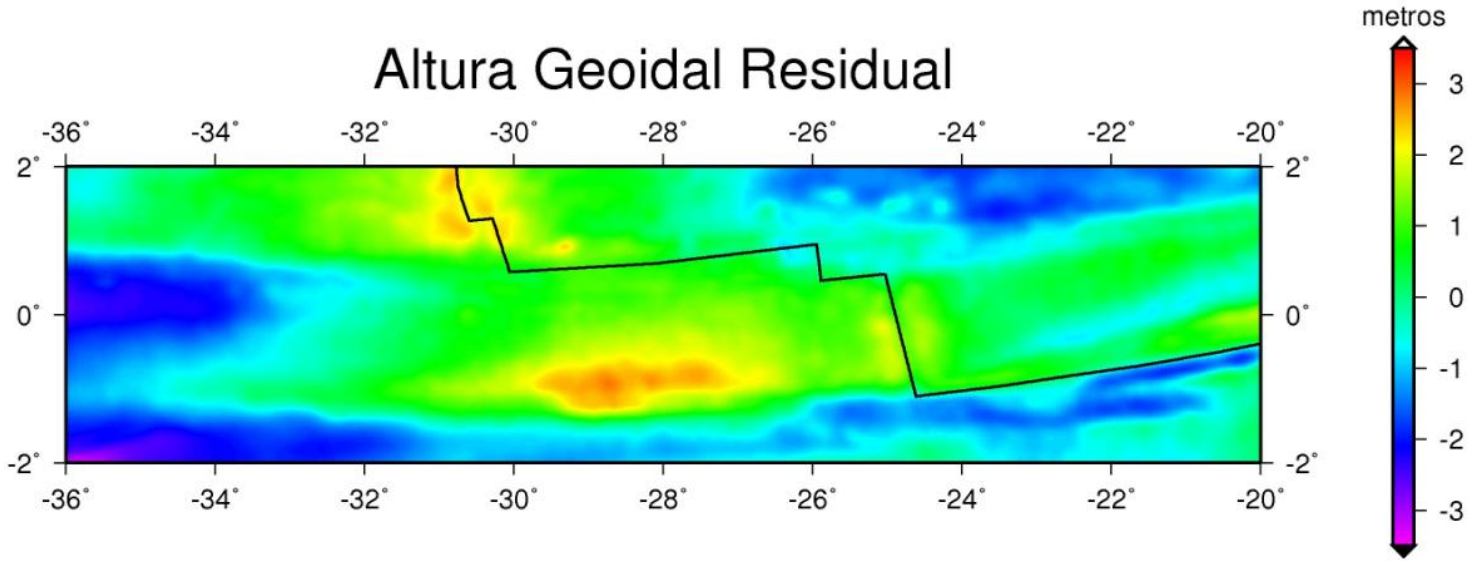

MAPA 7: ALTURA GEOIDAL RESIDUAL GRAU 30 A 2160. RESOLUÇÃO 1 MIN.

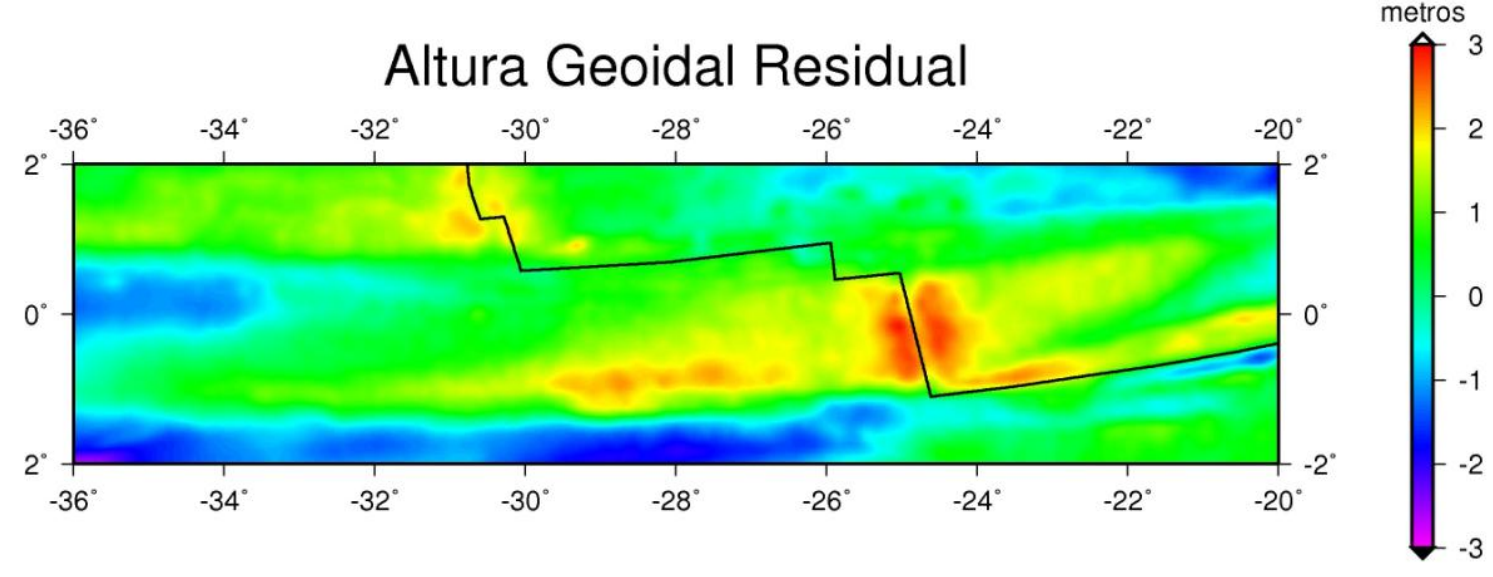

MAPA 8: ALTURA GEOIDAL RESIDUAL GRAU 35 A 2160. RESOLUÇÃO 1 MIN. 
Encontrou-se uma ondulação positiva próxima a área da dorsal a partir do residual grau 20 a 2160. Uma segunda feição apareceu a partir do grau 30 a 2160 e desapareceu no grau 40 a 2160.

A ondulação geoidal sendo positiva indicaria um excesso de massa, pois as ondulações positivas têm sido assim correlacionadas (Vaníček e Christou, 1993). Isto torna mais plausível a hipótese de slab. Se fragmentos de placas subductados estivessem mergulhados no manto superior, provavelmente estes pedaçõs seriam mais densos e mais frios do que o manto seu entorno. Indicando um constraste de densidade positivo e também um constraste negativo de temperatura, ou seja, a diferença de temperatura entre o slab e o manto em seu entorno (algo menos frio circundado por algo mais quente) resultaria numa temperatura final menor.

Entretanto, não se conhece a real composição do slab e nem sua natureza (continental ou oceânica). Entretanto, sabe-se que composição da litosfera oceânia fria é desconhecida. Torna-se difícil especificar a porcentagem de cada mineral em função de sua mudança de fase mineral.

Mudanças nas propriedades elásticas das placas subductadas estão associadas a mudanças nas fase minerais que controlam a densidade da placa. De acordo com Anderson (1989), mudanças na fase mineral são capazes de alterar a densidade de uma placa subductada e com isto alterar a estrutura térmica do manto. A expressão desta condição é visível a partir de anomalias de altura geoidal e alterações na velocidade de ondas sísmicas.

Bowin (1983) demonstrou através de equações a possiblidade de estimar a profundidade máxima da fonte a partir do grau de contribuição dos harmônicos esféricos do modelo geopotencial a geração de altura geoidal. Relacionando o grau dos coeficientes harmônicos a profundidade possível da fonte. Sendo assim, anomalias geoidais de longo comprimento indicam uma contribuição elevada dos graus menores do modelo gepotencial. Referente à fontes profundas no manto. Enquanto, as anomalias de curto comprimento indicam uma maior contribuição dos graus mais elevados do modelo geopotencial. Referente à fontes mais rasas localizadas na crosta e no manto superior. Considerando que a feição aparece no grau 20 seguindo a equação: $R / n-1$ onde $R$ é o raio médio da Terra $(6371 \mathrm{~km})$ e n é o grau do harmônio esférico. Neste caso, 
considerando o grau 20, a profundidade estimada para a fonte da anomalia é $335,3157895 \mathrm{~km} \cong 335 \mathrm{~km}$. Isto indicaria, a localização da fonte na região do manto superior.

Entretanto, considerando o estudo pioneiro de Haxby e Turcotte (1978) cujo modelo térmico isóstatico aplicado a dorsal mesoatlântico indicou que os dados de altura geoidal recebem contribuições de muitas fontes diferentes tais como parâmetros termais de resfriamento de placas litosféricas, batimetria, idade da litosfera etc (Chaise et al., 1985) Foi realizada a análise da correlação (coeficientes de Person) entre os dados de batimetria e de altura geoidal residual.

Utilizando dados de batimetria obtidos no site da NOAA (The National Oceanic and Atmospheric Administration) através do GEODAS grid translator selecionando a opção de latitude e longitude e resolução da grade (ETOPO 1') $<$ <ttp://www.ngdc.noaa.gov/mgg/gdas/gd_designagrid.html?dbase=grdet1>. Em seguida, a grade de batimetria foi filtrada através do filtro média móvel. Através do script moverage.m (Chaves, 2008) a fim de obter uma grade de resolução $5^{\prime}$ x $5^{\prime}$.

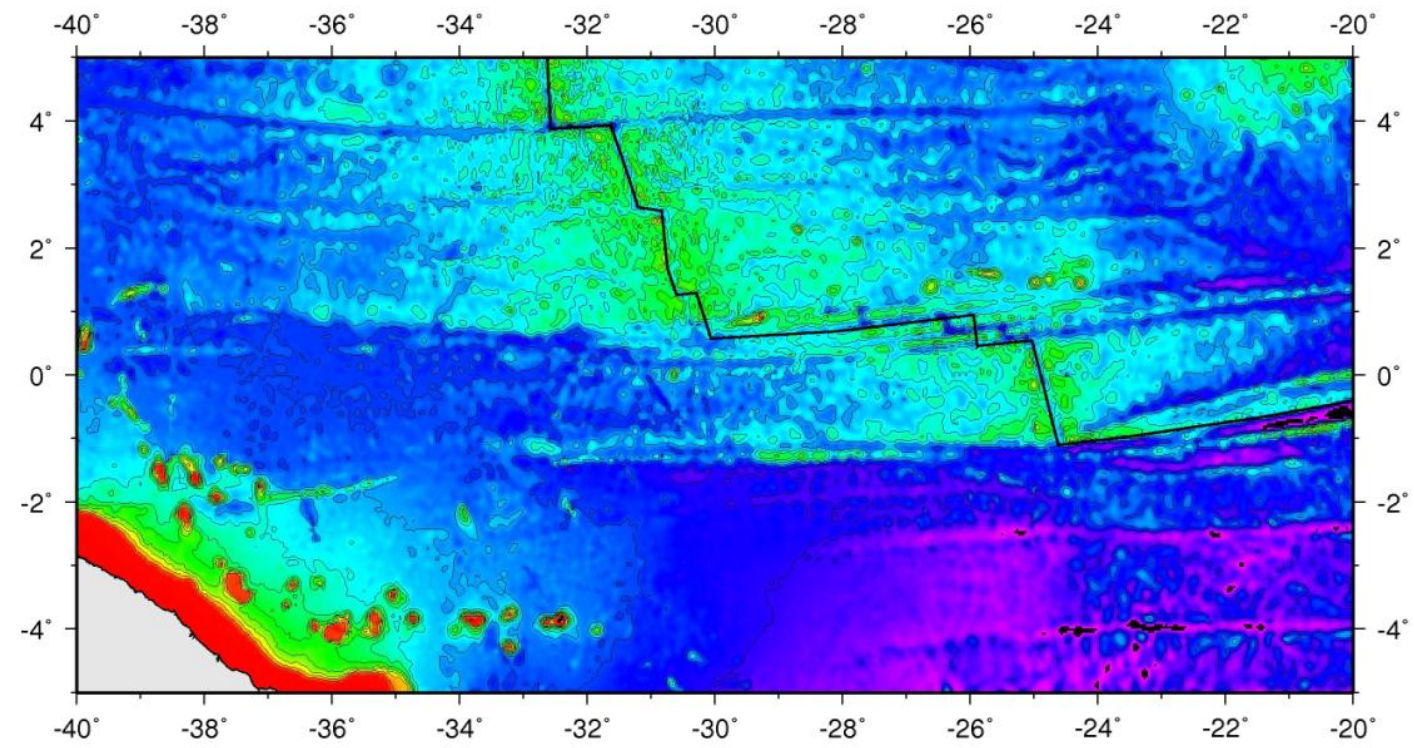

GM7 2009 Sep 30 23:32:20 TOPOGRAFIA ETOPO 1

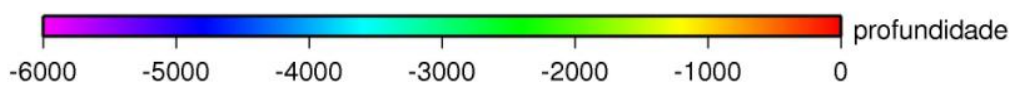

MAPA 9: MAPA BATIMÉTRICO DA ZFSP. DADOS OBTIDOS PELO GEODAS. RESOLUÇÃO 1MIN. 
O coeficiente de correlação de Pearson $(\rho)$ indica se existe uma correlação positiva ou negativa entre os fatores analisados. Quando $\rho$ está em torno de 0.7 para mais ou para menos indica uma forte correlação. Quando $\rho$ está entre 0.3 a 0.7 indica uma correlação moderada tanto para mais ou para menos e quando está abaixo de 0.3 indica fraca correlação.

$$
\begin{aligned}
& \quad \rho=\frac{\sum_{i=1}^{n}\left(x_{i}-\bar{x}\right)\left(y_{i}-\bar{y}\right)}{\sqrt{\sum_{i=1}^{n}\left(x_{i}-\bar{x}\right)^{2}} \cdot \sqrt{\sum_{i=1}^{n}\left(y_{i}-\bar{y}\right)^{2}}}=\frac{\operatorname{cov}(X, Y)}{\sqrt{\operatorname{var}(X) \cdot \operatorname{var}(Y)}} \\
& \text { sendo } \quad \bar{x}=\frac{1}{n} \cdot \sum_{i=1}^{n} x_{i} \quad \& \quad \bar{y}=\frac{1}{n} \cdot \sum_{i=1}^{n} y_{i}
\end{aligned}
$$

Foram comparadas as grades de altura geoidal residual a grade de batimetria, ambos com a mesma resolução. Foi encontrada uma forte correlação entre a batimetria e a altura geóide residual nos graus 2160-20 e 2160-25 (em torno de 0.50 ). Conforme se observa a seguir. Sugerindo que há uma significativa contribuição da batimetria na feição encontrada na altura geoidal residual:

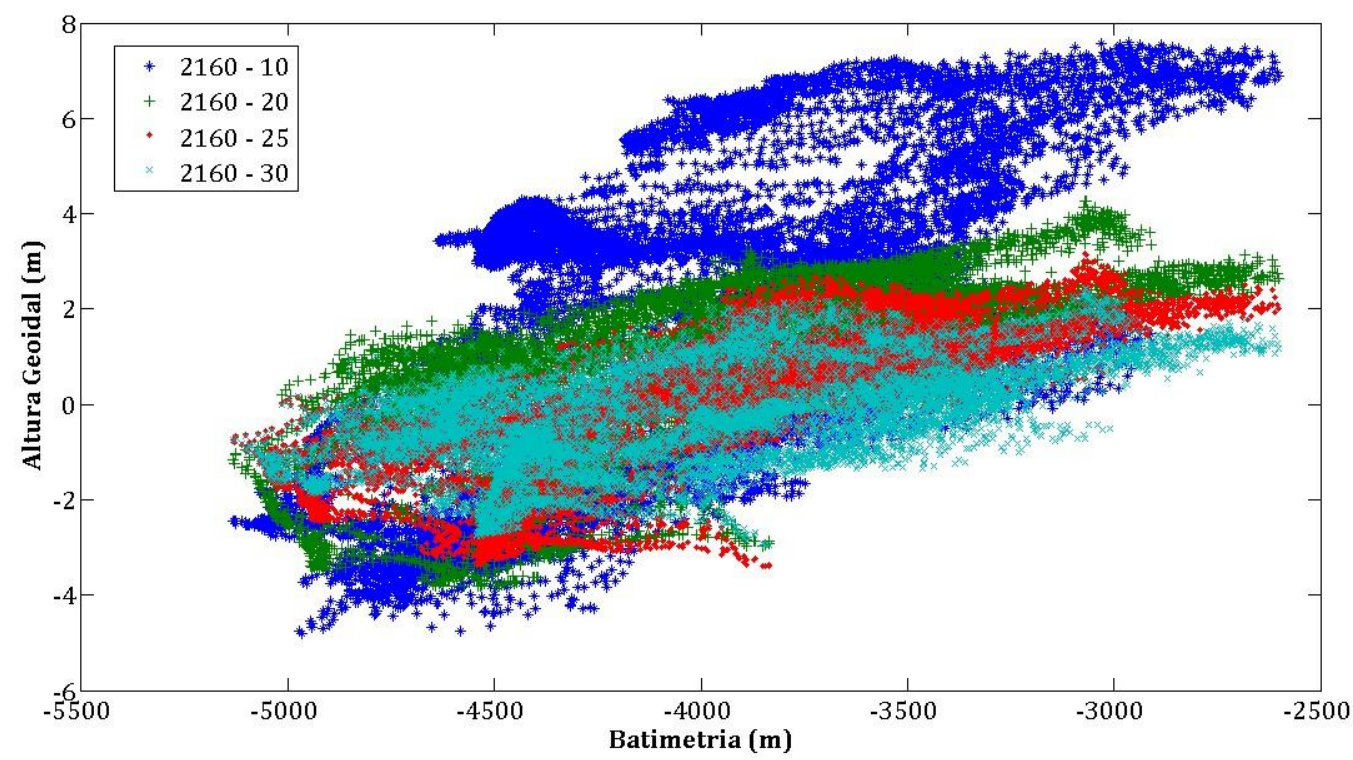

GRÁFICO 1: CORRELAÇÃO POSITIVA ENTRE A GRADE GERADA DE BATIMETRIA E A GRADE DE ALTURA GEOIDAL RESIDUAL. 

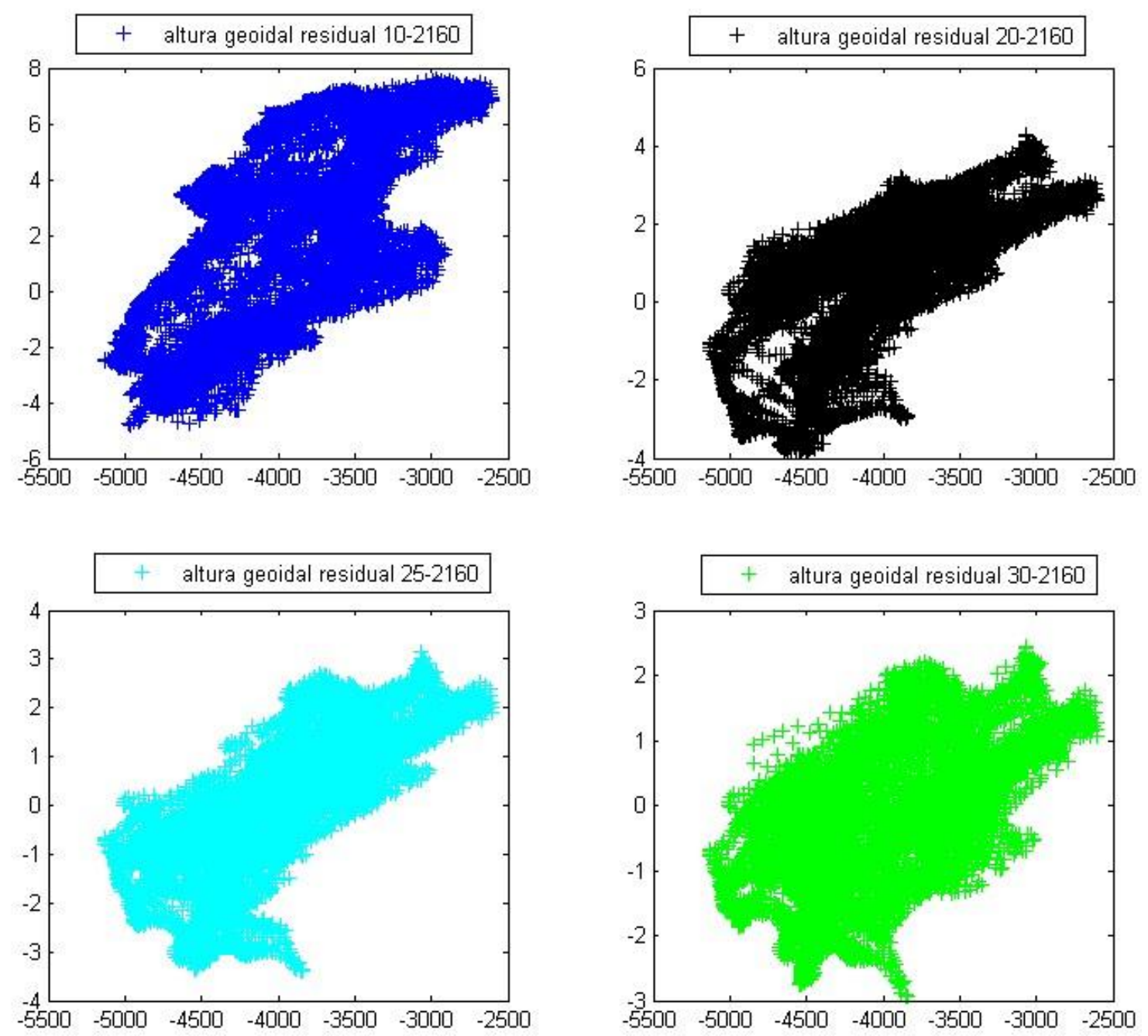

GRÁFICO 2 A 5: DETALHE DA CORRELAÇÃO ENTRE AS GRADES DE BATIMETRIA E ALTURA GEOIDAL RESIDUAL.

Tornou-se necessário estimar esta contribuição, ou seja, estimar o efeito da batimetria sobre a altura geoidal residual. Desta forma, utilizando-se o programa prisma3D (Chaves, 2007) foi simulada a presença da batimetria sobre o geóide através da construção de prismas (cujas densidades variaram entre 2900 a $1030 \mathrm{~kg} / \mathrm{m3}$ ). Como resultado obteve-se uma grade de altura geoidal influenciada pela batimetria, conforme plotado na página 32 . 


\section{Altura Geoidal devido a batimetria}

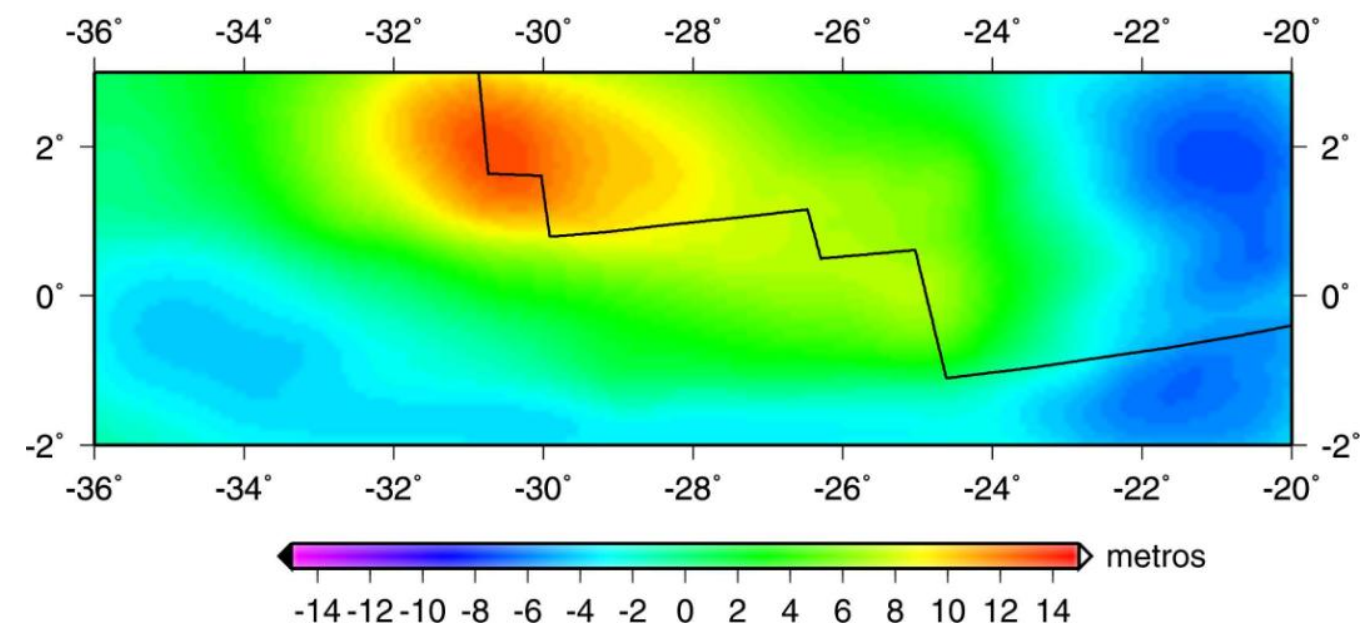

MAPA 10: GRADE OBTIDA APÓS ESTIMATIVA DO EFEITO DA BATIMETRIA SOBRE O GEÓIDE SIMULANDO A CONSTRUÇÃO DE PRISMAS ATRAVÉS DO PROGRAMA PRISMAS3D (CHAVES. 2007).

Após a estimativa do efeito da batimetria sobre o geóide, subtraiu-se a grade com este efeito das demais resultando em uma grade de altura geoidal residual sem o efeito da batimetria. De forma singular, a feição encontrada anteriormente não foi visualizada após a remoção deste efeito. Conforme visualizado nas páginas a seguir. Para validar estes resultados foram realizadas análises da gravidade na área de estudo, de anomalia ar livre, anomalia bouguer e de tensor gradiente da gravidade cujos resultados serão discutidos a diante.

\section{Anomalia Geoidal Residual}

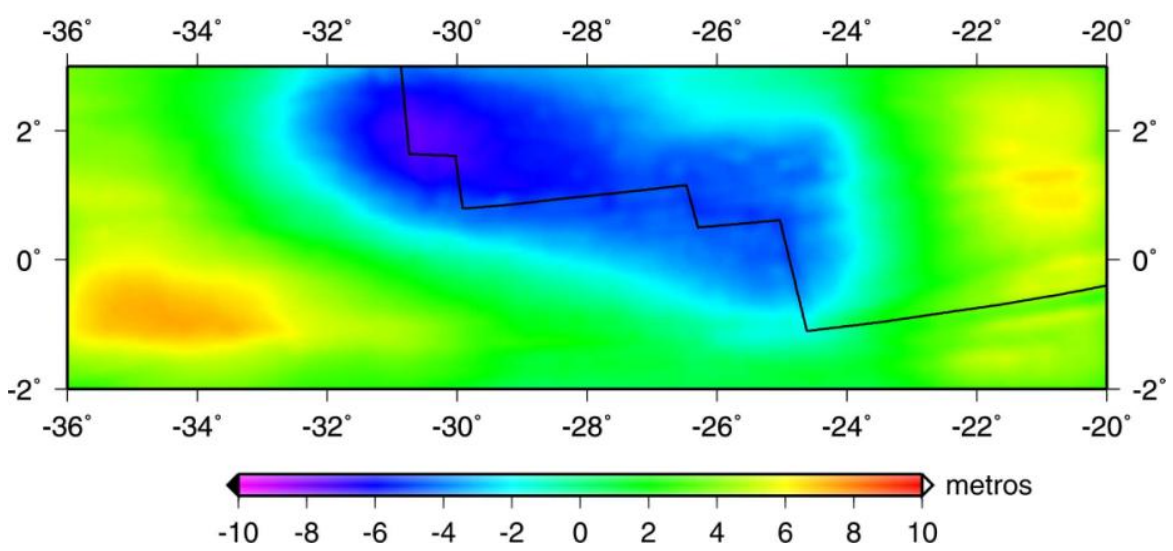

MAPA 11: ANOMALIA DE ALTURA GEOIDAL RESIDUAL GRAU 10 A 2160 SUBTRAÍDO EFEITO BATIMÉTRICO. RESOLUÇÃO 1 MIN. 


\section{Anomalia Geoidal Residual}

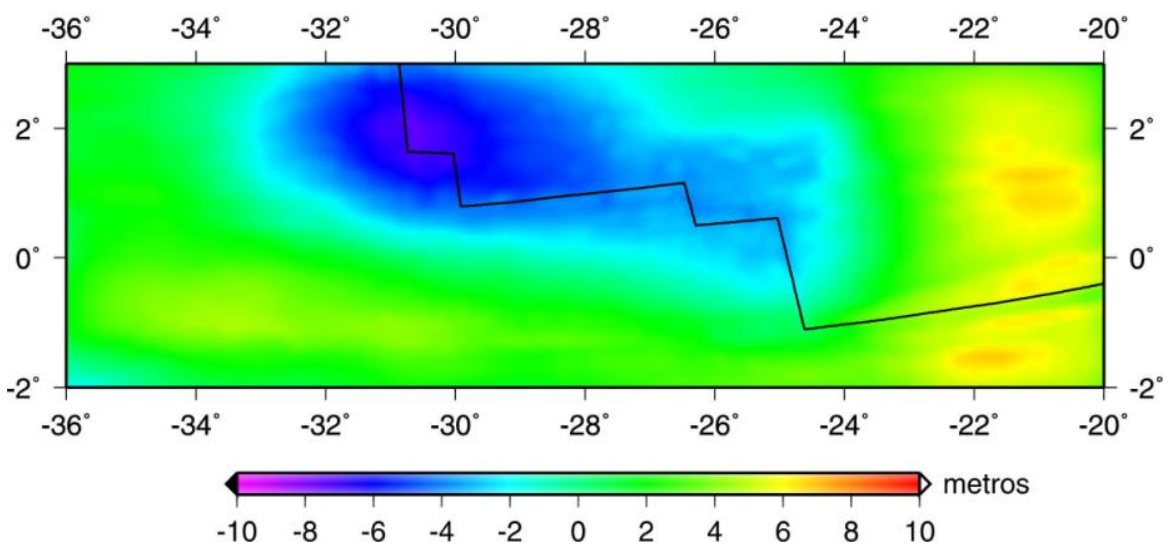

MAPA 12: ANOMALIA DE ALTURA GEOIDAL RESIDUAL GRAU 15 A 2160 SUBTRAÍDO EFEITO BATIMÉTRICO. RESOLUÇÃO 1 MIN.

\section{Anomalia Geoidal Residual}

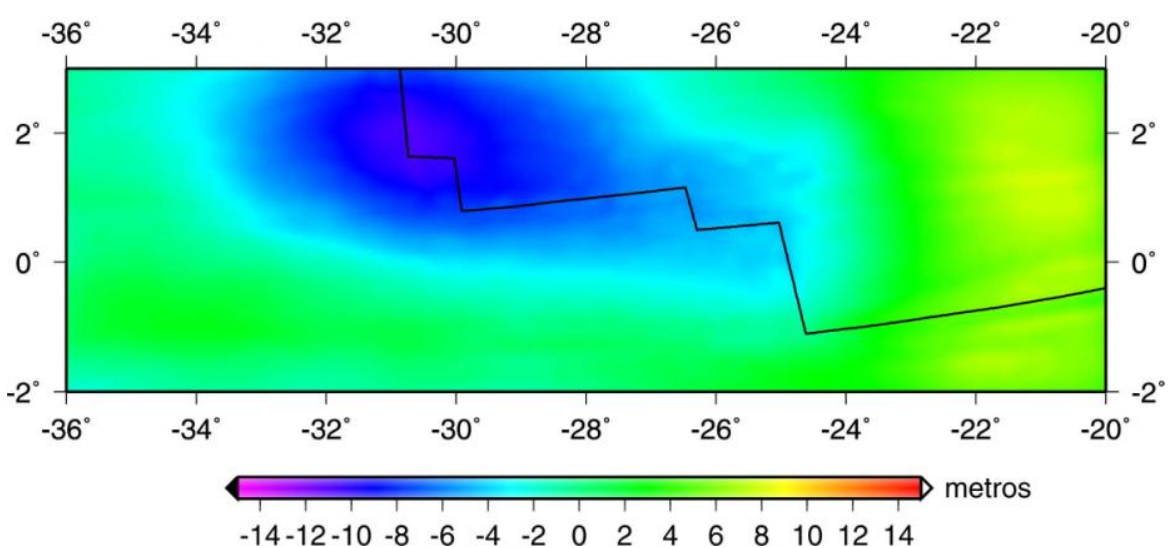

MAPA 13: ANOMALIA DE ALTURA GEOIDAL RESIDUAL GRAU 20 A 2160 SUBTRAÍDO EFEITO BATIMÉTRICO. RESOLUÇÃO 1 MIN.

\section{Anomalia Geoidal Residual}

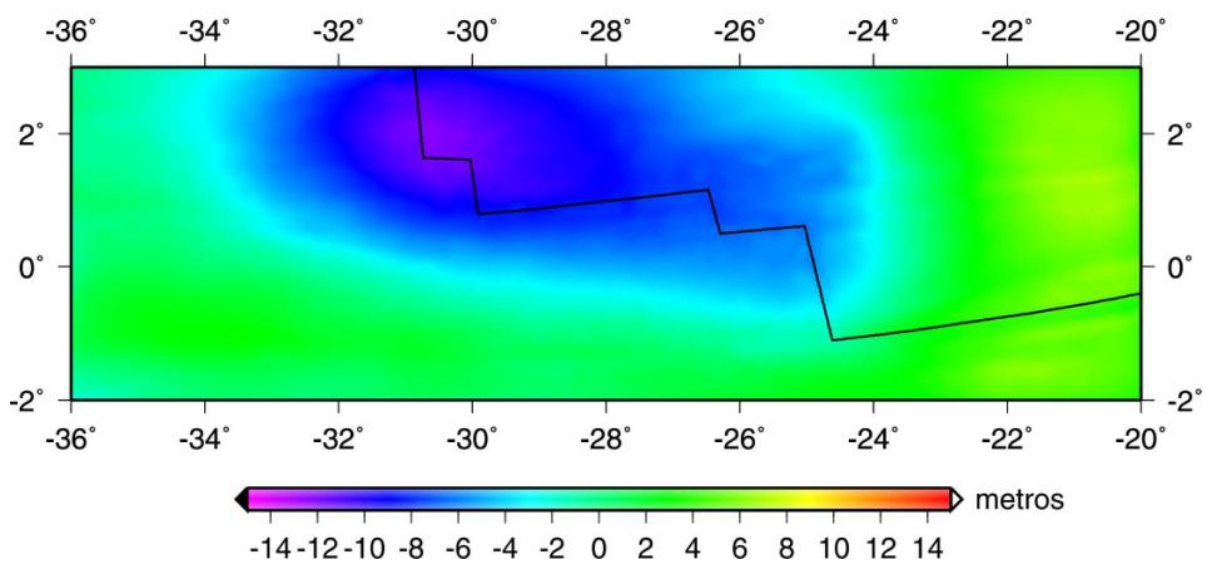

MAPA 14: ANOMALIA DE ALTURA GEOIDAL RESIDUAL GRAU 20 A 2160 SUBTRAÍDO EFEITO BATIMÉTRICO. RESOLUÇÃO 1 MIN. 


\subsection{ANOMALIA AR LIVRE E ANOMALIA AR LIVRE RESIDUAL}

Os valores medidos de g estão sujeitos a diferentes tipos de reduções conforme o objetivo do estudo. Uma anomalia é obtida ao subtrair do valor medido um valor padrão. A anomalia ar livre é conhecido por ser o gradiente vertical da gravidade, sendo obtida após a correção ar livre ou redução "ao nível do mar". É realizada através da seguinte expressão: $\Delta g=g+0,3086 . h-\gamma$

Onde $g$ é o valor medido, h é altitude ortométrica e $\gamma$ é a gravidade teórica obtida através da fórmula internacional da gravidade (Gemael, 2002).

Os valores de anomalia ar livre foram calculados a partir de um conjunto de programas disponibilizados pela Universidade de Trieste (Itália) em parceria com a Universidade de Tecnologia da Eslováquia (M. Šprlák and J. Janák, 2006) disponiblizados no curso realizado em setembro de 2008 no IAG.

A partir os programas grafim.job, e g2grd_grafim.exe obtevem-se as grades com resolução de 5 min para a anomalia ar livre segundo o modelo gepotencial EGM 2008 nos seguinte graus: 0 a 10, 0 a 15, 0 a 20, 0 a 25, 0 a 30 e de 0 a 2160. A obtenção das anomalias ar livre diretamente do modelo gepotencial segue a seguinte equação (Heiskanen \& Moritz, 1967):

$$
\Delta g=\frac{G M}{r^{2}} \sum_{n=2}^{n_{\operatorname{mgx}}}(n-1)\left(\frac{a}{r}\right)^{n} \sum_{m=0}^{n}\left[\bar{C}_{n m} \cos (m \lambda)+\bar{S}_{n m} \operatorname{sen}(m \lambda)\right] P_{n m}(\operatorname{sen} \theta)
$$

Os mapas de anomalia ar livre foram plotados para os mesmos graus do modelo que obteve os valores de altura geoidal residual. Obtendo-se assim valores de anomalia ar livre de acordo com os graus 10 a 2160, 15 a 2160, 20 a 2160,25 a 2160,30 a 2160 e 35 a 2160 . Os mapas plotados poderão ser visualizados nas páginas 35 e 36 . Observa-se que existe uma correspodência entre a batimetria e a anomalia ar livre residual. 


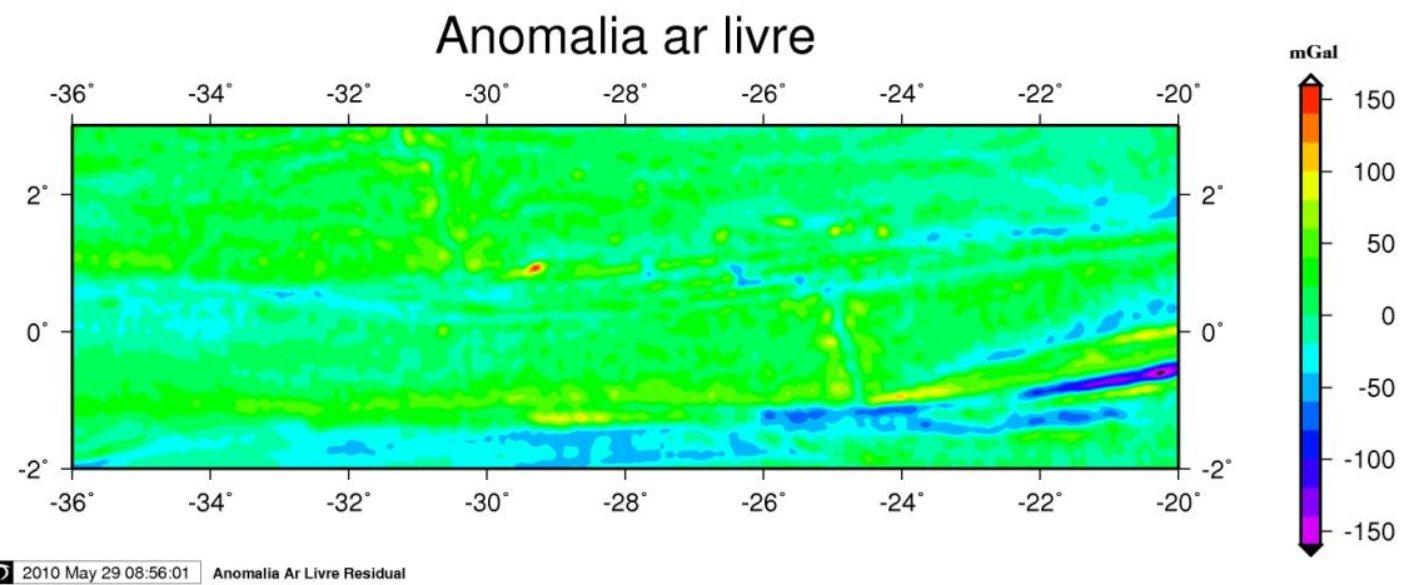

GM] 2010 May 29 08:56:01 Anomalia Ar Livre Residual

MAPA 15: ANOMALIA AR LIVRE RESIDUAL GRAU 10 A 2160. RESOLUÇÃO 5 MIN.

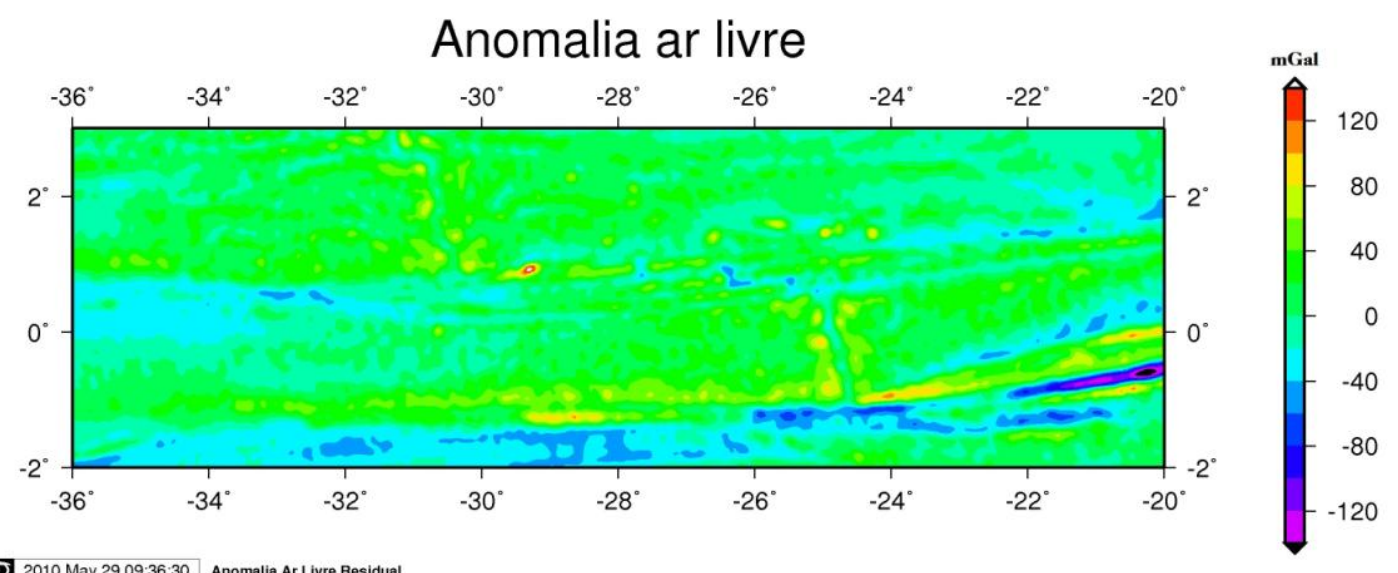

GM] 2010 May 29 09:36:30 Anomalia Ar Livre Residual

MAPA 16: ANOMALIA AR LIVRE RESIDUAL GRAU 15 A 2160. RESOLUÇÃO 5 MIN.

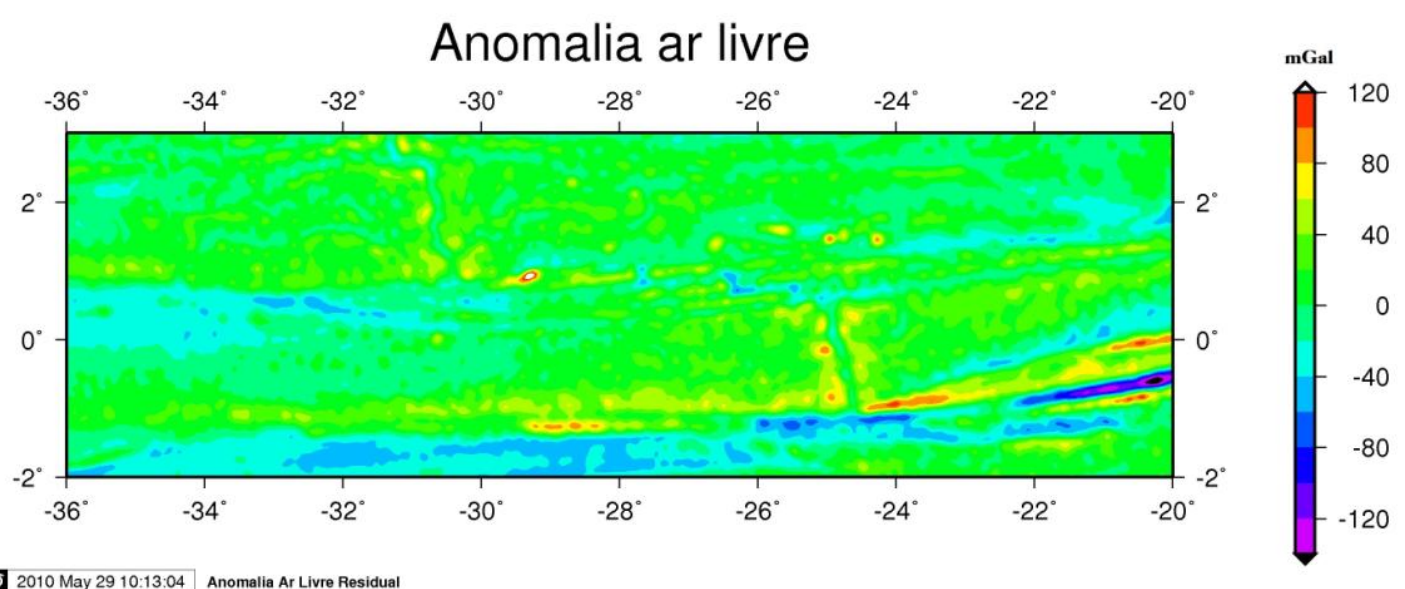

MAPA 17: ANOMALIA AR LIVRE RESIDUAL GRAU 20 A 2160. RESOLUÇÃO 5 MIN. 


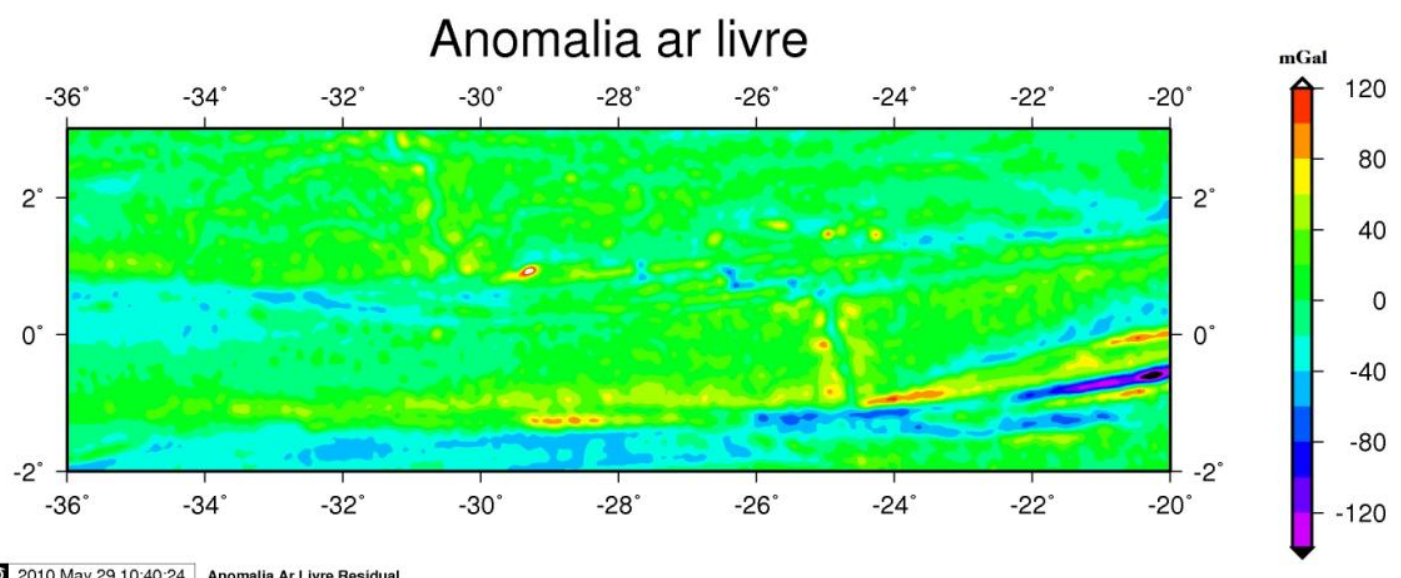

GM7] 2010 May 29 10:40:24 Anomalia Ar Livre Residual

MAPA 18: ANOMALIA AR LIVRE RESIDUAL GRAU 25 A 2160. RESOLUÇÃO 5 MIN.

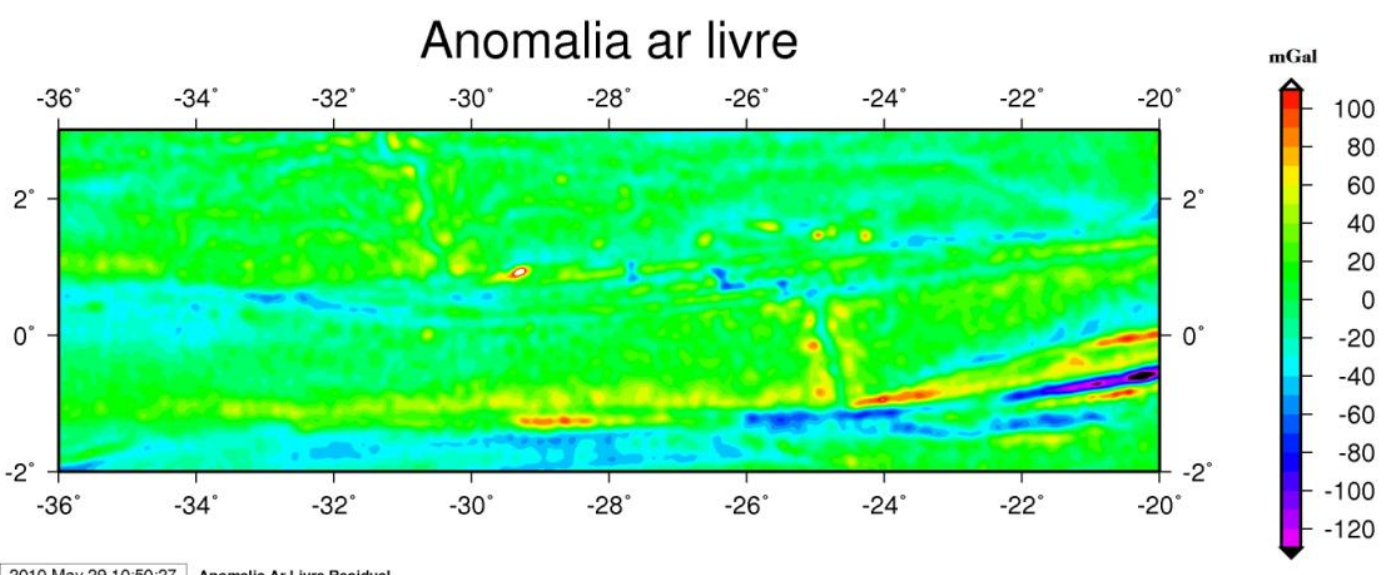

GM] 2010 May 29 10:50:27 Anomalia Ar Live Residual

MAPA 19: ANOMALIA AR LIVRE RESIDUAL GRAU 30 A 2160. RESOLUÇÃO 5 MIN.

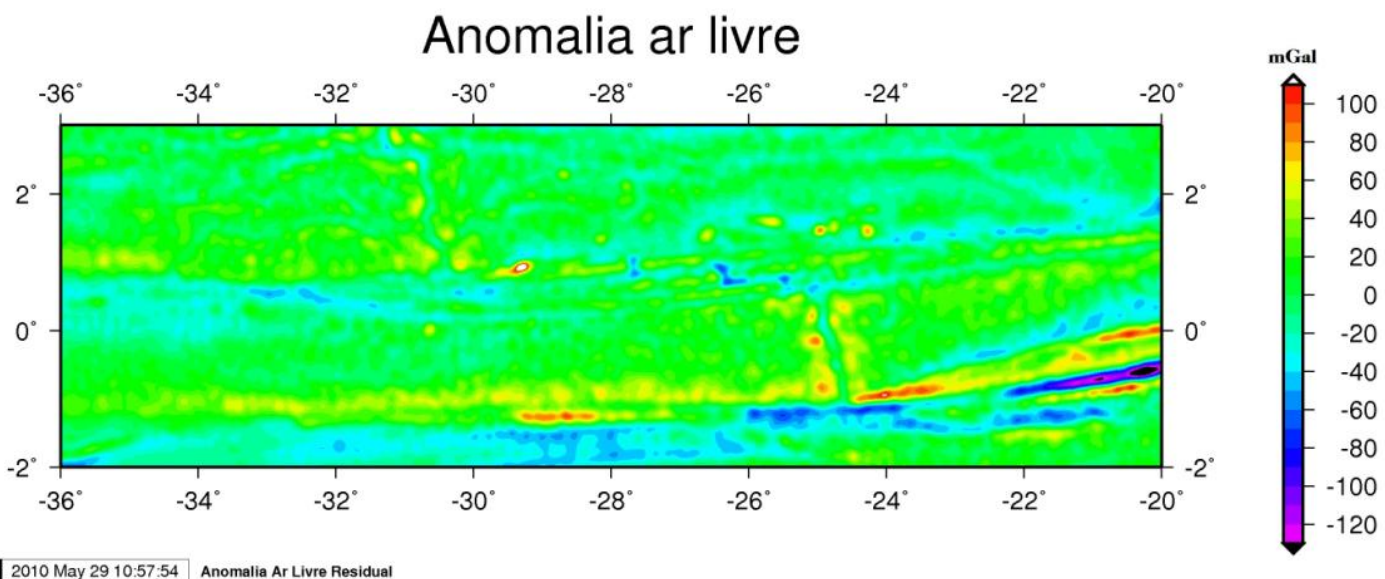

GM] 2010 May 29 10:57:54 Anomalia Ar Live Residual

MAPA 20: ANOMALIA AR LIVRE RESIDUAL GRAU 35 A 2160. RESOLUÇ̃̃O 5 MIN. 


\subsection{ANOMALIA BOUGUER}

A partir dos dados de anomalia ar livre e dos dados de batimetria foi possível a obtenção da grade de anomalia Bouguer. Foi criada uma rotina em $\mathrm{C}$ a fim de aplicar a correção Bouguer cuja componente vertical de atração é realizada pelo plateu de Bouguer (de espessura h). Neste caso, a região de estudo está abaixo do nível do mar somou-se a correção Bouguer para obter a anomalia.

$$
\Delta g_{B}=g_{\text {ahs }}-\gamma(\varphi)+0,3086 \cdot h-2 \pi G \rho \cdot h
$$

Onde :

- Y $(\varphi)$ é a gravidade teórica;

- h é a altitude ortométrica usada para a anomalia ar livre;

- $G$ é a constante gravitacional $\left(G=6,67300 \times 10^{-11} \mathrm{~m}^{3} \mathrm{~kg}^{-1} \mathrm{~s}^{-2}\right)$;

- $\rho$ é a densidade $\left(2800 \mathrm{~kg} / \mathrm{m}^{3}-1030 \mathrm{~kg} / \mathrm{m}^{3}\right)$;

- h é a batimetria (valores negativos);

\section{Anomalia Bouguer}

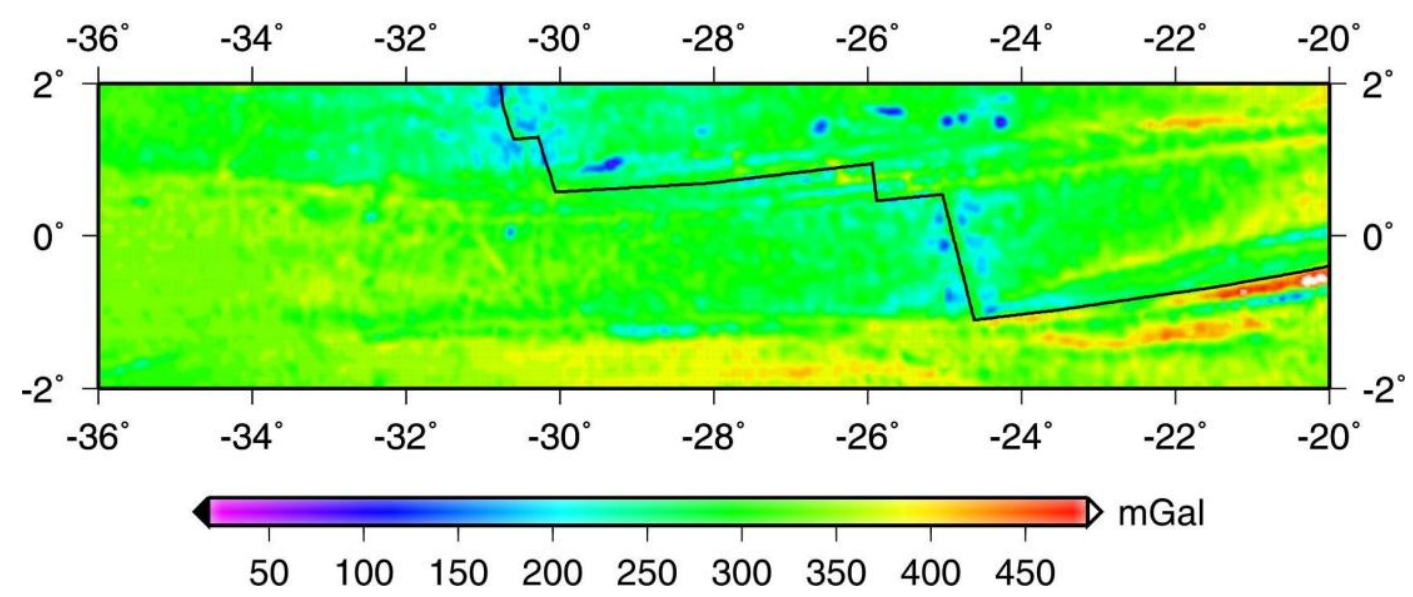

MAPA 21: ANOMALIA BOUGUER (CAMPO TOTAL) A PARTIR DE ANOMALIA AR LIVRE (0 A 2160). 


\subsection{SEPARAÇÃO DE COMPONENTES: RESIDUAL E REGIONAL}

A interpretação de dados de gravimetria está estritamente relacionado a remoção de componente regional a fim de obter o componente residual (Dehlinger, P. 1978)

Dentre as técnicas que existem para separação dos componentes regional e residual destacam-se os seguintes métodos: gráfico, espectral e polinomial (Nettleton 1976 apud Beltrão et al., 1991).

Quando se utiliza o ajuste gráfico removem-se experimentalmente os comprimentos de onda conforme as informações geológicas disponíveis sobre o campo regional.

O método espectral manipula funções no domínio da freqüência através da aplicação de um "filtro" separando os espectros de acordo com uma "janela de freqüências". Porém, feições de curto comprimento de onda estão sobrepostas a feições de longo comprimento e a separação completa não é possível.

O método chamado ajuste polinomial subtrai superfícies polinomiais do campo observado a fim de obter a componente residual. O ajuste da superfície polinomial é dado pelo grau do polinômio. Sendo assim, se subtrai as superfícies formadas por polinômios de primeiro, segundo e terceiro graus conforme a suavidade esperada.

A componente regional também pode ser entendida como um efeito causado por estruturas profundas. Por exemplo, Talwani e et al. (1965) realizaram a modelagem gravimétrica da dorsal mesoceânica correlacionado dados de batimetria, anomalia ar-livre e Bouguer com modelos de densidade a fim de caracterizar uma zona de baixa densidade sob o vale axial da cordilheira. 


\subsection{AJUSTE POLINOMIAL PARA A INTERPRETAÇÃO DE DADOS DE GRAVIDADE RESIDUAL E IMPLEMENTAÇÃO DO MÉTODO DE PARKER}

Os valores de gravidade residual foram calculados a partir de um conjunto de programas disponibilizados pela Universidade de Trieste (Itália) em parceria com a Universidade de Tecnologia da Eslováquia (M. Šprlák and J. Janák, 2006) disponiblizados no curso realizado em setembro de 2008 no IAG.

A partir os programas grafim.job, e g2grd_grafim.exe obtevem-se as grades com resolução de 5 min para a gravidade nos seguinte graus: 0 a 10, 0 a 15,0 a 20,0 a 25, 0 a 30 e de 0 a 2160 .

O campo da gravidade pode ser expresso através do potencial anômalo (diferença entre o geopotencial e o esferopotencial para o exterior das massas atrativas): $T=W-U=\boldsymbol{\mho}_{W}+\Phi_{W}=\boldsymbol{\mho}_{U}+\Phi_{U}{ }_{-}$

Pela Fórmula de Bruns é possível relacionar a ondulação do geóide ao potencial anômalo (conhecendo o valor da gravidade sobre o elipsóide de referência): $\quad N\left(\right.$ ) $=\frac{T(e)}{\gamma}$

Se o potencial centrífugo é constante tanto em $\mathrm{W}$ e U, logo a subtração resultará apenas na diferença de potencial gravitacional, sendo esta função harmônica. Logo, $T$ também é uma função harmônica no espaço exterior às massas satisfazendo à equação de Laplace, ou seja: $\Delta T=0$. Sendo assim, o desenvolvimento em série do potencial anômalo T permite obter a anomalia da gravidade $\Delta \mathrm{g}$ e da altura geoidal N (Heiskanen \& Moritz, 1967):

$$
T(r, \theta, \lambda)=\sum_{n=2}^{\infty}\left(\frac{R}{r}\right)^{n+1} T_{n}(\theta, \lambda), r>R
$$

onde:

- $T_{n}(\theta, \lambda)$ são os harmônicos de superfície de grau $\mathrm{n}$ do potencial $\mathrm{T}$;

- R é o raio médio terrestre; 
- r é o raio vetor do ponto de coordenadas $(\theta, \lambda)$, respectivamente colatitude e longitude geocêntricas.

A expansão da anomalia da gravidade será dada por (Heiskanen \& Moritz, 1967):

$$
\Delta g=\Delta g(r, \theta, \lambda)=\frac{\partial T}{\partial r}=\sum_{n=2}^{\infty} \Delta g_{n}=\frac{1}{r} \sum_{n=2}^{\infty}\left(\frac{R}{r}\right)^{n+1} T_{n}(\theta, \lambda)
$$

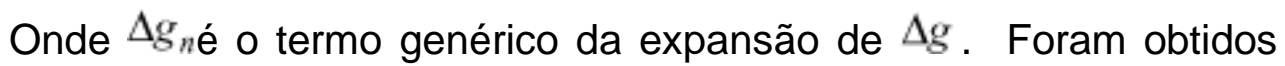
valores de gravidade residual para os graus descritos anteriormente. $O$ ajuste polinomial por mínimos quadrados foi aplicados aos valores de gravidade a fim de remover as superfícies geradas pelos polinômios de primeiro, segundo e terceiro graus. Com o intuito de obter um campo residual. Também foi utilizado o método de ajuste por polinômio robusto para esse mesmo fim. As grades plotadas encontram se nas páginas 42 e 43.

Entretanto, não ocorreu uma separação consistente entre os campos residual e regional. Dessa forma optou-se por aplicar o método proposto por Parker (1973) com o programa parker.m (Chaves, 2008). Tendo em vista que efeito da topografia foi anteriormente identificado nos valores de altura geoidal residual.

No algoritmo de Parker (1973) são calculados os valores da anomalia gravimetrica esperada devido a variacão da profundidade de uma superfície que separa dois meios com densidades diferentes. O efeito gravitacional no domínio espacial é obtido através da transformada inversa de Fourier da equação abaixo:

$$
\mathfrak{I}[\Delta g]=-2 \pi G \rho \exp \left(-|\vec{k}| z_{0}\right) \sum_{n=1}^{\infty} \frac{|\vec{k}|^{n-1}}{n !} \mathfrak{I}\left[h^{n}(\vec{r})\right]
$$

Onde:

- $\quad \mathfrak{I}$ é a transformada de Fourier

- G é a constante gravitacional; 
- $\quad \rho$ é o valor do contraste de densidade entre dois meios separados por uma interface suave;

- $z_{0}$ é o valor da profundidade media da interface;

- h e o valor da interface interpolada;

- $\vec{k}$ é o vetor de onda da funcão transformada;

- $\vec{r}$ é a projecao das coordenadas $(\mathrm{x}, \mathrm{y}, \mathrm{z})$ no plano $\mathrm{x}-\mathrm{y}$;

No programa encontram-se definidos os parâmetros: contraste de densidade, profundidade média da interface, ordem de expansão da série que deve ser >10 para uma maior precisão da expansão e dos valores da profundidade da interface.

Com base na aplicacação da transformada inversa de Fourier obteve-se a solução que estava no domínio da frequência para o domínio do espaço. Considerando esta aproximação linear entre o efeito gravimétrico da topografia e a compensacão em profundidade (a partir dos valores de densidade que separam dois meios diferentes) subtrai-se a grade de valores de gravidade gerada pelo programa parker.m da grade de valores de gravidade residual. Novamente, a anomalia de gravidade encontrada foi removida indicando que devido ao intenso fraturamento existente na área de estudo a separação entre a crosta e o manto está a um profundidade mais rasa. Sendo este tipo de compensação elástica um efeito muti sentido sobre o campo da gravidade. Os mapas com a grade gerada pelo programa parker.m e a grade residual encontram-se plotados na página 45. 
Residual após remoção do polinômio $1^{\circ}$

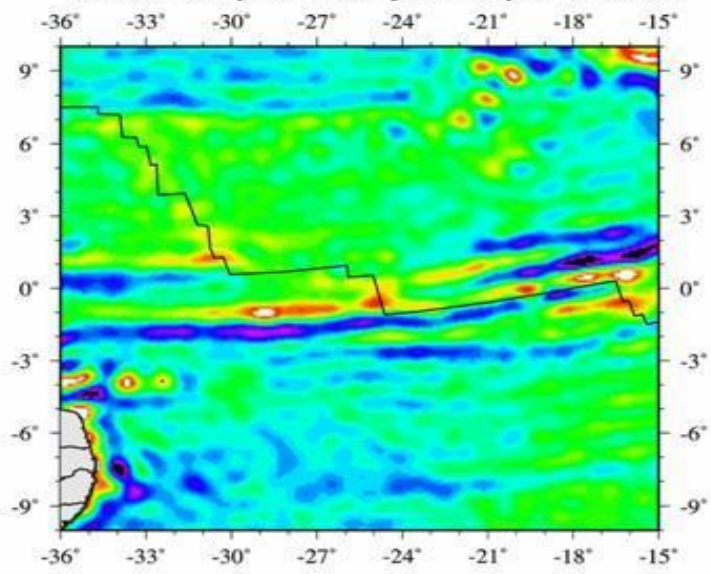

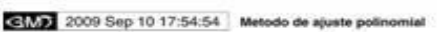

Residual após remoção do polinômio $2^{\circ}$

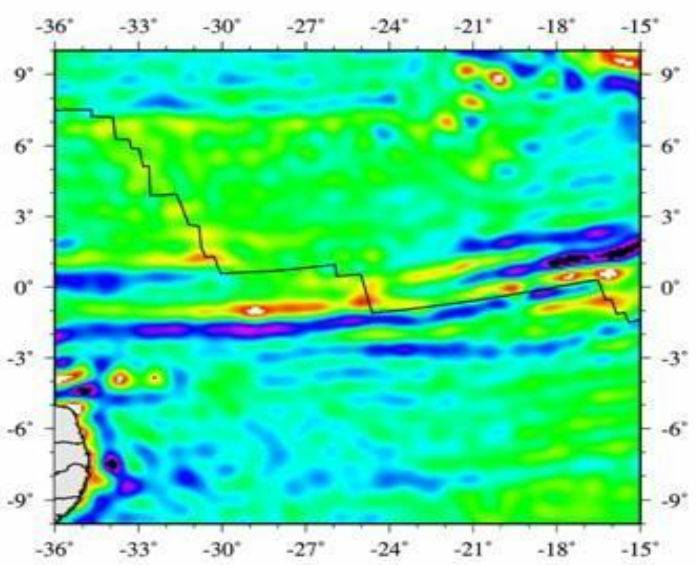

बलग

Residual após remoção do polinômio $3^{\circ}$

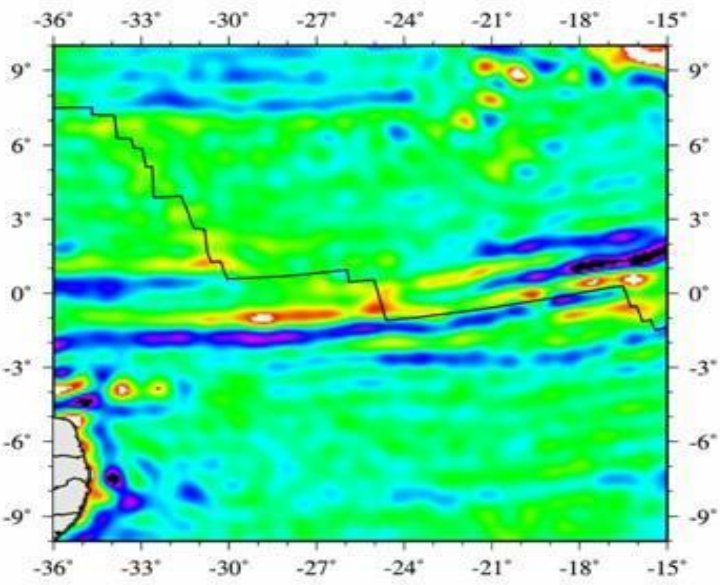

319] $2009 \operatorname{Sep} 10$ 17:59:09
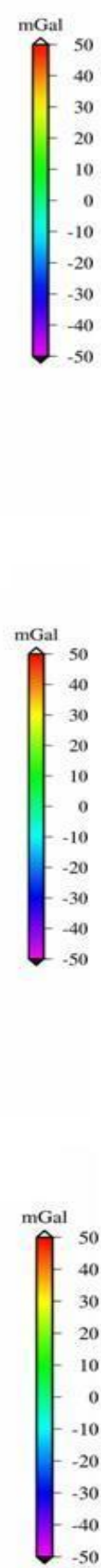

Residual após remoção do polinômio $1^{\circ}$ (robusto)

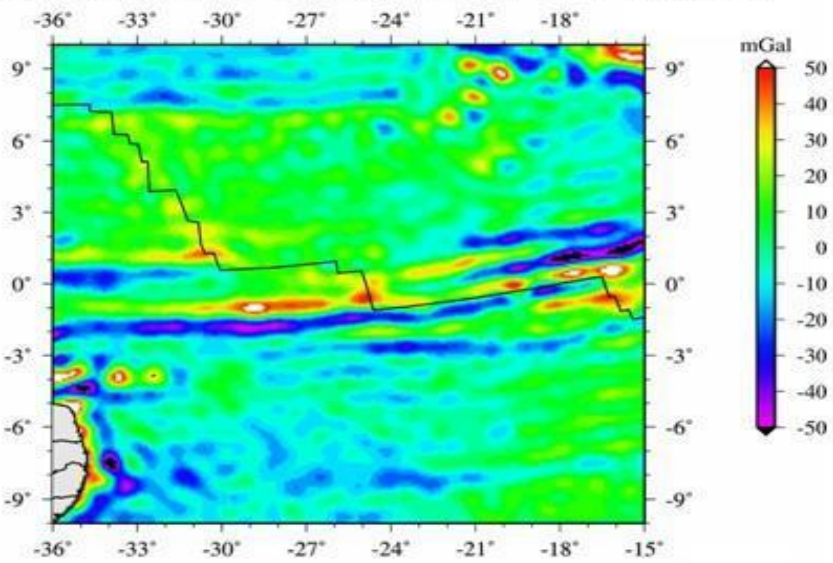

बM] 2009 Sep 10 17:55-18 Metodo de ajuste polinemial robuuto

Residual após remoção do polinômio $2^{\circ}$ (robusto)

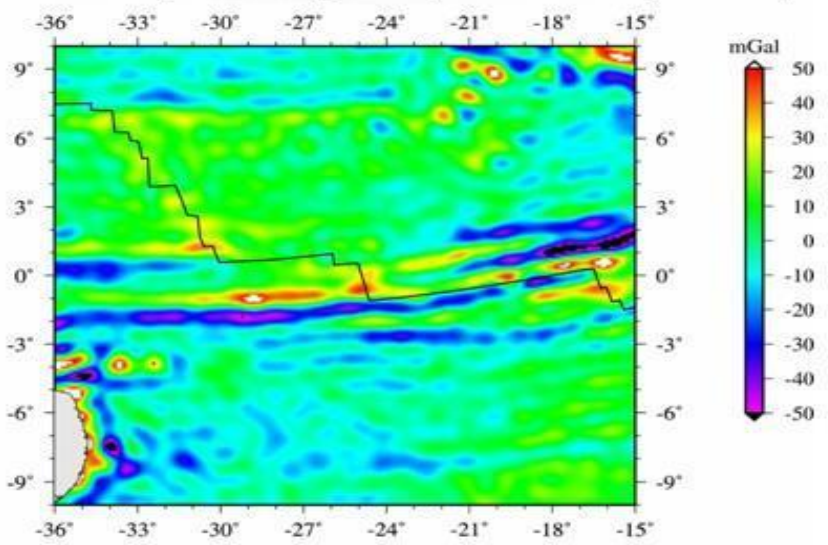

बक्य] $2000 \operatorname{sep} 1017.00 \cdot 14$

Residual após remoção do polinômio $3^{\circ}$ (robusto)

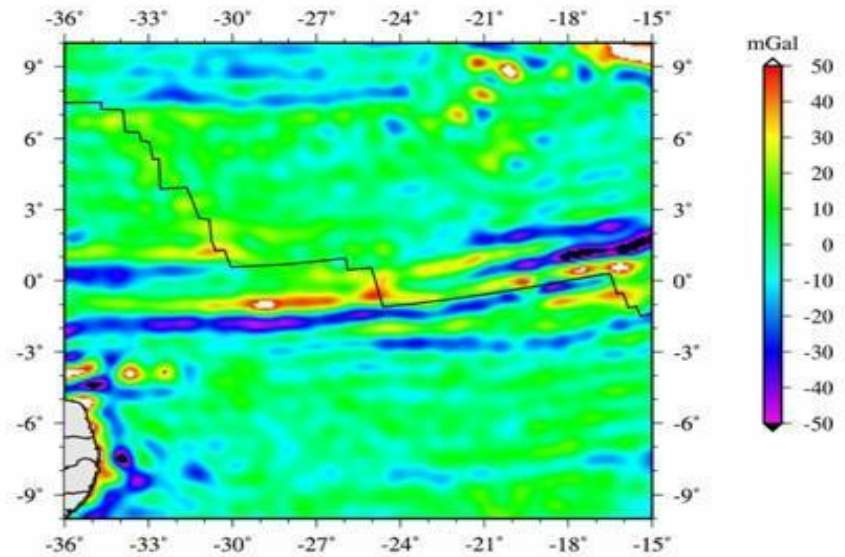

बM] 2009 Sep $101759-28$ Metoso do ajusto polinomiat robusto

MAPAS 22 A 27: GRAVIDADE RESIDUAL OBTIDA PELO PROGRAMA GRAFIM.JOB A PARTIR DO MODELO EGM 2008 (30 A 2160) APLICANDO O MÉTODO DE AJUSTE POLINOMIAL 


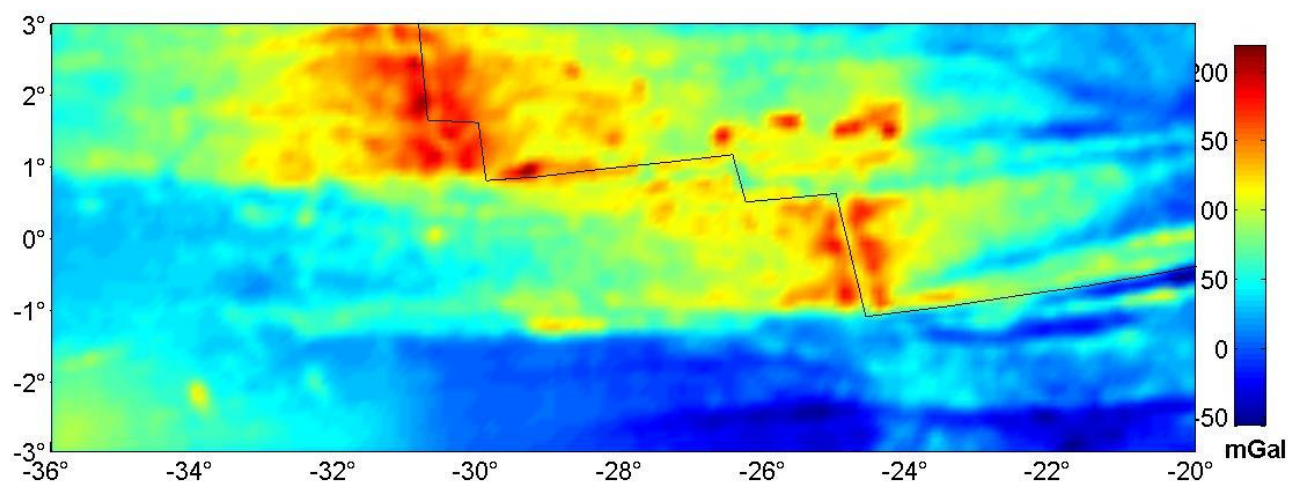

MAPA 23: GRAVIDADE CONSIDERANDO O EFEITO DA COMPENSAÇÃO ISOSTÁTICA CUJOS VALORES FORAM OBTIDOS A PARTIR DO PROGRAMA PARKER. M (CHAVES, 2008).

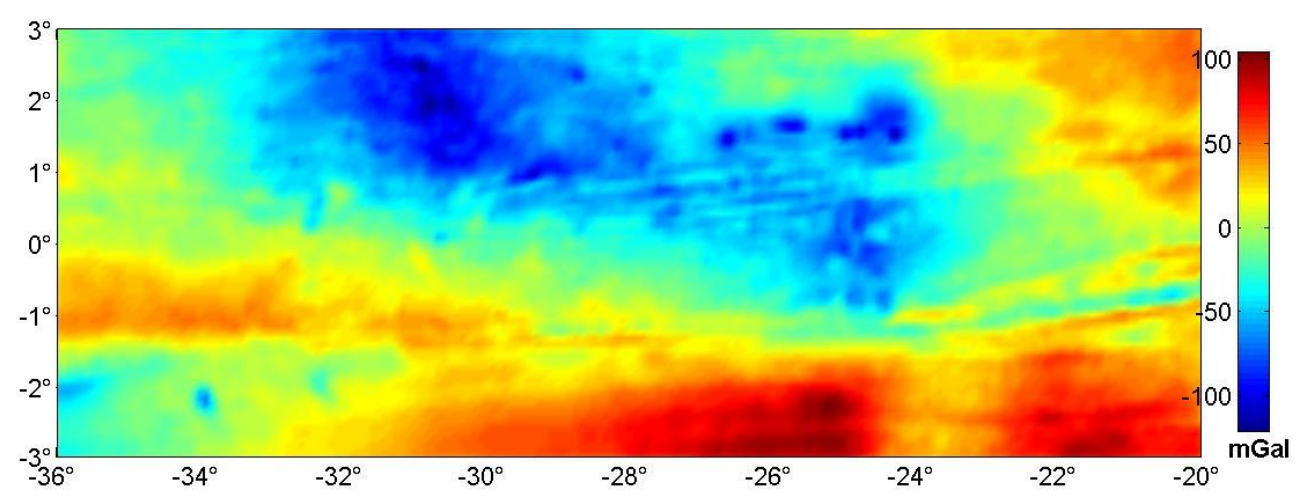

MAPA 24: GRAVIDADE RESIDUAL APÓS SUBTRAÇÃO DO EFEITO DA COMPENSAÇÃO ISOSTÁTICA.

Portanto, havendo uma carga sobre a litosfera a mesma se flexiona, compensando, dessa forma a carga sobre ela. Esse é o modelo conhecido por modelo flexural e difere dos modelos isostáticos de Airy e Pratt, pois nesses outros dois modelos não é assumida nenhuma propriedade especial para a litosfera. Quando uma carga é "colocada" sobre a placa ela irá flexionar-se e parte desta pertencente a crosta irá "entrar" no manto. Essa raiz flexural compensará a carga depositada sobre ela. Este efeito é sentido no campo da gravidade, pois é uma área intensamente fraturada com ascensão do manto. 


\subsection{TENSOR GRADIENTE DA GRAVIDADE}

A partir do programa TGG (Bueno, 2007) foram obtidos dados do tensor gradiente gravimétrico. Este programa utiliza dados do componente vertical da aceleração de gravidade para calcular os componentes do vetor gradiente da gravidade. Trata-se de uma matriz $3 \times 3$ onde cada elemento é a derivada parcial de segunda ordem do campo da gravidade. Indicando a taxa de variação dos componentes do vetor segundo as direções $X Y Z$. De acordo com a equação de Laplace, para um campo externo à distribuição de massas, a soma dos componentes da diagonal da matriz é zero:

$$
g_{x x}+g_{y y}+g_{z z}=0
$$

Logo, a matriz sendo simétrica em relação à diagonal apenas cinco componentes são independentes e os outros quatro serão calculados.

$$
g_{x y}=g_{y x} \rightleftharpoons g_{x z}=g_{z x}=g_{y z}=g_{z y}
$$

Entretanto, o programa foi elaborado para a entrada de grades em $\mathrm{km}$ a partir de valores de continuação para cima. Foi necessária uma adaptação a fim de receber valores da grade em graus (lon/lat). Os dados de entrada foram os valores de anomalia ar livre. Foram calculadas as componentes gxx, gxy,gxz, gyx, gyy e gyz e gzx, gzy e gzz (variação vertical da gravidade).

Sabe-se que o tensor gradiente da gravidade "percebe" os curtos comprimentos de onda do campo gepotencial. Neste caso, é visualizada a grande influência da dorsal ao campo geopotencial. A variação da gravidade na direção vertical (gzz) e a variação da gravidade na direção OX (gxz) indicam delineadamente a feição batimétrica. 

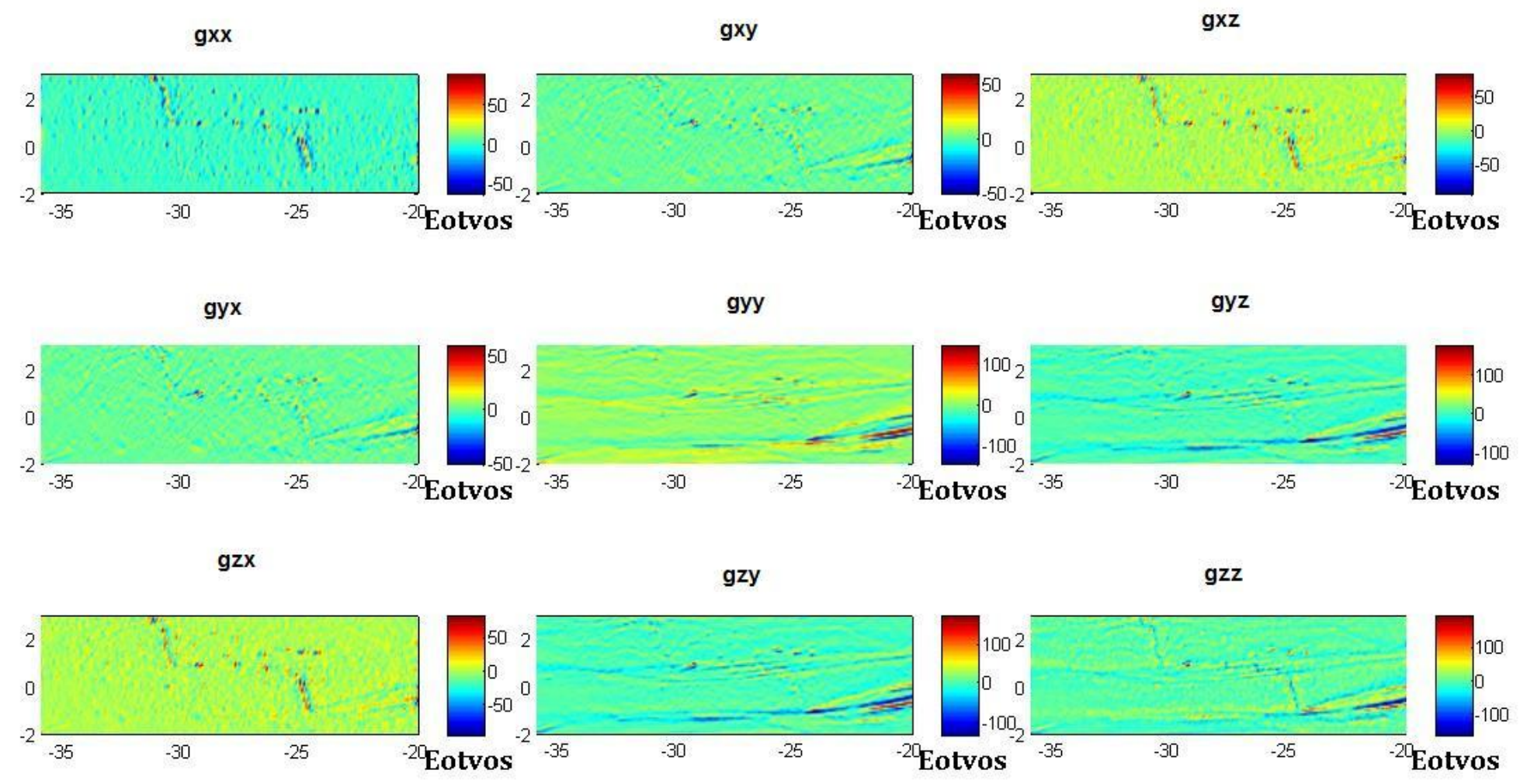

MAPA 25: TENSOR GRADIENTE DA GRAVIDADE CALCULADO NA ZFSP. 


\section{CAPÍTULO 5 \\ 5. CONCLUSÃO}

A ZFSP é uma região onde ocorrem muitos processos geológicos simultâneamente. Além a formação de crosta oceânica há uma relativa atividade sísmica e inclusive ocorreu o soerguimento de peridotitos que constituem hoje o ASPSP. Os valores de altura geoidal residual apontaram inicialmente uma anomalia positiva. Para subtrair o efeito da batimetria sobre o geóide foi implementada uma simulação deste efeito desta através de prisma. Após a subtração desta grade, a anomalia em questão foi removida. De forma semelhante, ocorreu com os valores de gravidade residual encontrados. Para subtrair o efeito da compensação isostática sobre a gravidade foi implementando o método de Parker. Após a subtração desta grade, a anomalia em questão havia sido removida.

Pode-se concluir que a caracterização gravimétrica em uma área de estudo localizada sobre uma placa litosférica oceânica (mais jovem, mais fraturada e próxima ao centro de acresção) como é a ZFSP os efeitos da compensação isostática são sentidos de forma abrangente.

Devido a proximidade a dorsal, qualquer análise gravimétrica nesta região exige muita cautela em relação aos reais efeitos que se pretende distinguir. Ao se aplicar o geóide que "visualiza" longos comprimentos de onda pode-se diluir as feições batimétricas ao sinal obtido.

Desta forma para encontrar algum vestígio da anomalia térmica nesta região no geopotencial é aconselhada a junção de métodos geofísicos tais como tomografia sísmica e análise de fluxo térmico a fim de acrescentar mais resultados as análises petrológicas e geoquímicas já realizadas na área de estudo. 


\section{CAPÍTULO 6 \\ 6. REFERÊNCIAS BIBLIOGRÁFICAS}

Agapova, C.V. Morfology of the eastern active segment of the St. Paul fracture zone (The Equatorial Atlantic). Oceanology, America Geophysical Union. English translation, vol. 34, n. 1, p. 99-103, 1994.

Anderson, D.L. Phase changes and Mantle Mineralogy In:_. Theory of the earth. Blackwell Scientific Publication. p. 337-353, 1989.

Alves, E.C. 2002. Zonas de Fratura Oceânicas e suas Relações com a Compartimentação Tectônica do Sudeste do Brasil. Tese, Departamento de Geologia da Universidade Federal do Rio de Janeiro, pp. 247

Amos, M.J., Featherstone, W.E. Comparisons of recent global gepotential models with terrestrial gravity field data over New Zealand and Australia. Geomatics Research Australasia. 2003. Disponível em:<http://www.cage.curtin.edu.au/ will/Featherstone_GRA_78_67-84.pdf>. Acesso em: 15 jun. 2009.

Asmus, H.E., Guazelli, W. Descrição sumária das estruturas da margem continental brasileira e das áreas oceânicas e continentais, adjacentes. Hipótese do tectonismo causador, e implicações para os prognósticos do potencial de recursos minerais. Série Projeto REMAC, n. 9, Petrobras, Rio de Janeiro, p.187-261, 1981.

Beltrão, J.F., Silva, J.B.C., Costa, J.C. Robust Polynomial Fitting Method for Regional Gravity Estimation. Geophysics. 1991. Disponível em: <http://scitation.aip.org/dbt/dbt.jsp?KEY=GPYSA7\&Volume=56\&lssue=1>. Acesso em: 10 jul. 2009.

Blakely, R. J. Potential Theory in Gravity and Magnetic Applications. Cambridge University Press. p. 411. 1996.

Bonatti, E. O Manto sob os oceanos. As formas mutantes da Terra. Scientific American Brasil. Edição Especial. n. 20. Outubro. 2007.

Bonatti, E. Anomalous opening of the Equatorial Atlantic due to an equatorial mantle thermal minimum. Earth and Planetary Science Letters. vol. 250, n. 4977, p. 107- 111, 1996.

Bonatti, E, Seyler, M. and Sushevskaya, N. A cold suboceanic mantle belt at the Earth's equator. Science, vol. 261, n. 5119, pp. 315 -320, 1993.

Bonatti, E, Peyve, A., Kepezhinskas, P., Kurentsova, N., Seyler, M. Skolotnev, I. S., and Udintsev, G. Upper Mantle Heterogeneity Below the 
Mid-Atlantic Ridge $0^{\circ}-15^{\circ}$ N. J. Geophys. Res., vol. 97, n. B4, p. 4461-4476, 1992.

Bonatti, E. Subcontinental mantle exposed in the Atlantic Ocean on St.

Peter-Paul islets. Nature. $1990 . \quad$ Disponível em: <http://www.nature.com/nature/journal/v345/n6278/pdf/345800a0.pdf>.

Acesso em: 15 jul. 2008.

Bonatti, E. Not so hot "hot spots" in the oceanic mantle. Science. vol. 250. n. 4977, pp. $107-111,1990$.

Bonatti, E. et al. Final Desiccation of the Afar Rift, Ethiopia. Science. vol. 172. n. 3982, p. 468 - 469, 1971.

Bonfim, E. Utilização dos dados do Grace para a caracterização da variabilidade das massas de água do aqüífero Guarani. Dissertação de mestrado. Universidade de São Paulo. São Paulo, p. 141, 2006.

Bowin, C. Topography at the core-mantle boundary. Geophysical Research Letters, vol. 13, n. 13, p. 1513-1516, 1986.

Bowin, C.: Depth of Principal Mass Anomalies Contributing to the Earth's Geoidal Undulations and Gravity Anomalies, Mar. Geod., Vol. 7, p. 61-100, 1983.

Campos T.F.C., Virgens Neto, J. das, Sirivastava, N.K., Petta, R.A., Hartmann, L.A., Moraes J.F.S. de, Mendes L., Silveira S.R.M. Arquipélago de São Pedro e São Paulo. Soerguimento tectônico de rochas infracrustais no Oceano Atlântico. 2005. Disponível em: <http//www.unb.br/ig/sigep/sitio 002/sitio 002.pdf>. Acesso em: 15 jul. 2008.

Chaves, C. A. M., Detectabilidade de plumas mantélicas profundas a partir de anomalias do geóide. Trabalho de graduação do curso de Bacharelado em Geofísica. Universidade de São Paulo, São Paulo, p. 36, 2007.

Chase, C.G., The geological significance of the geoid: Earth and Planetary Science Letters 13,p. 97-113, 1985.

Daziel, I.W.D. A Terra muito antes da Pangea. As formas mutantes da Terra. Scientific American Brasil. Edição Especial. n. 20. Outubro. 2007.

Daziel, I.W.D. Neoproterozoic-Paleozoic geography and tectonics: Review,hypothesis, environmental speculation. GSA Bulletin. vol. 109, n.1, p. 16-42, 1997.

Dehlinger, P. Marine Gravity. Elsevier, N.Y., p. 322, 1978.

Equatorial Segment of the Mid-Atlantic Ridge (EQUARIDGE). 1996. Initial Results of the Geological and Geophysical Investigations under the EQUARIDGE Program. Cruises of r/v 'Akademik Nikolaj Strakhov' in 1987, 
1990, 1991. Intergovernmental Oceanographic Commission Technical Series. Unesco. p. 128.

Fowler, C.M.R. Past Plate Motions. In:_ . The Solid Earth. An Introduction to Global Geophysics. Cambridge University Press. p. 43-99, 2005.

Gemael,C., 2002. Introdução à Geodésia Física. 2ª Ed. UFPR, p.302 .

Gorini, M. A. The tectonic fabric of the equatorial Atlantic and adjoining continental margins: Gulf of Guinea to Northeastern Brazil. In: Asmus, H. E. (ed.). Estruturas e Tectonismo da Margem Continental Brasileira, e suas Implicações nos Processos Sedimentares e na Avaliação do Potencial de Recursos Minerais (Relatório Final). Rio de Janeiro: PETROBRAS/CENPES/DINTEP. Série Projeto REMAC, 9, p. 11-116, 1981.

Hager, B.H. Subducted slabs and the geoid constraints on mantle rheology and flow. Journal of Geophysical Research, vol. 89, n. B7, p. 6003-6015, 1984.

Hekinian, R., Juteau, T., Gracia, E., Sichler, B., Sichel, S., Udintsev, G., Apprioual, R. and Ligi, M. Submersible observations of Equatorial Atlantic mantle: The St. Paul Fracture Zone region. Marine Geophysical Researches. vol. 21, p. 529-560, 2000.

Heiskanen, W. A., Moritz, H. Physical Geodesy. San Francisco: W. H. Freeman and Company, 1967.

ICGEM (International Center for Global Gravity Field). Calculation of Gravity Field Functionals on Ellipsoidal Grids. Disponível em: <http://icgem.gfzpotsdam.de/ICGEM/Acesso em: 11 set. 2009.

Li X, Götze H-J. Ellipsoid, geoid, gravity, geodesy and geophysics - A Tutorial. Geophysics 66 (6), p. 1660-1668, 2001.

National Geospacial Intelligency Agency. Description of Files Related to using the EGM2008 Global Gravitational Model to compute Geoid Undulations with respect to WGS84. Disponível em: <http://earthinfo.nga.mil/GandG/wgs84/gravitymod/egm2008/README_WGS84_2.pdf>. Acesso em: 10 set. 2009.

Mello, S. L. M. Tectonics and Volcanism of the Mid-Atlantic Ridge at $45^{\circ} \mathrm{N}$. Tese de Doutoramento. University of Leeds, Leeds, p. 200, 1999.

Molina, E. C. Ajustamento e integração de dados gravimétricos e de altimetria por satélite na representação do campo de gravidade no Atlântico Sul. Tese de doutoramento. Universidade de São Paulo, São Paulo, p. 201, 1996. 
Moraes, J. F. S. de. Caracterização Petrográfica e Química das Rochas do Arquipélago de São Pedro e São Paulo. Companhia de Pesquisas de Recursos Minerais. Superintendência Regional de Recife. 1996.

Moutinho, L., Desenvolvimento de Programa de Computador para Modelagem de Anomalias Gravimétricas. Trabalho de graduação do curso de Bacharelado em Geofísica. Universidade de São Paulo, São Paulo, p. $26,2000$.

NGA - National Geospatial Intelligence Agency. Earth Gravitational Model 2008 (EGM2008). WGS84 Version. Disponível em: <http://earthinfo.nga.mil/GandG/wgs84/gravitymod/egm2008/index.html>. Acesso em: 10 set. 2009

NGDC (NATIONAL GEOPHYSICAL DATA CENTER). Disponível em: $<$ http://map.ngdc.noaa.gov/website/mgg/trackline/viewer.htm>. Acesso em: 15 jul. 2008.

Parker, R.L. The Rapid Calculation of potencial Anomalies. Geophys. J.R. astr. Soc. 31,p. 447-455, 1973.

Palma, J. J. C. Morfotectônica e gravimetria da falha transformante de Ascensão e crista da Cordilheira Mesoatlântica de $6^{\circ} 20^{\prime} S$ a $10^{\circ} 05^{\prime} S$. São Paulo. Tese de doutorado. Universidade de São Paulo, São Paulo, p. 106, 1998.

Pavlis, K. N., Holmes, S. A., Kenyon, S. C. and Factor, J. K. 2008. An Earth Gravitational Model to Degree 2160: EGM2008. In: 2008 General assembly of the European Geosciences Union, April 13-18, 2008. Austria. Disponível em:<http://www.dgfi.badw.de/typo3_mt/fileadmin/2kolloquium_muc/2008-1008/Bosch/EGM2008.pdf>. Acesso em: 12 agost. 2008

Pavlis, N.K., S.A. Holmes, S.C. Kenyon, and J.K. Factor, An Earth Gravitational Model to Degree 2160: EGM2008, presented at the 2008 General Assembly of the European Geosciences Union, Vienna, Austria, April 13-18, 2008.

Press, F., Siever, R., Grotzinger, J., Jordan, T.H. A Evolução dos Continentes. In: Para Entender a Terra. 4ª edição. Bookman. p. 195-226, 2006.

Relatório técnico produzido pela Universidade de Bretagne Ocidental, IFREMER e LAGEMAR, 1996.

Saatkamp, E. D., Moraes, C. V. de, Farret, J.C. Avaliação do modelo geoidal EGM2008 para o Brasil.2009. Anais do XIV Simpósio Brasileiro de Sensoriamento Remoto, Natal, Brasil, 2009, p. 4303-4310. 
Santos, H. B. e Ussami, N.Tensor Gradiente Gravimétrico da Bacia do Paraná: Prevendo Observações da Missão GOCE-ESA. Trabalho de graduação do curso de Bacharelado em Geofísica. Universidade de São Paulo, São Paulo, p. 40, 2008.

Schilling, J.G., Ruppel, C. Davis, A. N., McCully, B., Tighe, S.A., Kingsley, R. H. and Lin, J. Thermal structure of the mantle beneath the equatorial MidAtlantic Ridge: Inferences from the spatial variation of dredged basalt glass composition. Journal of Geophysical Research. vol. 100, n. B7. p. 10.05710.076, 1995.

Sichel, S. E., Motoki. A., Esperança, S, Horan, M. F., Maia, M., Szatmari, P., Mello, S L.M. and Alves, E. C. 2008. Geophysical and geochemical evidence for cold upper mantle beneath the Equatorial Atlantic Ocean. Revista Brasileira de Geofísica. vol. 26, n. 1, p. 69-86, 2008.

Smith, W. H. F., and D. T. Sandwell, Global seafloor topography from satellite altimetry and ship depth soundings, Science, v. 277, p. 1957-1962, 26 Sept., 1997.

Šprlák, M., Janák, J.: Gravity field modeling. New program for gravity field modeling by spherical harmonic functions. p.1-8,2006.

Stanton, N., Mello, S. L., Sichel, S. E. 2006. Morfoestrutura da Cordilheira Mesoceânica no Atlântico Sul entre $0^{\circ} \mathrm{S}$ e $50^{\circ} \mathrm{S}$. Revista Brasileira de Geofísica Vol. 24. n. 2, p. 231-241.

Talwani, M., Worzel, J.L. and Landisman, M. Rapid Gravity Computations for Two-dimensional Bodies with Applications to the Mendocino Submarine Fracture Zone. Journal of Geophysical Research, vol. 64, p. 49-59, 1959.

Tucholke, B.E., Fujoka, K., Ishihara, T., Hirth, G. and Kinoshita, M. Submersible study of na oceanic megamullion in the central North Atlantic. Journal of Geophysical Research, vol. 106, n. B8, p. 145-161, 2001.

Tucholke, B.E., Lin, J. and Kleinrock, M. C. Megamullion and mullion structure defining oceanic metamorphic core complexes on the Mid-Atlantic Ridge. Journal of Geophysical Research, vol.103, n. B5, p. 9857-9866, 1998.

Vaníček, P and Christou, N. T. 1993 Geoid and its geophysical interpretations. CRC Press. p. 340.

Wessel, P. and Watts, A. B. On the accuracy of marine gravity measurements. Journal of Geophysical Research, vol. 93, p. 393- 413. 1988.

Winter J.D. 2001. An Introduction to Igneous and Metamorphic Petrology. Prentice Hall, 697p. 